\title{
Tailored Approaches in Drug Development and Diagnostics: From Molecular Design to Biological Model Systems
}

\author{
Cecilia Sahlgren, Annika Meinander, Hongbo Zhang, Fang Cheng, Maren Preis, Chunlin Xu, \\ Tiina A. Salminen, Diana Toivola, Daniel Abankwa, Ari Rosling, Didem Şen Karaman, \\ Outi M. H. Salo-Ahen, Ronald Österbacka, John E. Eriksson, Stefan Willför, Ion Petre, \\ Jouko Peltonen, Reko Leino, Mark Johnson, Jessica Rosenholm, and Niklas Sandler*
}

Approaches to increase the efficiency in developing drugs and diagnostics tools, including new drug delivery and diagnostic technologies, are needed for improved diagnosis and treatment of major diseases and health problems such as cancer, inflammatory diseases, chronic wounds, and antibiotic resistance. Development within several areas of research ranging from computational sciences, material sciences, bioengineering to biomedical sciences and bioimaging is needed to realize innovative drug development and diagnostic (DDD) approaches. Here, an overview of recent progresses within key areas that can provide customizable solutions to improve processes and the approaches taken within DDD is provided. Due to the broadness of the area, unfortunately all relevant aspects such as pharmacokinetics of bioactive molecules and delivery systems cannot be covered. Tailored approaches within (i) bioinformatics and computer-aided drug design, (ii) nanotechnology, (iii) novel materials and technologies for drug delivery and diagnostic systems, and (iv) disease models to predict safety and efficacy of medicines under development are focused on. Current developments and challenges ahead are discussed. The broad scope reflects the multidisciplinary nature of the field of DDD and aims to highlight the convergence of biological, pharmaceutical, and medical disciplines needed to meet the societal challenges of the 21 st century.

\section{Introduction}

Society is facing serious challenges in diagnosing and treating complex diseases, such as cancer and inflammatory disease and complications from chronic diseases. In addition, there is a rapidly increasing need to fight antibiotic resistance. Advances in medical research and emergence of new technologies and new materials are important to improve detection of, and provide novel and effective therapies for these diseases in healthcare. Improved knowledge of the underlining causes of disease and mechanistic insight into disease mechanisms drive development of novel molecular therapies. However, the therapeutic discovery and development process is currently most often inefficient and lacks predictive power and results in very high costs ( $>1$ billion $€$ per launched drug) and long duration (up to $>15$ years) of the drug development and regulatory processes. Further, clinical translation of
Prof. C. Sahlgren, Prof. A. Meinander, Prof. F. Cheng, Prof. D. Toivola,

Prof. J. E. Eriksson

Faculty of Science and Engineering

Cell Biology

Åbo Akademi University

FI-20520 Turku, Finland

Prof. C. Sahlgren, Prof. J. E. Eriksson

Turku Centre for Biotechnology

Åbo Akademi University and University of Turku

FI-20520 Turku, Finland

Prof. C. Sahlgren, Prof. D. Abankwa

Department of Biomedical Engineering

Technical University of Eindhoven

5613 DR Eindhoven, Netherlands

Prof. H. Zhang, Prof. M. Preis, Dr. D. Sen Karaman,

Prof. O. M. H. Salo-Ahen, Prof. J. Rosenholm, Prof. N. Sandler

Faculty of Science and Engineering

Pharmaceutical Sciences Laboratory

Åbo Akademi University

FI-20520 Turku, Finland

E-mail: niklas.sandler@abo.fi
Prof. C. Xu, Prof. S. Willför

Faculty of Science and Engineering

Natural Materials Technology

Åbo Akademi University

FI-20500 Turku, Finland

Prof. T. A. Salminen, Prof. O. M. H. Salo-Ahen, Prof. M. Johnson

Faculty of Science and Engineering

Structural Bioinformatics Laboratory

Åbo Akademi University

FI-20520 Turku, Finland

Prof. D. Toivola

Turku Center for Disease Modeling

University of Turku

FI-20520 Turku, Finland

Prof. A. Rosling

Faculty of Science and Engineering

Polymer Technologies

Åbo Akademi University

FI-20500 Turku, Finland

DOI: 10.1002/adhm.201700258 
novel therapeutic approaches and drugs is hampered by several challenges, including aspects regarding safety and efficacy, pharmacokinetics, and bioavailability, and can only be solved with systematic multidisciplinary approaches. The heterogeneous nature of many diseases, the complexity of genetic variability, and the need for personalized medicine pose additional challenges, but at the same time give great opportunities in realizing future therapies. Often, diagnostic and therapeutic approaches need to be combined and tailored to the patient, and the development process should be adapted accordingly. In Table 1, we summarize some of the biggest medical challenges of the 21 st century.

In this review, we introduce recent developments and approaches within materials sciences and technology that address the needs that exist in the development of efficient therapies and sensitive diagnostic solutions (Figure 1). We also cover computational, engineered, and biological approaches as well as model systems that can provide customizable solutions to improve the processes and approaches taken within DDD. We discuss the state of the art and provide a critical analysis of the problems in the respective fields, addressing the challenges, limitations, and possible solutions. The scope of the review is large to emphasize the need of interdisciplinary approaches. The cross-disciplinary scope is also intended to familiarize the reader with the possibilities and limitations of other fields, to hopefully render crossover approaches more effective.

\section{Computational Approaches in Molecular Design and Drug Discovery}

\subsection{Structural Bioinformatics and Computer-Aided Drug Design in Drug Development and Diagnostics}

The study of individual molecules and collections of molecules, isolated and in the cellular or organismal context, is important for identifying synthetic and natural molecules in drug development and diagnostic applications. Structural biology can define the biological complex, while structural bioinformatics

\author{
Prof. R. Österbacka \\ Faculty of Science and Engineering \\ Physics \\ Åbo Akademi University \\ FI-20500 Turku, Finland \\ Prof. I. Petre \\ Faculty of Science and Engineering \\ Computer Science \\ Åbo Akademi University \\ FI-20500 Turku, Finland \\ Prof. J. Peltonen \\ Faculty of Science and Engineering \\ Physical Chemistry \\ Åbo Akademi University \\ FI-20500 Turku, Finland \\ Prof. R. Leino \\ Faculty of Science and Engineering \\ Organic Chemistry \\ Johan Gadolin Process Chemistry Centre \\ Åbo Akademi University \\ FI-20500 Turku, Finland
}

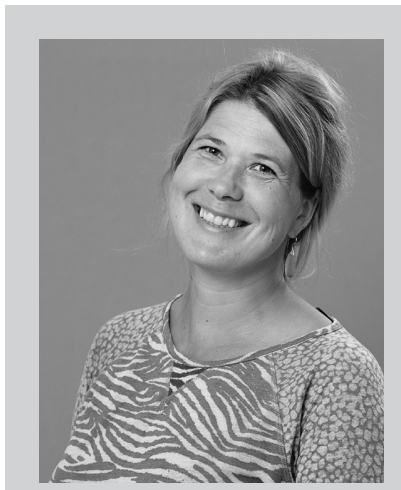

Cecilia Sahlgren is a professor of cell biology at Åbo Akademi University (AUU) and holds an affiliated position in biomedical engineering at Eindhoven University of Technology (TU/e). She graduated from ÅU in 2002, was a postdoctoral fellow at Karolinska Institute, Sweden, a principal investigator and Academy of Finland Fellow at the Turku Centre for Biotechnology. In 2013, she was appointed as associate professor in biomedical engineering at TU/e. In 2016, she became a professor in cell biology at AAU. She heads the cellfate group (http://cellfatelab.github.io) that focuses on mechanisms and technologies of cell fate control in tissue regeneration and disease. She works together with colleagues and coauthors of this review within the Drug Development and Diagnostic strategic profiling area of the AAU.

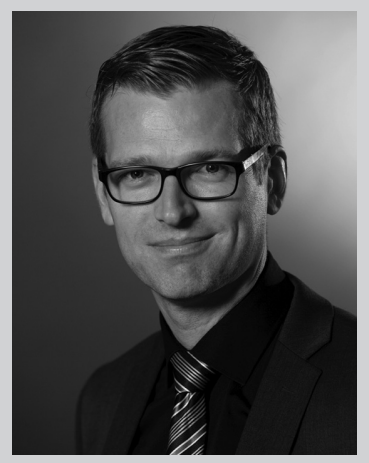

Niklas Sandler is a professor of pharmaceutical technology and vice rector at Åbo Akademi University (AAU). He graduated from the University of Helsinki in 2003. He has been a postdoctoral fellow at the University of Otago, New Zealand, a senior researcher at AstraZeneca Pharmaceutical and Analytical $R \& D$, UK, and a professor in Industrial Pharmacy at the University of Helsinki. In 2009, he was appointed as professor in Pharmacy AAU, where he heads the research in pharmaceutical technology. He has pioneered in research around printable drug delivery systems. He works together with colleagues and co-authors of this review within the Drug Development and Diagnostic strategic profiling area of the AAU.

seeks to assimilate a wide range of information to make predictions, when structural and functional details are incomplete. ${ }^{[1]}$ Different computer-aided drug design techniques can utilize the available structural information from either known smallmolecule compounds (i.e., ligands) or the target macromolecules, which usually are proteins. In the ideal case, structural and biological data from a panel of diverse ligands, as well as from the target protein and close homologs of the target provide a rich pool of information to exploit. In order to be able to efficiently employ the existing and ever-increasing molecular information for facilitating the design and discovery of novel drug candidates or diagnostic compounds, one also needs to be aware of the limitations and risks involved in using computational approaches. 
Table 1. Medical challenges of the 21 st century. ${ }^{[16]}$

\begin{tabular}{|c|c|c|c|}
\hline Disease & Impact & Challenges & Need \\
\hline Cancer & $\begin{array}{l}14 \text { million deaths in } 2012 \text {, expected to } \\
\text { increase to } 24 \text { million by } 2035\end{array}$ & $\begin{array}{l}\text { - Tumor heterogeneity } \\
\text { - Therapy resistance } \\
\text { - Adverse side effects } \\
\text { of novel compounds }\end{array}$ & $\begin{array}{l}\text { - Predictive drug screening } \\
\text { - Targeted drug delivery } \\
\text { - Sensitive diagnostics } \\
\text { - Immunotherapies } \\
\text { - Personalized medicine } \\
\text { (dose and drug combinations) }\end{array}$ \\
\hline Chronic wounds & $\begin{array}{l}\text { 2015: worldwide } 50 \text { million diabetes } \\
\text { related chronic wounds and 10-15 } \\
\text { million amputations } \\
\text { - } 2.4-4.5 \text { million people affected by chronic } \\
\text { lower extremity ulcers in the United } \\
\text { States only }\end{array}$ & $\begin{array}{l}\text { - Multiple genetic and environmental factors } \\
\text { contribute to delayed healing } \\
\text { - Therapy selection often not evidence based } \\
\text { - Lack of efficacy evaluation of existing wound } \\
\text { care products }\end{array}$ & $\begin{array}{l}\text { - Deep understanding of the } \\
\text { underlying pathophysiology } \\
\text { - Advanced therapy systems (bioactive } \\
\text { wound dressing) } \\
\text { - Personalized medicine (selection } \\
\text { of an appropriate therapy based on } \\
\text { a systematic evaluation of patients } \\
\text { and their wounds) }\end{array}$ \\
\hline Inflammatory disorders & $\begin{array}{l}\text { Asthma } \\
\text { - } 250000 \text { deaths annually } \\
\text { Allergies } \\
\text { - One tenth of the population suffers from } \\
\text { drug allergies. } \\
\text { - } 400 \text { million people from rhinitis } \\
\text { - } 250 \text { million people from food allergies } \\
\text { Autoimmune diseases } \\
\text { - Affect more than } 5 \% \text { of the population in } \\
\text { Europe and North America } \\
\text { Chronic inflammation } \\
\text { - Over } 1 \text { million residents in the United } \\
\text { States and } 2.5 \text { million in Europe are } \\
\text { estimated to have inflammatory bowel } \\
\text { disease (IBD). }\end{array}$ & $\begin{array}{l}\text { - Treatments affecting inflammatory responses } \\
\text { that do not compromise the host's ability to } \\
\text { fight infections } \\
\text { - Chronic disorders tend to require life-long } \\
\text { medication. } \\
\text { - Disorders are usually multifactorial, and suc- } \\
\text { cessful treatments, thus, will vary in patients. }\end{array}$ & $\begin{array}{l}\text { - Controlled dosage and specific } \\
\text { targeting for prolonged treatments } \\
\text { - Immunotherapy and desensitizing } \\
\text { therapies } \\
\text { - Efficient, but noninvasive } \\
\text { diagnostics } \\
\text { - Specific diagnosis and further } \\
\text { subclassification of disorders } \\
\text { - Development of drugs for specific } \\
\text { disorders }\end{array}$ \\
\hline Antibiotic resistance & $\begin{array}{l}\text { - 2014: WHO's global antibacterial resis- } \\
\text { tance surveillance: antibiotic resistance } \\
\text { risk treatment of common infections } \\
\text { - 2017: WHO's list of antibiotic-resistant } \\
\text { "priority pathogens": a catalogue of } 12 \\
\text { families of bacteria that pose the greatest } \\
\text { threat to human health } \\
\text { - Deaths caused by drug-resistant bacteria } \\
\text { in the EU amount to } 25000 \text { annually, } \\
\text { costing society } € 1.5 \text { billion } \\
\text { - Deaths caused by drug-resistant bacteria } \\
\text { in } 2050 \text { could be as enormous as } \\
10 \text { million per year }\end{array}$ & $\begin{array}{l}\text { - Bacteria develop resistance mechanisms } \\
\text { faster than new antibiotics are being } \\
\text { developed. } \\
\text { - Bacteria can pass on genetic material to other } \\
\text { bacteria to acquire drug resistance. } \\
\text { - Misuse of antibiotics harms the commensal } \\
\text { microbiota. } \\
\text { - Research funding for development of anti- } \\
\text { microbial drugs is scarce and Big Pharma } \\
\text { does not see high enough potential for future } \\
\text { profits or return of investment. }\end{array}$ & $\begin{array}{l}\text { - Urgent need for new antimicrobial } \\
\text { therapies and alternative strategies } \\
\text { to treat bacterial diseases } \\
\text { - Developing new treatments against } \\
\text { drug-resistant bacteria } \\
\text { - Circumventing resistance mecha- } \\
\text { nisms, by using new natural com- } \\
\text { pounds with antibacterial activity, } \\
\text { focusing on compounds that do not } \\
\text { increase the selection pressure } \\
\text { - Prevention of inappropriate use of } \\
\text { existing antibiotics } \\
\text { - Species-selective antibacterial treat- } \\
\text { ments for protection of commensal } \\
\text { microbiota }\end{array}$ \\
\hline
\end{tabular}

\subsubsection{Macromolecular 3D Structures}

Known 3D structures of proteins are available in the Protein Data Bank (PDB). ${ }^{[2]}$ To solve protein structures experimentally, X-ray crystallography or nuclear magnetic resonance (NMR) spectroscopy give the highest resolution. However, lower resolution structural data from experimental techniques such as (cryo)electron microscopy (EM), small-angle X-ray scattering (SAXS), or fluorescence resonance energy transfer (FRET) can also be utilized to solve structural models with the help of computational tools. ${ }^{[1]}$ A single experimental structure is informative, but seldom sufficient, especially if it does not reflect a protein in complex with a ligand or an important conformational state. Structures with and without bound ligands, as well as mutational and functional data elucidating molecular interactions and activity states, would provide a more complete description of the dynamics taking place upon ligand binding, during reactions, and interactions with other molecules in the surroundings.

In reality, structural data from X-ray crystallography and NMR spectroscopy and especially from the lower resolution experimental techniques are rarely complete, and structural representatives of the protein of interest may not be forthcoming despite intense efforts. Structural bioinformatics can 

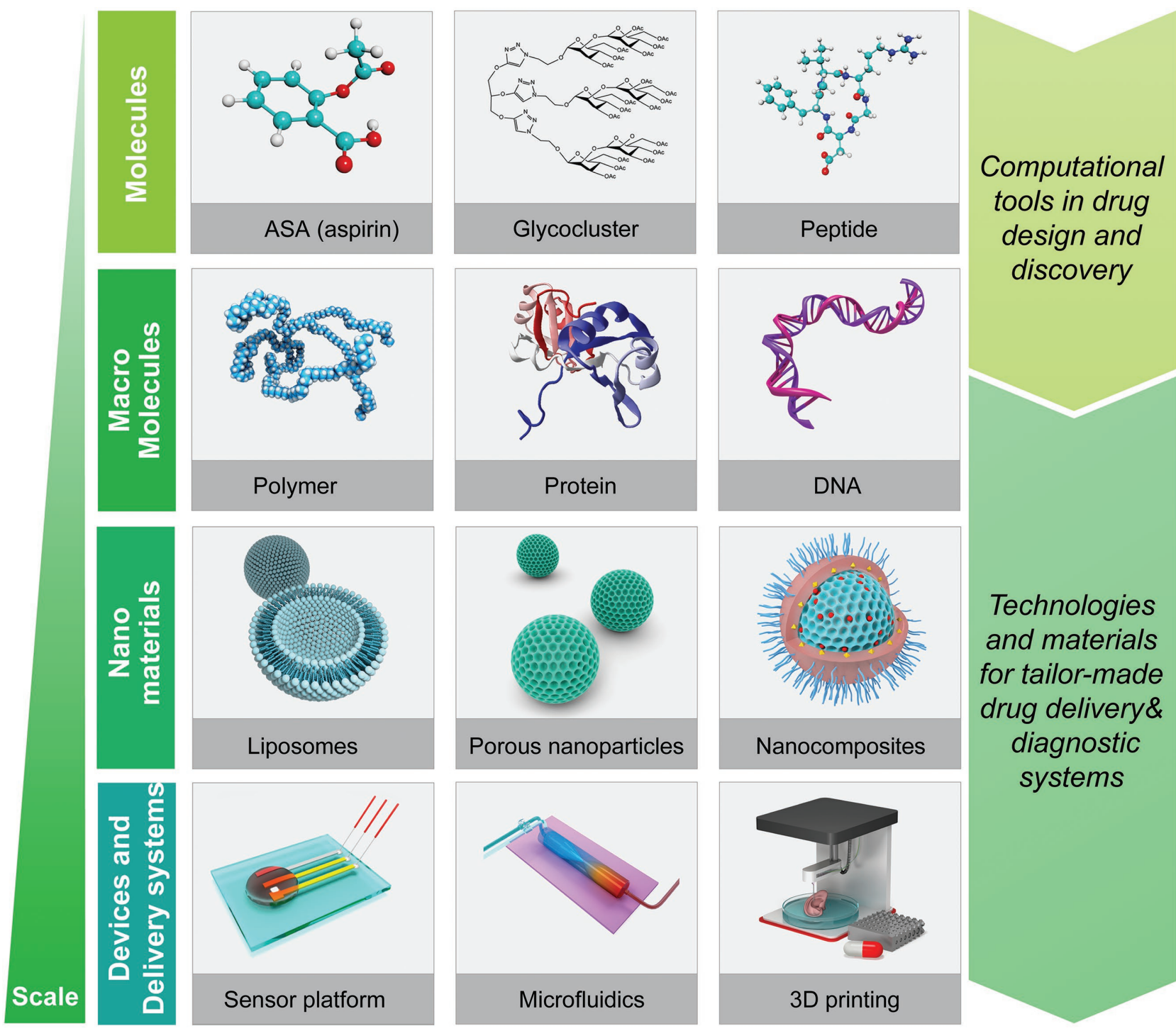

\section{Technologies and materials for tailor-made drug delivery\& diagnostic systems}

Scale
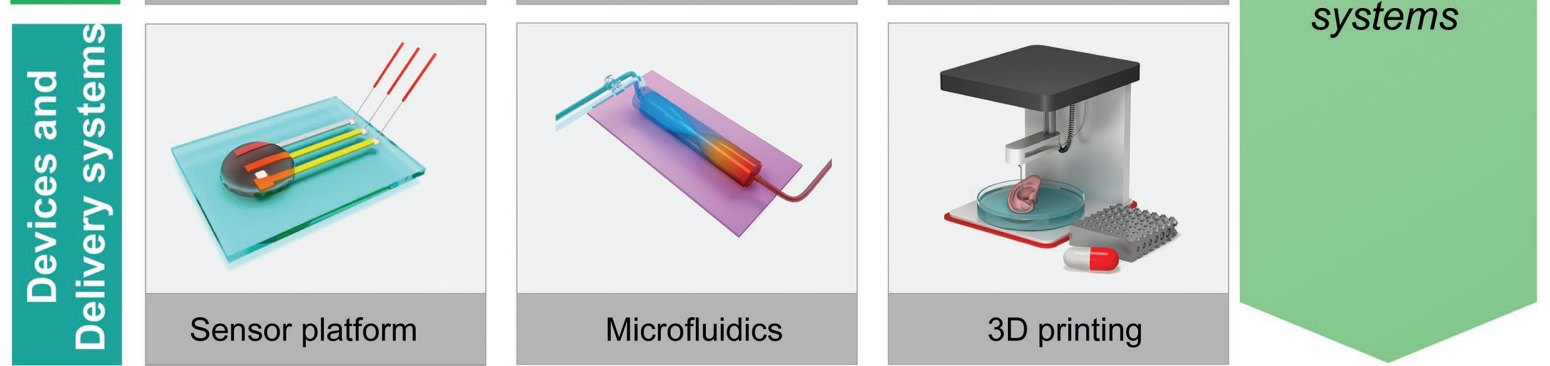

Figure 1. Examples of key technologies enabling drug development.

fill in this gap, but the methods involved need to be applied with good background knowledge on the molecule in question, related molecules, and ligand complexes and any other available biological data on function, binding, and mutants. For this purpose, details from the literature, reflecting experiments made by researchers, who are focusing specifically on the particular molecules, as well as sequence data and information about solved related structures, are of outmost importance. A common strategy is to begin crystallization trials with the goal of obtaining experimental structures over the long term to give more accurate data, while simultaneously employing the bioinformatics approach to construct a 3D structure model in order to have structural data for immediate use. This strategy has proven valuable in several projects; for example, the 3D model of vascular adhesion protein- $1^{[3]}$ was first utilized to study its peptide-binding properties ${ }^{[4,5]}$ and to locate the N-glycosylation sites, ${ }^{[6]}$ before solving the first X-ray structure of the protein..$^{[7,8]}$

\subsubsection{Template-Based Modeling}

Template-based modeling relies on the available experimental structures and includes both traditional comparative modeling (also called homology modeling) and automated template-based methods. ${ }^{[9-11]}$ Both methods consist of four steps: (1) retrieval of target and related sequences and identification of known structures to be used as templates; (2) sequence alignments for modeling; (3) building the 3D structure for the target protein by copying parts of the template structure; and (4) building the side chains and unaligned loops including refinement of the 3D model (Figure 2). Various computational approaches have been developed to assess the quality of the 3D models, which take into account the molecular environment, hydrogen bonding, secondary structure, solvent exposure, pairwise residue interactions, and molecular packing. ${ }^{[12]}$ The extent of modeling can vary from introducing the side chain for a mutant form of the known protein structure to modeling a novel conformation not 

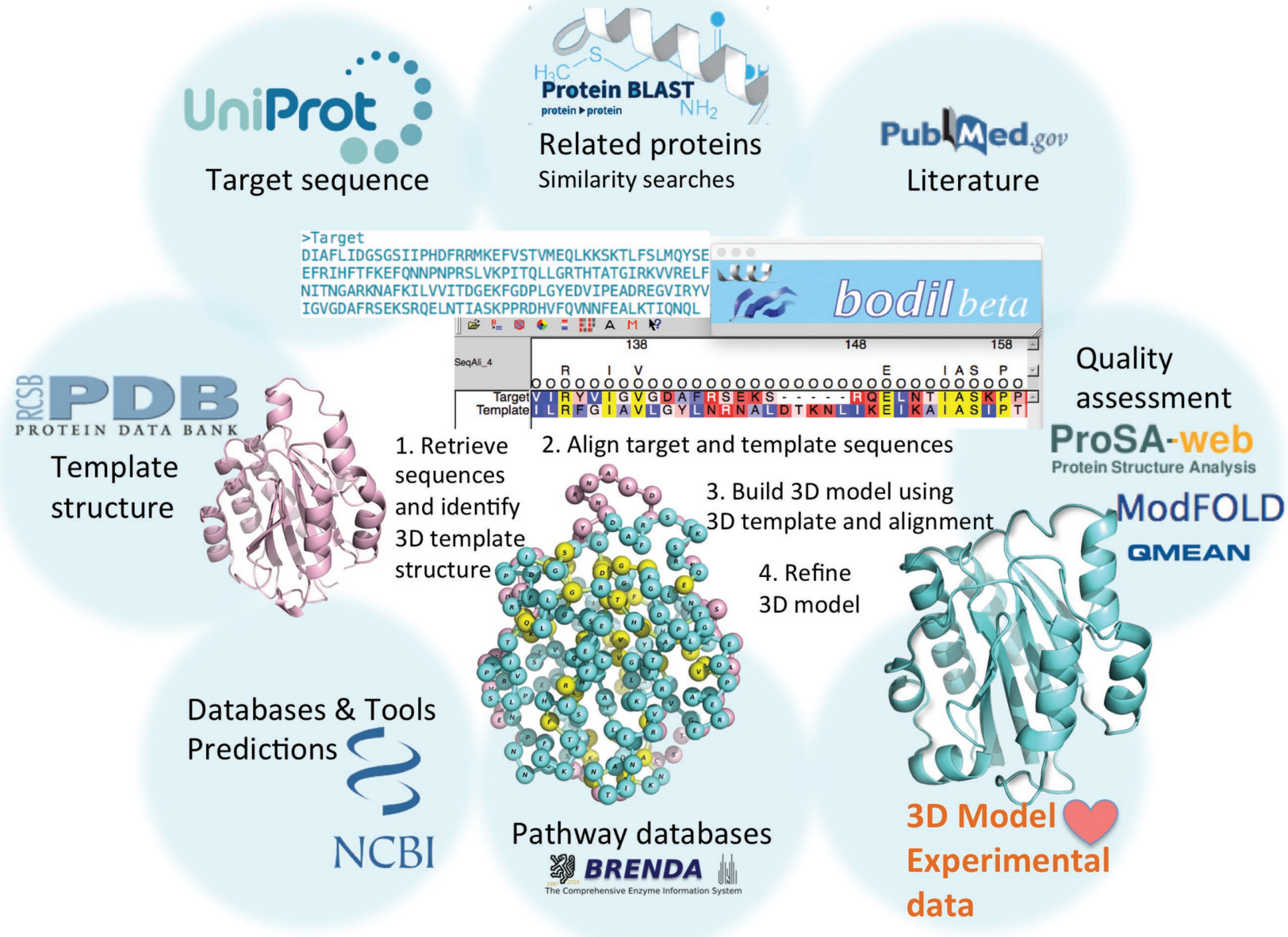

Figure 2. Association cloud for knowledge-based protein modeling. ${ }^{[1-6]}$

seen in the available structures of that protein, modeling the complete protein, or modeling a small molecule ligand bound or a protein-protein complex with a larger interface of interaction.

A 3D model that is based on a template structure with a very high sequence identity can be extremely useful to access sitespecific mutants, for example, in designing specific mutations to test a structural or functional hypothesis, interpreting experimental results from functional studies with mutants, ${ }^{[13]}$ and in understanding why certain variants of a protein have improved catalytic properties $^{[14,15]}$ or may cause a disease. ${ }^{[16,17]}$ Such model structures can also be instrumental for planning protein engineering of more complex constructs, for example, single-chain avidins based on the tetrameric structure capable of recognizing multiple ligands. ${ }^{[18]}$ Furthermore, structural models can predict species-specific ligand-binding properties, since the sequence identity between orthologous proteins in human and in model organisms is typically high, and structural models for orthologous proteins are thus reliable enough for the comparison of binding sites. For example, the sequences of human and mouse vascular adhesion protein-1 (hVAP-1 and mVAP-1, respectively) are $83 \%$ identical. ${ }^{[19]}$ However, pyridazinones, which are potent noncovalently binding, anti-inflammatory inhibitors designed toward hVAP-1, do not effectively inhibit the function of the mouse protein. ${ }^{[20]}$ The 3D model of mVAP-1 successfully explained why the mouse cannot be used as a model organism for the design of inhibitors against hVAP-1 (Figure 3A).

Since structural models are predictions, they include varying degrees of error and misinformation. An estimation of the reliability of the model can be obtained from the level of sequence identity with the template structure(s). However, even when a family of proteins shares low sequence similarity, the fold is conserved and key structural and functional features are often retained across the family. ${ }^{[21]}$ Multiple sequence alignments together with structure-based sequence alignments of related structures can reveal the structurally conserved and variable areas, providing valuable information that can then be used to improve the alignment between the template and model sequences. ${ }^{[22]}$ Additional guiding information can be obtained from various databases and from the literature on the likely importance of key residues in the family; for example, reports on effects of engineered mutations on binding or catalysis and whether residues positions are exposed to a binding cavity. ${ }^{[23]}$ Such knowledge-based approaches (Figure 2) have been valuable in many studies and significantly increased the reliability of the modeling results. ${ }^{[3,24,25]}$ Often it is not even necessary to model the entire protein, and this is frequently useful when the overall sequence similarity is low and 


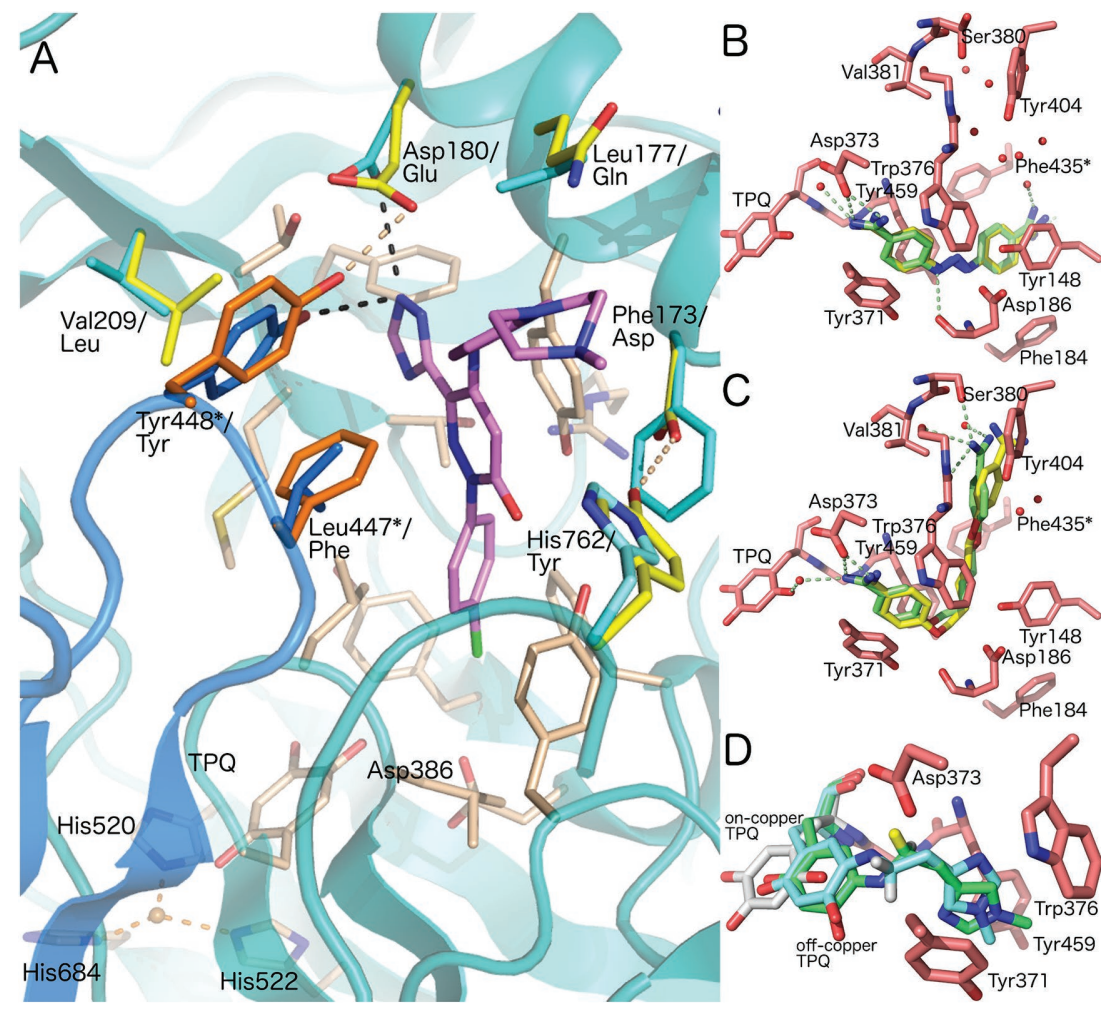

Figure 3. A) Homology modeling in understanding species-specific binding properties of the ligand-binding sites of human and model system proteins. Homology model of mouse VAP-1 (mVAP-1) provides explanation why pyridazinone (pink sticks), an anti-inflammatory inhibitor designed toward human VAP-1 (hVAP-1) does not inhibit mouse protein. Asp180 (cyan) and Tyr448* (blue; from the other monomer) of hVAP-1 form hydrogen bonds with the inhibitor. In the homology model of mVAP-1, the residues corresponding to Asp180 and Val209 (cyan) in hVAP-1 are replaced by larger glutamate and leucine residues (yellow) blocking pyridazinone binding to mVAP-1. [7] B,C) Successful control docking using Glide in the Schrödinger suite. Control docking results of berenil (B) and pentamidine (C) (yellow) to human diamine oxidase (hDAO) are in well agreement with their experimental binding mode (green): pentamidine (C) binds into a side cavity that is filled by water molecules (red spheres) in the berenil complex (B). Prior to the docking experiment, these water molecules should be removed, whereas the inhibitor-binding water molecules near TPQ should be restored in the binding site. D) Knowledge-based analysis of Glide docking results. hDAO is involved in histamine and ethylhistamine degradation but there is no X-ray structure available for the hDAO-substrate complex. The analysis of methylhistamine docking results reveals two similar binding modes but only the best-ranked pose of methylamine (green) has geometrically right position for the hydrogen atom (yellow) that is abstracted by the catalytic base (Asp386) during catalysis (Lopes de Carvalho, unpublished results).

the overall alignment is unreliable. For many purposes, a model structure limited to the ligand-binding site is adequate, if the binding site residues and their spatial arrangement are reasonably well conserved. Such binding site models can be used, for example, for designing novel ligands, analyzing species-specific ligand-binding properties, discovering targets for polypharmacological approaches and for predicting off-target proteins for drug compounds or drug candidates. ${ }^{[34]}$

\subsubsection{Computational Approaches Utilizing the Structural Data in Drug Design and Discovery}

There are multiple rational and innovative ways of exploiting molecular structures in drug design, discovery, and development. ${ }^{[26-31]}$ The most common and straightforward approach is to simply examine the molecular structures with a suitable software to draw insights. Visual analysis of target protein-ligand interactions can give ideas on how to improve the binding affinity of the ligands, for example, by introducing a polar functional group that would form a new hydrogen bond or a nonpolar group to anchor the ligand to a hydrophobic pocket nearby. Calculation of so-called molecular interaction fields to characterize the binding site can further increase the knowledge of the different functional group's contribution to the binding interaction. ${ }^{[32]}$ In cases when we do not know exactly where the ligands bind, there are several tools that can help identify the possible ligand-binding sites in the target protein structure. ${ }^{[33]}$ Similarly, protein-protein interfaces can be computationally evaluated for possible "hot spot" binding regions in order to target them with putative protein-protein interaction (PPI) inhibitors. ${ }^{[34-36]}$ Moreover, in the absence of the experimental target-ligand complex structure, molecular docking or protein-protein docking can be used to predict ligandbinding modes to assist in the interaction analysis. ${ }^{[37-40]}$

Predicting ligand-binding modes by docking still has many challenges. The flexible nature of small compounds is usually taken into account by the current docking algorithms, whereas the estimation of ligand-binding affinity ${ }^{[41]}$ and the conformational flexibility of the large protein structures including changes in side chains, backbone, and domains upon ligand binding is more complex to address. ${ }^{[42-45]}$ To reveal limitations on the docking software performance, it is advisable to test several docking programs and analyze the consistency of the predicted ligand-binding modes. If possible, the performance of a certain docking program should be tested by control docking, where the ligand from the X-ray structure of a protein-ligand complex is docked back to the crystal-binding site and the docking result is compared with the original X-ray complex. The control docking of berenil (an antitrypanosomal drug; Figure 3B) and pentamidine (used to treat pneumocystis pneumonia; Figure 3C) into human diamine oxidase (hDAO) structure gives a good example of a successful control docking result. Both of them bind in the minor groove of DNA, but also to hDAO, which is an off-target for several diamine derivatives used as drugs. ${ }^{[46]}$ Docking methods produce an ensemble of molecular poses ranked by a scoring function that attempts to evaluate the binding energy between the target and the ligand. ${ }^{[47,48]}$ Since the highest scoring result may not reflect the actual binding mode due to the limitations in scoring functions, ${ }^{[47,48]}$ it is important 


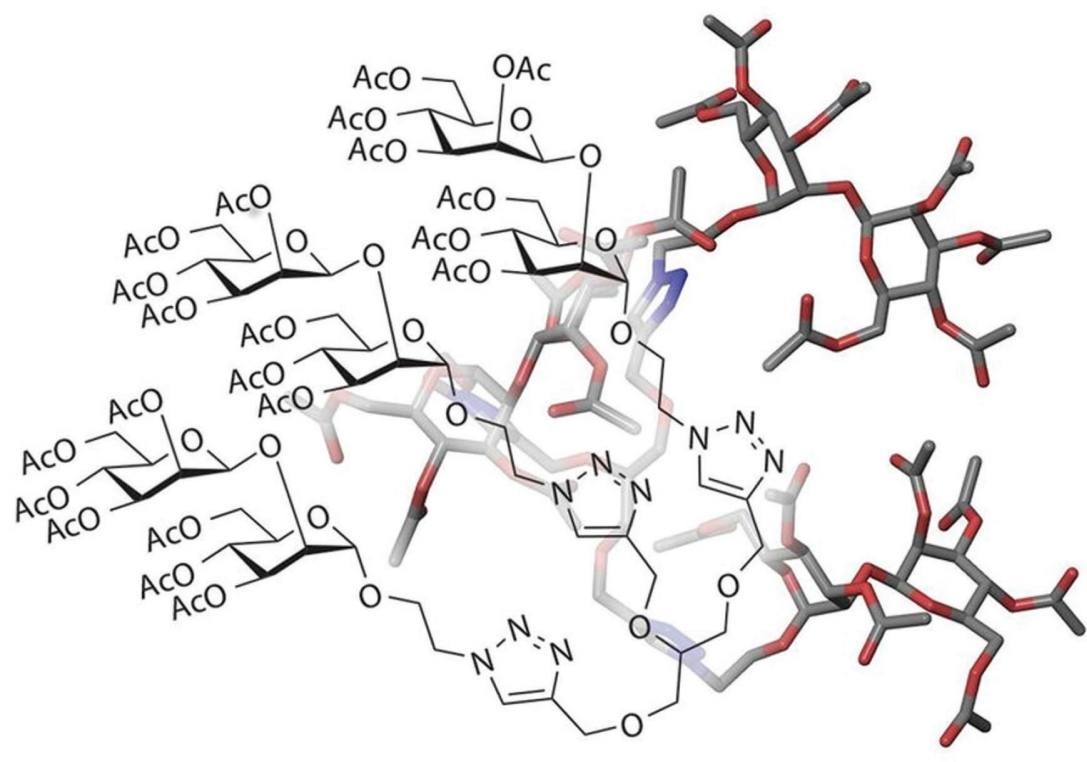

Scheme 1. Molecular design of immunostimulatory carbohydrate assemblies. Glycoimmunology is emerging as a highly topical research area with significant interest directed toward development of a Th1 and Treg response inducing immunostimulants. Synthetic $\beta-(1 \rightarrow 2)$ linked mannobiose derived trivalent glycoclusters, mimicking the cell surface oligomannans of C. albicans are now shown to possess considerable potential as immunostimulatory adjuvants both in vitro and in vivo for specific allergen immunotherapy (SIT), with superior activity profiles compared to the earlier described CPG-ODN and monophosphorylated lipid A adjuvants. ${ }^{30-32]}$ Such oligovalent synthetic carbohydrate assemblies, also subjected to structural and conformational analysis by NMR spectroscopy, molecular modeling, and MD simulations, ${ }^{[32]}$ may potentially mimic the natural display of high-affinity ligands ${ }^{[33]}$ and rapidly enter the market as components in allergy vaccines, as such or in combination with existing allergens, including birch, grass, and ragweed, with long history and efficacy and safety data. Chemical structure of synthetic $\beta$ - $(1 \rightarrow 2)$-linked mannobiose derived trivalent glycocluster. The 3D conformation of the glycocluster at the background is based on the MD simulation studies of the molecule's minimum energy conformation (shown as sticks; atom color code: gray - carbon; red - oxygen; blue - nitrogen; hydrogen atoms are omitted for clarity).

to consider all the ligand-binding modes predicted by computational docking studies, taking into account ligand similarities, ${ }^{[49]}$ protein-ligand interaction fields based on many X-ray structures, ${ }^{[50-52]}$ and existing experimental data. Among others, binding strength of related molecules, effects of mutants on binding strength or catalysis, and effects of different inhibitors and knowledge on the catalytic mechanism should be taken into account. For example, copper amine oxidases bind substrates covalently to the topaquine (TPQ) cofactor and knowledge on the catalytic reaction mechanism is crucial for the analysis of docking results (Figure 3D).

Molecular dynamics (MD) simulations have been widely used in studying the conformational flexibility of proteins, other biomolecules, as well as small molecules. ${ }^{[53-55]}$ An analysis of the conformational space of a small molecule can aid in the molecular design of new therapeutic compounds. MD simulations were, for example, utilized in the design of trivalent glycoclusters as new immunostimulatory adjuvants ${ }^{[56]}$ (Scheme 1). Such immunostimulants of carbohydrate origin have gained significant recent interest in medical biotechnology and drug development. Furthermore, MD simulations can help one explore alternative conformations of drug targets, ${ }^{[57,58]}$ aid in locating transient pockets at protein-protein interfaces, or even be a guide toward personalized medicine when studying the effect of a single nucleotide polymorphism (SNP) on target protein-ligand interactions. ${ }^{[59]} \mathrm{MD}$ is also frequently used for refining protein models and docked ligand-target complexes or for examining their stability. ${ }^{[24,60,61]}$ However, simulations may as well be counterproductive and add additional uncertainty and error to a model. The free binding energy of the bound ligands can also be evaluated with the help of MD simulations, though it requires sufficient conformational sampling. ${ }^{[62]}$ In fact, in addition to the inaccurate molecular mechanics force fields, insufficient conformational sampling remains an important limitation of MD simulations, even though various enhanced and biased sampling methods have been developed to help overcome this challenge. ${ }^{[63,64]}$ For example, large conformational changes related to the function of proteins such as inactive-active or closed-open transitions can be investigated with biased MD methods such as targeted molecular dynamics (TMD). ${ }^{[65]}$

A very often used method in lead discovery is virtual screening (VS). ${ }^{[62,66-68]}$ In this approach, large compound databases that can contain up to millions of molecules are screened computationally to find potential bioactive compounds against a particular target. ${ }^{[69,70]}$ For example, novel opioid analgesics with reduced side effects were recently discovered from over three million molecules using a VS approach. ${ }^{[71]}$ The procedure starts by preparing the database compounds; for example, 2D structures are converted to 3D structures; stereoisomers, tautomers, and possibly alternative conformers are generated. It is also useful to prefilter the compounds with unwanted properties from the database, for example, according to the Lipinski Rule of Five (Ro5) ${ }^{[72]}$ that aims to remove compounds that might not be orally bioavailable. The actual screening criteria may be based on either the $2 \mathrm{D}$ or $3 \mathrm{D}$ structures of known active compounds or the structure of the binding site in the target protein, or both. In structure-based VS, one also needs to carefully select if the target protein structure is a single model, an experimental structure, or an ensemble of target conformers and prepare it by, for example, adding hydrogen atoms, checking the protonation state of the binding site residues, and including possible cofactors, metal ions, or conserved water molecules involved in the ligand binding. Ligand-based VS utilizes, for example, pharmacophore modeling or similarity searches to find matching compounds from the database, whereas structure-based VS includes docking and scoring of all the database compounds in the target-binding site. ${ }^{[73,74]}$ To address the uncertainty of scoring functions that rank the compound poses, one should always perform the control docking and try different software if possible. If there are many known active compounds, 
a retrospective docking analysis can be performed to see how well the VS protocol can enrich the known active compounds to the group of top-ranked compounds from a database of decoys. In addition, consensus scoring that combines several different scoring functions could be employed to help selecting the top hits for biological testing. ${ }^{[75]}$ To reduce the number of hits selected, the best-ranked compounds can be further filtered, for example, according to chemical diversity, ease of synthesis, or patentability (Figure 4). General pitfalls in VS have been comprehensively reviewed in ref. [76]. In practice, VS can identify molecules that are true binders, but also assign nonbinders among the top-ranked, or miss true binders.

Quantitative structure-activity relationships (QSAR; also called quantitative structure-property relationships, QSPR) is a ligand-based approach commonly used for lead optimization and selection of candidate compounds for synthesis or testing. ${ }^{[77,78]}$ The QSAR methods aim at establishing a quantitative correlation between the chemical structure of a set of molecules and their experimentally known biological activity (e.g., binding affinity or G-protein activation ${ }^{[78]}$ ) or property (e.g., ADMET properties such as solubility, permeability, liver enzyme metabolism, or heart toxicity ${ }^{[79,80]}$ ). QSAR models are used to predict the activity and property of untested compounds on the basis of their chemical structure. Traditional 2D-QSAR employs only the 2D structures of compounds and is mostly used to optimize the substituents on a common chemical scaffold structure. 3D-QSAR methods also take into account the
3D structure of the compounds and are widely used in drug design. When one builds a QSAR model (Figure 5), the general underlying assumptions and limitations of QSAR modeling should be taken into account, and the model's applicability domain has to be clearly defined to obtain a useful and acceptable model with predictive power. ${ }^{[77]}$ See Table 2 for a summary of the critical aspects, risks, and limitations that should be taken into account when using the computational approaches we have discussed above.

\subsection{Computational Network Modeling for Polypharmacology}

Computational network modeling is a widely used approach to describe and understand complex biological systems. It has become a key tool to integrate many omics data sets, and to investigate questions ranging from onset of disease, as support for diagnostics and therapeutics, and to aid drug target identification. ${ }^{[81-84]}$ There are many types of computational modeling approaches, supported by excellent software tools. ${ }^{[85-89]}$ For example, models can be presented as networks, where the nodes represent the genes or proteins of interest, and the edges between them describe the dynamic interaction between them. ${ }^{\left[{ }^{90}\right]}$ A recent example of such a network model is a proteome-scale map of the human interactome network. ${ }^{[1]}$

The network control theory is a powerful tool for analyzing network models. ${ }^{\left[{ }^{[2]}\right.}$ In the network, control is sought over a given

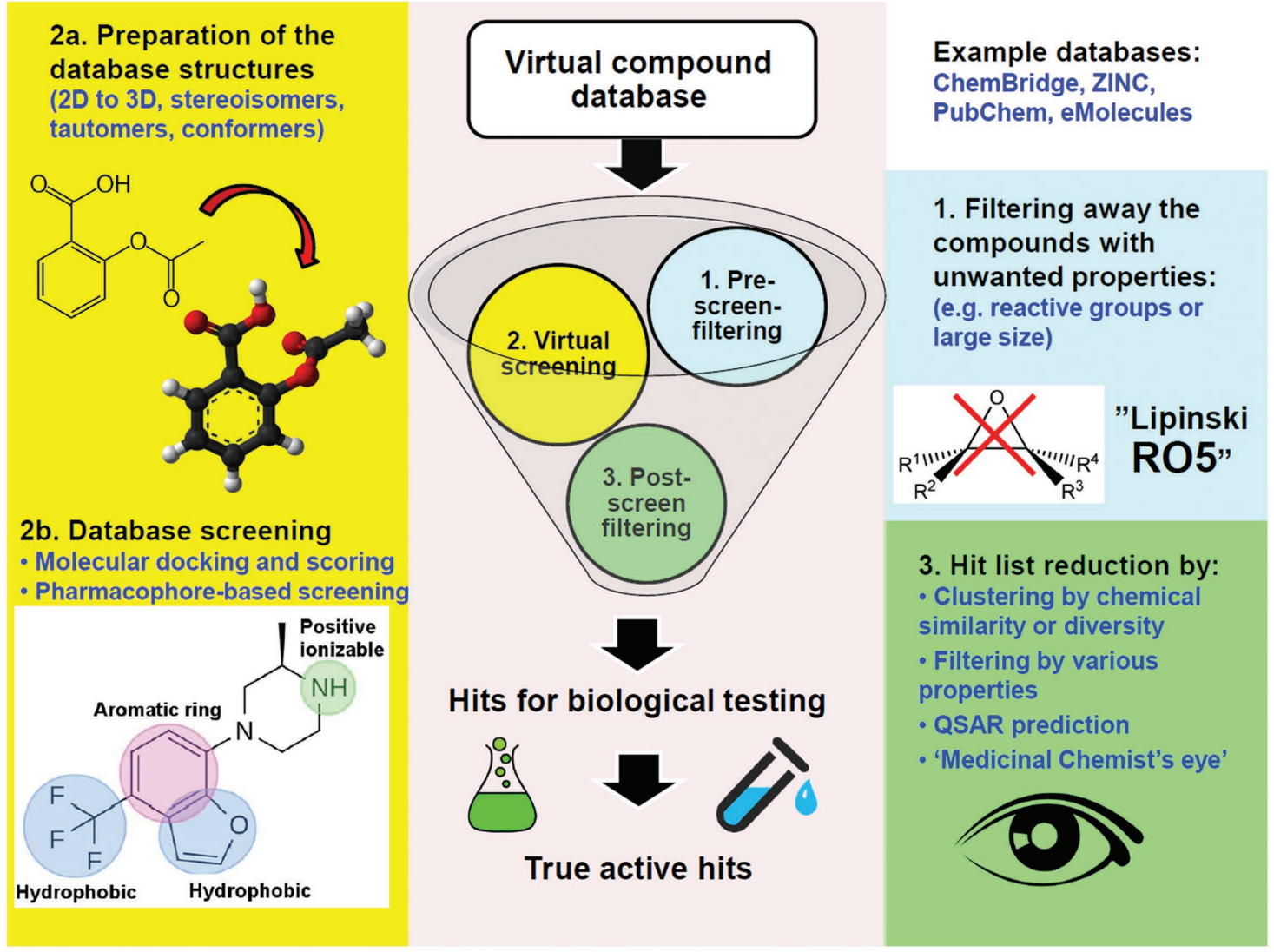

Figure 4. A general virtual screening workflow. 


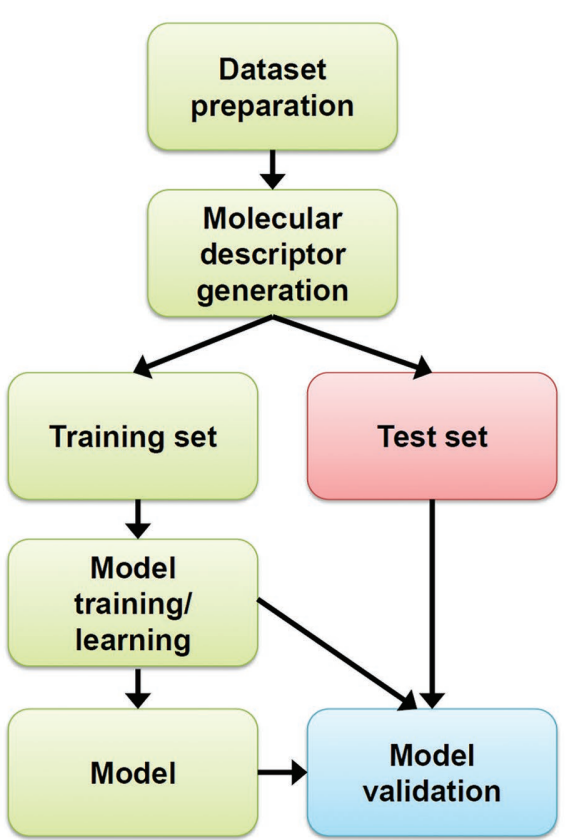

Figure 5. General workflow for building a QSAR model.

set of targets, in the sense of being able to change their configuration through external interventions on some well-chosen input nodes in the network, taking advantage of the network topology. The intuition behind this problem formulation is to find suitable combinations of drug targets acting on some nodes of the network, which through their cascading effect throughout the network may change the target's quantitative configuration from an unfavorable (e.g., disease-specific) setup to a favorable one (e.g., physiological). The dynamics of such a network may be described as a discrete linear dynamical system, and the target controllability problem is to find the smallest number of input nodes that make the system target controllable. ${ }^{[93]}$

For example, one can identify a set of cancer-specific genes that are required for survival of cancer cells using a diseasespecific network model. The target controllability problem in this case is to predict minimum combinations of drug targets and drugs acting on them, which may be able to switch off the disease-specific genes for any patient-specific starting configuration of the network (Figure 6). We are currently developing a disease-specific network for cancer applications using a big data-driven approach to build a directed protein-protein interaction network based on an automatic scanning of several data sources, including the KEGG pathway database, Pathway Commons, and WikiPathways, as well as the DrugBank and a list of FDA-approved drugs to identify drug targets in the network [RogojinTR2016]. The tool may even include user-generated data on, for example, patient-specific highly expressed genes. Finally, the tool compares the generated network with cancerspecific essential gene data from the COLT-Cancer database. ${ }^{[94]}$

However, formulation of the target controllability problem as an optimization problem is computationally hard, even if simplified to focus just on the structural part of the network,

\section{NOTE}

Check dataset quality: adequate number of compounds, wide activity range, consistent biological activity data

$>$ Compute / measure experimentally a number of molecular descriptors (terms) reflecting the physicochemical properties of a compound for each compound in the data set; critically consider which descriptors to use

Select the compounds used for (a) model building (training set) and (b) examining the predictive ability of the model (test set)

Derive a quantitative correlation between the molecular descriptors and the activity using statistical methods. Critically consider which statistical model to use.

Internal validation in the training phase: model's ability to explain the variance in the biological activity; external validation: predictive power of the model (test set) while ignoring its precise weights. ${ }^{[95]}$ More specifically, the time needed to find the smallest control for a given network grows exponentially with the size of the network. Several alternative solutions aiming for fast approximations of the optimal solutions exist, including approaches to obtain therapeutic suggestions and cell type-specific combinations of drugs. ${ }^{[93,95,96]}$ If the network model takes patient-specific data into account, these suggestions may even contribute to personalized therapeutics. Importantly, one may also obtain suggestions for repurposing existing drugs, currently in use for other types of diseases, thus positively contributing to the problem of expensive drug discovery.

The network controllability problem does not come without limitations. Its most clear drawback is that it is only applicable to linear networks; this limits its applicability to a wider, often nonlinear, set of biological interactions. Another limitation is that it assumes a simplified model of drug effects, ignoring possible powerful off-target effects and synergistic effects of drug combinations. Finally, another limitation is that of the mathematical model assuming arbitrary input functions, which may correspond to unrealistic or nonviable combinations of drug dosages and assumptions of their decay rate in an organism. Addressing all these issues should improve the wider applicability of the network controllability approach in the biomedical and the pharmaceutical domain.

\section{Nanotechnology as an Enabling Tool in Drug Development}

Nanomedicine, "the application of nanotechnology to health," makes use of nano-sized tools in the form of nanomaterials for diagnosis, monitoring, control, prevention, and treatment 
Table 2. Limitations, risks, and critical issues involved in using common computational approaches in drug discovery, design, and development.

\begin{tabular}{lll}
\hline Computational approach & Purpose in the drug design/discovery process & Limitations, risks, and critical issues \\
\hline $\begin{array}{l}\text { Traditional and automated } \\
\text { comparative modeling }\end{array}$ & $\begin{array}{l}\text { Provides a structural model in the absence of } \\
\text { an experimental structure; useful models can } \\
\text { aid a lot in structure-based drug design efforts. }\end{array}$ & $\begin{array}{l}\text { Requires critical thinking and careful integration of all } \\
\text { possible data; the risk of becoming a "black box" method } \\
\text { can be avoided if the sequence alignment can be carefully } \\
\text { built, analyzed, and adjusted. }\end{array}$ \\
\hline Drawing insights from the structural data
\end{tabular}

Examining molecular interactions Understanding the key interactions between the Requires critical thinking and careful integration of all

possible data, since the experimental structures can be incomplete or sometimes even wrong; good knowledge on the character of the noncovalent bonds in ligand-protein interactions is essential.

Mechanistic understanding of motions of molecules, refining of model structures, production of alternative molecule conformations, estimating of binding affinity of ligands.
Sufficient sampling is required; a lot of computational resources are needed to perform especially the longer simulations; currently, atomistic simulations can reach only about 1 ms time scale; MD force fields are still inaccurate in describing systems, where quantum effects are important; simulation of a modeled structure may add additional error and uncertainty to a model.

\begin{tabular}{lll}
\hline Molecular docking & $\begin{array}{l}\text { Predicting the ligand-binding site and pose and } \\
\text { the estimation of the binding energy enables } \\
\text { the ranking of the docked compounds and } \\
\text { selection of the candidate hits for biological } \\
\text { testing. }\end{array}$ & $\begin{array}{l}\text { Accuracy of the current scoring functions is limited; } \\
\text { validation of the selected scoring function should } \\
\text { be performed if possible; consensus docking and or } \\
\text { scoring might be needed to aid in selecting the best hits; } \\
\text { results dependent on the target structure quality and } \\
\text { Pharmacophore-based screening }\end{array}$ \\
$\begin{array}{ll}\text { Facilitates the discovery of novel compounds } \\
\text { that have the same chemical features than the } \\
\text { known active compounds. }\end{array}$ & $\begin{array}{l}\text { Alignment of different ligands can be challenging; bioac- } \\
\text { tive conformation might not be known. }\end{array}$ \\
\hline [27] & Quantitative structure-activity relationships \\
\hline Traditional (2D)-QSAR and 3D-QSAR & $\begin{array}{l}\text { Predicting the activity or other properties } \\
\text { of novel compounds on the basis of their } \\
\text { chemical structure. }\end{array}$ & $\begin{array}{l}\text { Alignment of different ligands can be challenging; } \\
\text { biological data must be of good quality; robust number of } \\
\text { ligands with known activities needed; rigorous validation } \\
\text { of the models should be performed. }\end{array}$
\end{tabular}

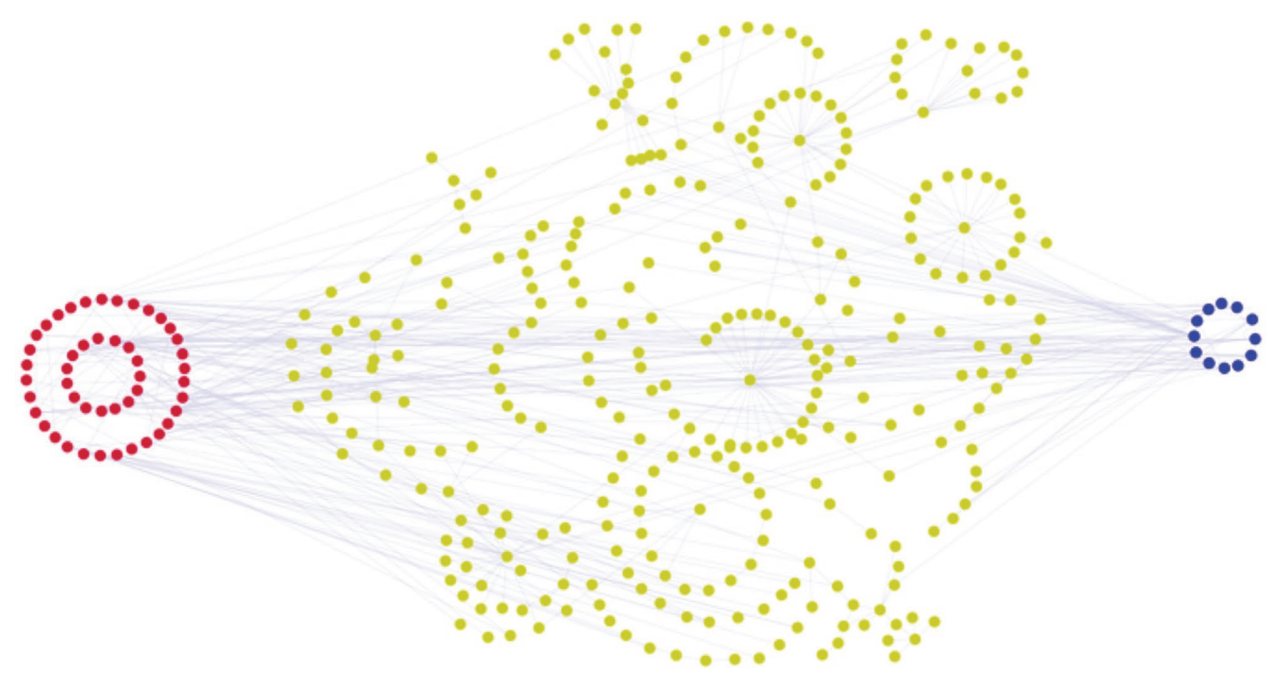

Figure 6. A directed protein-protein interaction network model for pancreatic cancer, constructed based on UniProtKB and literature data. The network nodes targetable by drugs from the DrugBank database (blue). Cancer-essential nodes from the COLT database (red). The rest of the protein nodes of the model (yellow). 
of disease. The field of nanomedicine consequently covers several application areas, including drug delivery, in vitro diagnostics, in vivo imaging, smart/responsive biomaterials, and active implants and coatings. ${ }^{[97]}$ In 2005, the European Technology Platform for Nanomedicine (ETPN) published a Vision Paper, which subdivided nanomedicine into three distinct research areas: (1) targeted drug delivery and release (nanopharmaceuticals); (2) nanotechnology-based diagnostics including imaging (nanodiagnostics); and (3) regenerative medicine. Since then, owing to the interdisciplinary nature of this research field, boosted by advances in chemistry, pharmacy, biology, medicine, and imaging, the development of so-called "theranostic" nanomedicines that simultaneously possess both diagnostic and therapeutic capabilities have further emerged. The preclinically most relevant applications of these involve validation and optimization of the properties of drug delivery systems, prescreening patients, and enabling personalized medicine. ${ }^{\text {[98] }}$

Nanomaterials essentially bridge the gap between molecules and macroscopic materials. Linking to the classical definition of nanotechnology, which emphasizes the unique phenomena that occur on the nanoscale, nanomedicine takes advantage of two such general phenomena: transitions in physico-chemical properties and transitions in physiological interactions, ${ }^{[99]}$ the latter generally referred to as the nano-bio interface. Nanoscale is also the scale of function in nature, which is the ideal example of a system that functions impeccably on the nanoscale with a high degree of optimization regarding involved materials, energy consumption, and data handling. ${ }^{100]}$ Consequently, many of the advantages, and risks, of nanomedicine are related to these unique physiological interactions that occur on the nano-bio interface in the size range between the molecular and microscopic scales. ${ }^{[99]}$ Being able to fully control these risks have hampered the clinical translation of nanomedicines, and regulatory bodies still struggle with the type of characterizations that should be carried out in order to introduce safe nanomedicines. The fabrication of nanomedicines is more complex than conventional dosage forms, ${ }^{[101]}$ as not only the physicochemical characteristics of the nanomedicines dictate their function, but also the manner in how each parameter affects functionality needs to be known. Emphasis is put on particle size and shape, chemical composition, surface charge, and functional groups, and both chemical and colloidal stability under relevant conditions, which all are critical material properties that govern the nanomedicine behavior in a living system. The last cannot be enough emphasized, as the physicochemical characteristics of a nanosystem will change after administration, the route of administration also being a parameter to take into account. The main responsible for this phenomenon is the protein corona formation that occurs upon contact with a biological fluid. Hence, the nanoparticle has a "synthetic identity" describing its characteristics upon standard materials characterization conditions, but acquires a "biological identity" after being introduced into a biological/physiological environment. ${ }^{[102]}$ Further, both physical and biological barriers such as diffusion, flow and shear forces, induced aggregation, phagocytic sequestration, and premature clearance ${ }^{[103]}$ need to be overcome to reach the target, which can be difficult to predict without methods standardized for the purpose. Methods for assessing drug molecule $\mathrm{ADME}(\mathrm{T})$ properties have been developed throughout the years, but additional levels of complexity arise for the application of these to nanosystems. Here, on one hand computational approaches (see Section 2) for predicting nanoparticle in vitro and in vivo behavior, ${ }^{[104]}$ as well as relevant model systems (see Section 5) combined with advanced imaging techniques will aid in elucidating a more realistic scenario for nanoparticle performance and function in order to enable faster translation.

\subsection{Nanopharmaceuticals}

The field of nanopharmaceuticals deals chiefly with the development on nano-sized drug delivery systems, where the nanomaterial serves as the drug carrier. Such nanoformulations are expected to increase the therapeutic outcome in many ways, due to their ability to guide drugs to the desired site of action with increased precision (targeted drug delivery) and provide controlled release, enhance drug solubility and rate of dissolution, extend the drug half-life in the body, improve the therapeutic index, reduce the dose needed, increase the drug stability, promote the transport across biological barriers, decrease drug resistance, and reduce toxicity and immunogenicity. These capabilities are essentially built into the nanomaterial carrier by rigorous materials design. Nanopharmaceuticals have consequently been defined by Rivera et al. as: "Pharmaceuticals engineered on the nanoscale, that is, pharmaceuticals, where the nanomaterial plays the pivotal therapeutic role or adds additional functionality to the previous compound." ${ }^{[105]}$ Nanoformulations of small-molecular compounds reached the market more than 20 years ago, when Doxil, a liposomal anticancer formulation, was introduced, and cancer is still accounting for approximately about $2 / 3$ of nanotherapeutics in development. The "real" benefit of cancer targeting by nanomedicines is currently being debated in the literature (see Section 3.3.1 below), but it is clear that proven benefits such as increased drug solubility and stability, prolonged circulation time in the body, improved biodistribution, reduced toxicity, and enhanced therapeutic efficacy via nanoformulation approaches have resulted in approval of a number of cancer nanomedicines. ${ }^{[106]}$ However, all drug molecules will not benefit from being nanoformulated, hence the rationale should be carefully contemplated and warranted. For instance, there is currently an exponential growth in interest for biological drugs, which could indeed benefit from being formulated as nanopharmaceuticals due to their sensitivity and unfavorable properties, making them challenging for many conventional formulations. In vivo gene delivery is another area, where nanoformulations have recently shown promising advances in protecting the fragile biomolecules during delivery. The typical nanoscaled carriers of today are increasingly complex systems, with sophisticated release mechanisms that can release the drug upon different endogenous ( $\mathrm{pH}$, temperature, biochemical reactions) or exogenous (light, magnetic field, ultrasound) stimuli. ${ }^{[107]}$ Notably, "molecular machines" are often utilized as gatekeepers; the principles of which were awarded the Nobel Prize in chemistry in 2016. While accumulated advances have spurred high hopes of nano-sized tools to revolutionize treatment of many diseases in a fashion that currently cannot be achieved with conventional dosage forms, ${ }^{[108]}$ it is most likely not the most complex 
systems that will actually reach the patients, as the more simplified systems are generally easier translated. ${ }^{[109]}$

\subsection{Nanodiagnostics}

Nanoscopic imaging probes have already made significant progress in overcoming limitations associated with conventional, molecular imaging agents. ${ }^{[110]}$ The nanostructures essentially can be either (1) inherently detectable by optical and biomedical imaging techniques, or (2) serve as carriers for existing, molecular imaging agents. ${ }^{[111]}$ Inorganic nanostructures are readily utilized as biomedical imaging probes due to their inherent detectability by a variety of different imaging modalities, for example, quantum dots, QDs, for optical imaging and superparamagnetic iron oxides, SPIONs, for magnetic resonance imaging (MRI). Due to the heavy metal composition of QDs, hampering their in vivo imaging translatability, ${ }^{[112]}$ research efforts have been put into developing alternative probes for optical imaging. These include carbon-based nanostructures, for example, carbon dots and fluorescent nanodiamonds, as well as upconverting nanophosphors (UCNPs). SPIONs in the form of ferrofluids are already in clinical use, but due to their negative contrast in MRI, other metal oxides such as manganese and gadolinium oxide nanoparticles with positive contrast are being developed. Novel nanoscopic MRI contrast agents are especially advantageous as constructs in multimodal or theranostic nanoparticulate systems. ${ }^{[113]}$

When nanoparticles are utilized as carriers for molecular imaging agents, traits including cellular uptake and intracellular release ability, capacity to carry high amounts of different compounds, allowing a protective and thus stabilizing environment for incorporated agents, and ability to retain the cargo within the particle for prolonged times are exploited similarly as in the design of nanopharmaceuticals. Utilizing this approach, sensitive fluorophores can be photostabilized and the dose of toxic imaging agents such as Gd-based, clinically used MRI contrast agents, which are organic complexes of $\mathrm{Gd}$ ions can be lowered while the imaging time-frame can be prolonged owing to retention of the nanocarrier at target sites. For both design approaches, the ability of the nanoscopic particles to provide access to sites unreachable by the molecule itself by crossing of biological barriers and prolonged circulation times in the body by changing stealth properties is exploited. Moreover, one nanoparticle can carry multiple specific targeting and imaging moieties, thus enabling a multivalent mode of attachment increasing avidity, which can enhance both the sensitivity of the signal (multiple imaging agents per binding event) and the probability for attachment to its target (multiple targeting moieties per particle). The imaging modality can be chosen depending on the nanoparticle design, where the combination of different nanomaterial constructs can even generate multimodal probes. ${ }^{[114]}$ One of the furthermost advantages with multimodal probes is that they can provide complementary information in one shot, for example, high resolution and high sensitivity, associated with the imaging modalities the probes are compatible with. ${ }^{[115]}$ While these types of systems are currently mostly avidly exploited in research, nano-based imaging agents have been stated to be important for personalized treatment, for preselection of patients that are supposed to benefit most from an intended therapy, and as constructs in theranostic nanomedicines in the future. ${ }^{[100]}$

\subsection{Nanomedical Applications}

The ETPN has identified the following diseases as potential beneficiaries of nanomedicine: cancer, atherosclerosis, diabetes, ocular diseases, Alzheimer's disease, arthritis, and infectious diseases. Overviews of the application areas within these diseases tied to the topics of the review are illustrated in Figure 7, and a couple of examples will be briefly introduced. For a comprehensive review on the topic, please see ref. [116].

\subsubsection{Nanomedicine in Cancer}

One of the main difficulties of cancer treatment is to achieve sufficient drug concentration at the site of the carcinoma, due to the numerous bio-barriers in different organs and cancer tissues. Further, high systemic exposure of anticancer agents leads to dose-related toxicity, giving rise to serious adverse effects, and resistance to therapeutic agents. The progress of nanotechnology during the last decades has imparted high hopes on improving especially cancer therapeutics. A multitude of different types of nanoparticles, including liposomes, polymersomes, polymeric particles, inorganic particles, etc., have been developed for anticancer drug delivery. Nanoparticles can also be designed to elicit immune response as nanovaccines for cancer treatment. ${ }^{[117,118]}$ Nanoparticles typically accumulate passively in tumor tissue due to the enhanced permeability and retention (EPR) effect, ${ }^{[119]}$ but the Holy Grail in nanomedicine is to be able to achieve even more selective delivery via active targeting. Porous nanomaterials are one type of nanoparticles that are widely used for drug delivery applications, due to their unique properties, including nano-sized pores for loading of both small molecules and large biomolecules (proteins, nucleic acids), good biocompatibility, biodegradability, and flexibility in terms of applicable surface functionalization strategies (Figure 8). Mesoporous silica (MSNs) and porous silicon (PSi) are typical examples, that have, for example, been functionalized with the small-molecular ligands folic acid and glucose, ${ }^{[120,121]}$ as well as tumor homing peptides such as CooP and iRGD, resulting in higher accumulation at the tumor site via active targeting. ${ }^{[122,123]}$ However, the clinical benefit of active targeting has been questioned, ${ }^{103]}$ and most anticancer nanomedicines on the market still rely on passive tumor targeting. Protein corona formation in vivo may hamper the access of the targeting ligands to cell surface receptors, and PEGylation was for long applied as a universal strategy to hide nanoparticles from the immune system (a.k.a. stealth particles). Certainly, the real-life scenario is more complex, but detailed investigation of the protein corona formation has not surfaced before quite recently. Critique has also been directed toward the in vivo models used to evaluate cancer nanomedicines, favoring tumor accumulation due to the EPR effect in mice, but with poor translatability to human cancers. ${ }^{[124]}$ Such misconceptions have led to overexaggerated expectations when it comes to the success of cancer nanomedicines. However, 


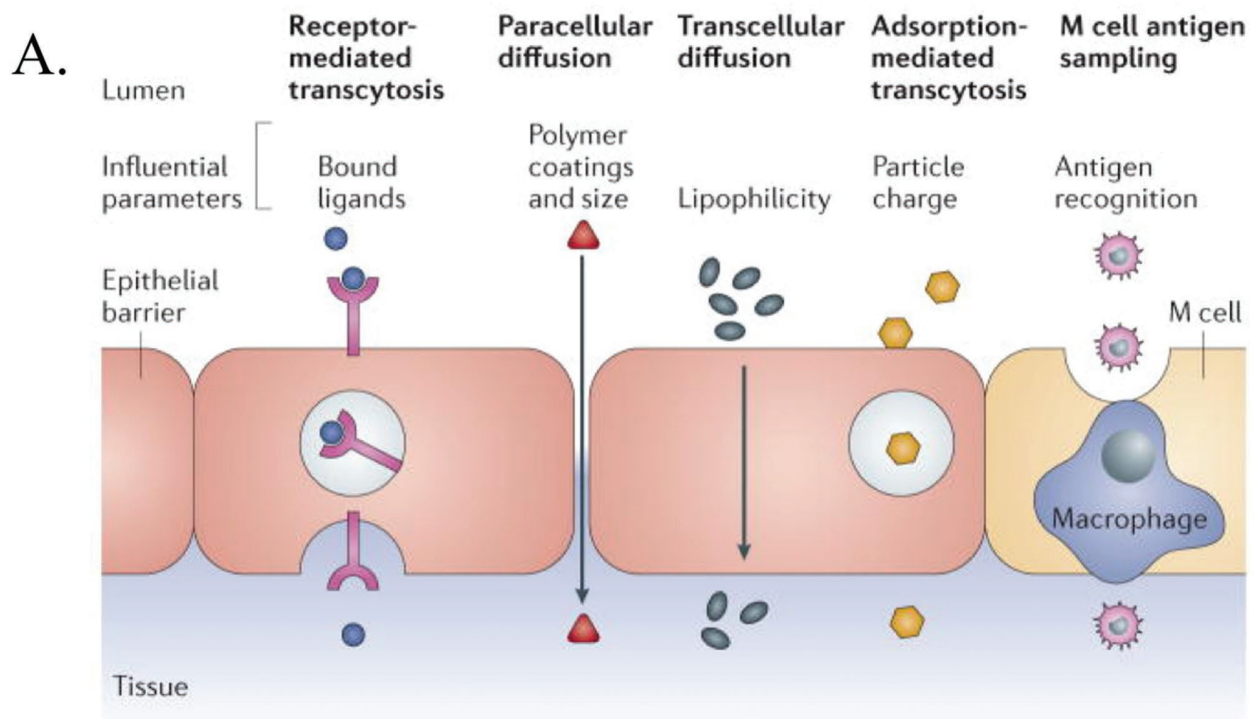

B.
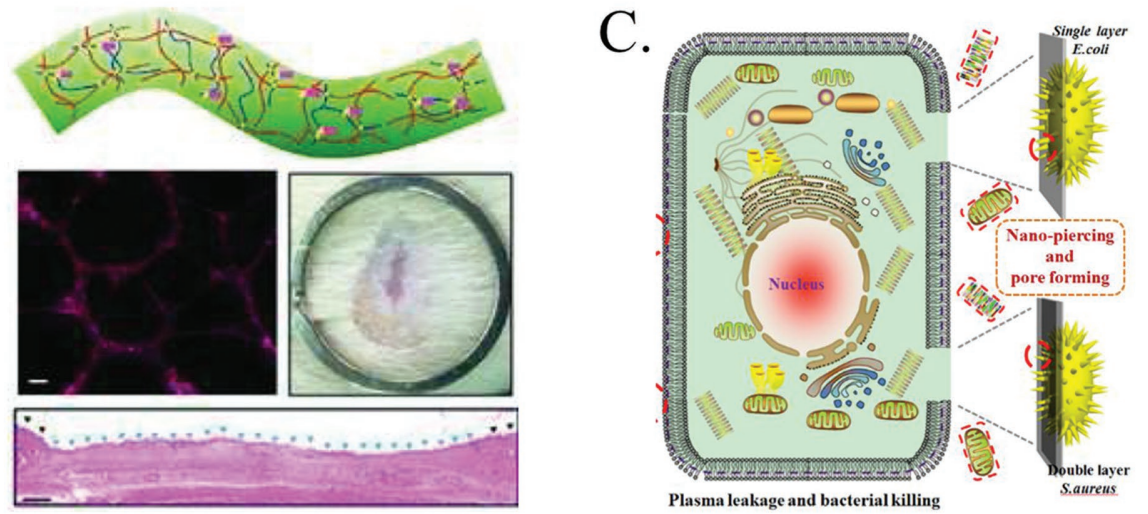

Figure 7. Examples of nanotechnology applications, including diabetes, wound healing, and combating bacterial resistance. A) Development of patientfriendly insulin delivery nanoparticle formulations. Various properties of nanoparticles can be tailored to exploit transepithelial transport mechanisms to facilitate systemic insulin delivery. Nanoparticles prepared with bound ligands for specialized receptors expressed on epithelial cell surfaces can be transcytosed across epithelial barriers. Ultrasmall nanoparticles with hydrophilic coatings can exploit paracellular diffusion to bypass epithelial barriers. Nanoparticles with tuned lipophilic physicochemical properties can permeate across epithelial barriers through a transcellular pathway. Cationic charged nanoparticles can exploit the adsorption-mediated transcytosis pathway for transport across epithelial barriers. Finally, nanoparticles that are transported across epithelial barriers by antigen sampling microfold cells ( $\mathrm{M}$ cells) could be developed. Reproduced with permission. ${ }^{[8]} \mathrm{B}$ ) The desferrioxamine-loaded hydrogel nanofibrous scaffolds can interfere with the required prolyl-hydroxylases cofactors by acting as $\mathrm{Fe}^{2+}$ chelators and upregulate the expression of $\mathrm{Hif}-1 \alpha$, leading to a significant increase of the neovascularization. Reproduced with permission..$^{[9]}$ Copyright 1994, Taylor and Francis. C) Illustration of the enhanced bacterial killing mechanism of prickly $\mathrm{Zn}-\mathrm{CuO}$ nanoparticles by a multidimensional nanopiercing process inducing accelerated cytoplasma leakage on the bacterial cell wall. Reproduced with permission. ${ }^{[10]}$ Copyright 2011 , Bentham Science Publishers Ltd.

recent exhortations call for "looking beyond the targeting" and focusing on the other aspects and clinical advancements of nanomedicine. For example, the first generic cancer nanomedicine was recently approved, and the delivery of two chemotherapeutic drugs in a therapeutically synergistic ratio by a single formulation and triggered release strategies are currently being evaluated in phase III clinical trials. ${ }^{[124]}$

\subsubsection{Nanoantibiotics: Nanomedicines as Modern-Era Antibiotics}

The challenging and dynamic situation in infectious diseases requires the investigation of novel platforms to bring alternative treatments for bacterial diseases. New antimicrobial drug developments cannot catch up with the microbial pathogens' fast and frequent development of resistance in a timely manner. Consequently, there have been efforts to create alternative treatments by employing antibacterial nanomaterials, to which pathogens may not be able to develop resistance. ${ }^{[125]}$ Antibacterial nanoparticles have been reported to offer advantages in reducing acute toxicity, overcoming resistance and reducing the cost, when compared with conventional antibiotics. ${ }^{[126,127]}$ Most of the studies to date have focused on inorganic nanoparticles containing silver, ${ }^{[128]}$ gold, ${ }^{[129]}$ cupper, ${ }^{[130]}$ zinc, titanium oxide, ${ }^{[131]}$ and cerium oxide as antibacterial agents. ${ }^{[125]}$ These materials can inherently exert antibacterial activity, and can further, similarly 

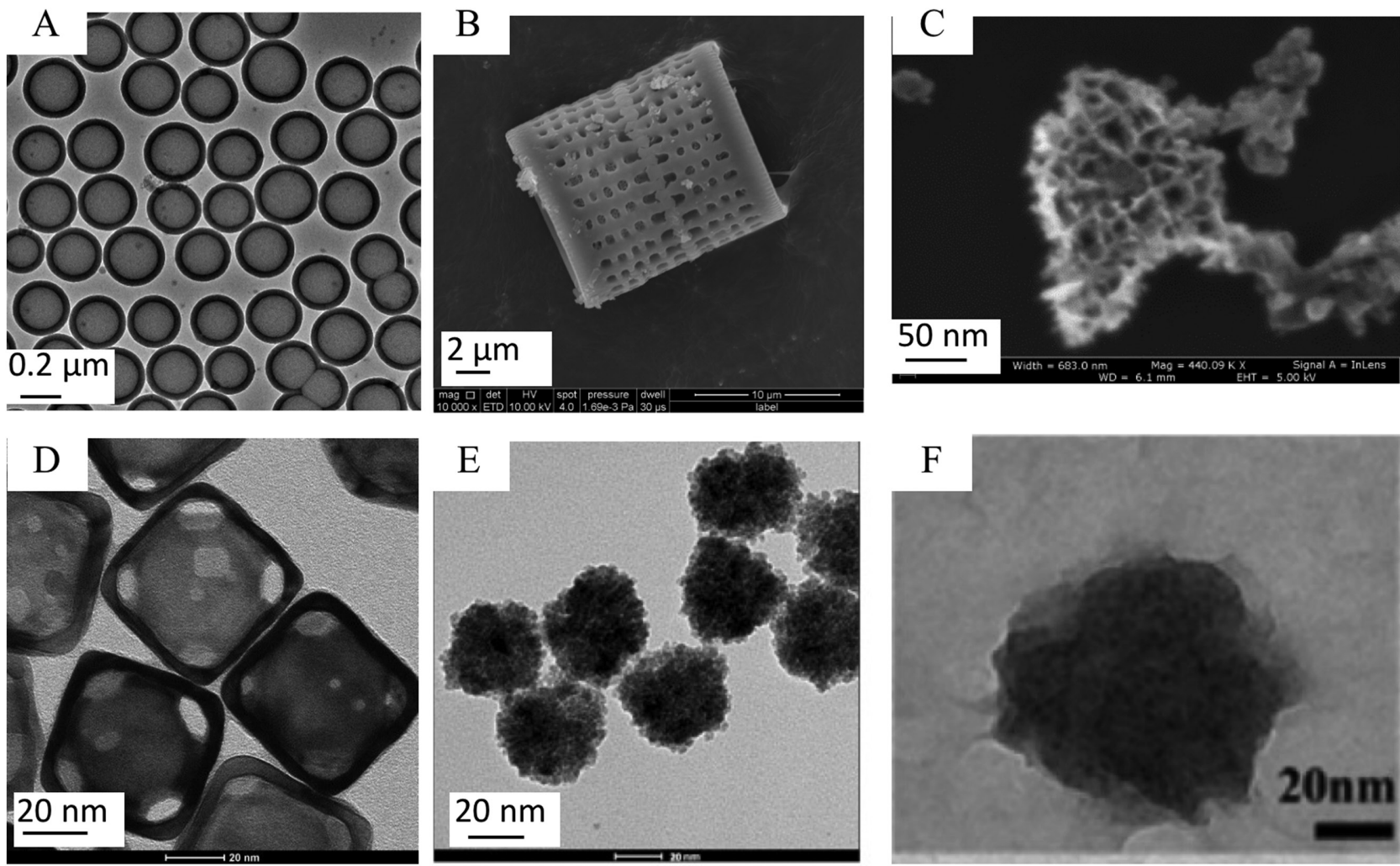

Figure 8. Porous materials in development for cancer treatment. A) Hollow-structured porous silica, B) diatom, C) porous silicon nanoparticle, D) gold nanocage, E) porous magnetic particle, and F) polymer-based porous nanoparticle. Reproduced with permission. ${ }^{[1]}$ Copyright 2010, Springer. Reproduced with permission. ${ }^{[12]}$ Copyright 2009, Elsevier. Reproduced with permission. ${ }^{[13]}$ Copyright 2011, ACS. Reproduced with permission. $\left.{ }^{[14]}\right]$

as for imaging agents, be used as constructs in systems additionally used for efficient delivery of novel antibacterial compounds. These strategies enable bacterial attack on many fronts, making it significantly more difficult for microbes to develop resistance simultaneously toward all modes of action. ${ }^{[132]}$ Further, the ability of zinc-doped $\mathrm{CuO}$ prickly nanoparticles to combat antibacterial resistance via physical methods, ${ }^{[133]}$ was recently portrayed in the media as a promising means of "winning the war against superbugs." ${ }^{[134]}$ Importantly, these physically acting nanomaterials can further be combined with chemical strategies, that is, loading of drugs to the same nanosystem or used in combinatorial therapy, thereby synergistically increasing their effect. ${ }^{[135]}$ The field of nanoantibiotics awakened later than the field of cancer nanomedicine. Consequently, the concepts and lessons learned during the development of the cancer nanomedicine field may enable avoiding previous pitfalls and boosting clinical advancement.

\subsubsection{Nanomedicine in Wound Healing}

Nanomedicine can elicit different functions in the wound healing process at the different stages of inflammation, proliferation, and remodeling, ${ }^{[136]}$ and the desired action of the nanomaterial can be structural or therapeutic. Different electrospun nanofibrous scaffolds have been developed for wound healing, the structure of which simulate the topographic appearance of endogenous extracellular matrix (ECM). For instance, electrospun photo-crosslinkable gelatin-hydrogel formed fibrous scaffolds can support vascularization and skin flap regeneration. Desferrioxamine-grafted fibrous scaffolds can induce Hif- $1 \alpha$ expression and activate angiogenesis in diabetic mouse models. ${ }^{[137]}$ Besides the nanofibrous scaffolds, gold and silver nanoparticles have also exhibited inherent wound healing properties, for reasons that are still unknown. ${ }^{[138,139]}$ In addition, nanoparticles and nanofibers have been utilized in combination. For example, antibacterial silver-containing nanofibers have been fabricated for wound healing purposes. The greatest benefits have been achieved by combining nanomaterials as constructs in macroscopic material structures via suitable manufacturing technologies, for example, electrospinning and 2D/3D printing (see Section 3.4).

\subsection{Tailored Approaches for Nanomedicines within Drug Development and Diagnostics}

The number of nanomaterials in the pharmaceutical and medical field has almost exponentially increased over the past 15 years, and predictions of the nanotechnology markets estimate a growth to tens of billions of dollars in the near future. Within the drug development process, the unique properties associated with nanomaterials can be exploited in a multifaceted manner. In the drug discovery phase, compounds with properties unfavorable for proper therapeutic efficacy could be formulated as nanopharmaceuticals. For early drug development, 
therapeutic and diagnostic nanomaterials can be integrated for simultaneous monitoring of drug delivery, uptake, safety, and therapeutic efficacy. For instance, nanoformulation could be part of the screening process, since the nanocarriers platform can be generic and not associated with a specific compound. The traits associated with nanoscopic carriers have been widely studied especially for nanopharmaceutical drug delivery applications, but regulatory and safety issues are still hampering a smooth transition forward for many next-generation nanomedical products, for which reason a European Nanomedicine Translation Hub have been established. ${ }^{[140]}$

From a commercial point of view, nanomedicine can provide benefits by (i) reformulation of existing drug molecules as nanopharmaceuticals, either due to previous failure in clinical trials due to severe side effects or (ii) by extending the product life cycle by extending its patent life as a new product. For instance, the active molecules of blockbuster drugs, whose patents are set to expire can be reformulated for repatenting them as novel products. ${ }^{[141]}$ It has thus been foreseen that in five years every Big Pharma company will have a nanomedicine program within their pipeline. ${ }^{142]}$ On the one hand, due to the high costs and extensive time periods that are required to develop new chemical entities (NCEs), making use of existing drug molecules may speed up the process and lower the costs. While developing a new drug delivery system is significantly less expensive and time consuming than developing a new drug, pharmaceutical companies can take advantage of novel drug delivery technology as a life-cycle management tool for their hit products. ${ }^{[143]}$ This aspect of repackaging an existing drug was acknowledged by Gregoriadis already in the 1970s and is commonly known as "putting old drugs in new clothing." ${ }^{[144]}$ On the other hand, active agents that failed in clinical trials in the form of conventional formulations due to unacceptable toxicity or pharmacokinetic profiles, poor bioavailability, solubility issues, or physical/chemical incapabilities, may overcome these issues by being reformulated as nanopharmaceuticals. ${ }^{[145]}$ While these approaches are already reality, the future visions that have been put forward can also be more grandiose, for instance, recently expressed in a Feature paper in Nature Nanotechnology, "the final goal of nanotechnology in medicine is to realize 'in-body hospitals', that is, smart virus-sized nanomedicines can migrate into the microenvironments in the body to provide diagnostic and therapeutic functionalities 24 hours a day. ${ }^{[100]}$ "

\section{Technologies and Materials for Tailor-Made Drug Delivery/Diagnostic Systems}

Although a great number of genes contributing to human illness have been defined over the recent years, genetic variability in patients affects the responses to different treatments. ${ }^{[146,147]}$ Hence, the molecular base of diseases needs to be specifically recognized and targeted. For this purpose, scientists and clinicians are developing and using diagnostic tests based on genetics and knowledge in the molecular mechanisms regulating disease, to better predict the responses of patients and to enable targeted therapies for the future. ${ }^{[148]}$ As the individual requirements of patients increase, the fabrication of drug delivery systems have to adapt and move toward more tailored solutions. This includes diagnostic aspects to not only identify the most effective treatment for a patient, for example, by making use of theranostic nanomedicines, but also the production of tailored delivery systems. This chapter aims to display what kind of possibilities new technology and novel materials can give to support drug development and diagnostic approaches.

\subsection{Drug Delivery Technology}

While early phase research in drug development have aimed at identifying potential NCE and to understand their behavior in vitro and in vivo, the challenges in this area are to develop and optimize carrier systems for any given drug. The administration route, the dose needed, as well as the physicochemical properties of a drug are playing an important role in this challenge. The excipients, serving as carriers and formulated alongside the active ingredient of a medication, have to be chosen carefully, and new functionalities need to be introduced, for example, by synthesizing new substances enabling specific targeted drug delivery. At the same time, all materials used have to be approved for pharmaceutical use. According to the regulatory guidelines, a manufacturer of a novel excipient has to develop safety information appropriate for the intended use. The suitability of a material to be used as an excipient in a particular type of dosage form is based on this information. ${ }^{[149,150]}$ Furthermore, the final delivery system, that is, the dosage form, has to be manufactured with a suitable technology that both ensure that all ingredients maintain their functionality and that the therapeutical value is covered. New functional materials and new manufacturing techniques pave the way for more individual patient treatment with tailor-made drug delivery systems. As most current manufacturing technologies are batch processes developed to produce high quantities of a given medicine, there is room for development in the area of individualized manufacturing.

\subsection{Polymeric Systems for Drug Delivery via Different Administration Routes}

As there are a multitude of administration routes for medicines, from oral to intravenous, different delivery systems are needed for different types of drug release requirements. For example, an orally taken drug may be delivered via an inert biostable polymer matrix in the form of a tablet. However, finding the correct matrix for a specific drug for optimal permeability and diffusion is difficult. ${ }^{[151]}$ To name a few examples, lipid-based drug delivery systems are one of the emerging technologies designed to address such challenges. Moreover, encapsulating or solubilizing the drug in lipid excipients can lead to increased solubilization and absorption, resulting in enhanced bioavailability. ${ }^{[152]}$

Implantable drug delivery systems have been studied broadly and several commercial products are on the market. Among the first one was the contraceptive Norplant device, a silicone rubber based, nondegradable matrix allowing a steadystate release of levonorgestrel during a period of five years. 
However, such diffusion out of the matrix is difficult to achieve with larger molecules due to poorer permeability. During the 1990 s, interest was focused on development of bioresorbable polymers. By choosing the right polymer, sustained release by diffusion, bulk, or surface erosion was obtained. Langer found that connective porosity is developed in poly(lactic-co-glycolic acid) (PLGA) during bulk degradation, enabling the release of larger macromolecules. ${ }^{[153]}$ Simultaneously, the development of surface-eroding polymers, especially polyorthoester and polyanhydrides, may lead to better-controlled drug release.

Currently, injectable polymeric systems are developed to enhance more accurate drug targeting and to avoid a too high plasma concentrations of a drug. These injection techniques also provide less invasive administration procedures. For injectability, correct rheological behavior needs to be considered, requiring development of material suitable for injection. Solutions including in situ formed hydrogel types of polymers ${ }^{[154]}$ and drug-containing microspheres ${ }^{[155]}$ are frequently used approaches that even may be combined. ${ }^{[156]}$ The in situ formed hydrogels are especially interesting for encapsulation of biologically active components such as viruses and proteins.

\subsection{Conventional and New Fabrication Technologies}

Most of the needs for production of therapeutical tools are still covered by traditional pharmaceutical manufacturing processes. Conventional dosage forms such as tablets, capsules, and ointments, and oral and parenteral solutions are manufactured with a multitude of established processing techniques typically producing high numbers of units in a relatively short time. New concepts have been introduced to produce high numbers of units in short time. Recently, modernizing efforts have been made both in the development of continuous manufacturing technologies for large-scale products and of process analytical tools (PAT) for real-time quality control of drug products. ${ }^{[157]}$ New dosage forms and new or optimized manufacturing processes are entering the area of pharmaceutical development and manufacturing, providing new possibilities for tailor-made solutions for personalized and niche drug products.

For example, computer-aided design (CAD) and printing technologies or additive manufacturing technologies have recently attracted interest in fabrication of different types of dosage forms. The activity in this research field is increasing and manufacturing of pharmaceutical products by printing has only recently emerged as a new viable option in drug manufacturing. ${ }^{[158,159]}$ As an example, in August 2015 FDA approved the market authorization of Spritam-a 3D-printed antiepileptic product. Printing technologies have been used to further ease administration of orodispersible dosage forms. This includes using drug-containing ink solutions that can be deposited in variable layers and patterns onto these edible substrates, enabling new and more individualized therapy options. ${ }^{[160]}$ Inkjet printing as a technology allows very precise deposition of small ink amounts, providing a promising technique for individual dosing approaches. ${ }^{[161]}$ The combination of different printing techniques, such as inkjet printing (noncontact) and flexography (contact), can provide solutions to apply different functional layers, offering possibilities for customized drug release properties. ${ }^{[162]}$ Whereas printing of liquid inks is a 2D printing technique, 3D printing, or free form manufacturing offers the opportunity to not only print drug-containing formulations, but also medical devices or combinatory products based on digital design. ${ }^{[163]}$ Personalizing dosage forms using printing technologies is a promising outlook for tailored therapies in the clinics in the future. ${ }^{[64,165]}$ Combining techniques such as electrospinning and printing can also offer new solutions for creating nanostructured materials with advanced functionality and accurate dosing of active substances. ${ }^{[160]}$

Also, microfluidic techniques are very promising for fabrication and encapsulation of different types of nano/microparticles. ${ }^{[166]}$ Droplet-based single emulsion and double emulsion techniques have been used to produce microparticles for cancer drug delivery. ${ }^{[167]}$ For example, doxorubicin-encapsulated PLGA nanoparticles produced with microfluidics have been successfully tested in mouse cancer models. ${ }^{[168,169]}$ As a technology for encapsulation, microfluidics are excellent to combine with porous materials. While a major limiting factor of porous materials in drug delivery applications is uncontrolled premature drug release due to the free accessible pores, the pores can be sealed with selected functional and responsive polymers to precisely control the drug release with the support of microfluidics. In addition, microfluidics may solve some major challenges in fabrication of polymeric particles. ${ }^{[170]}$ For example, the diversity of drugs that can be encapsulated by a certain polymeric particle is limited due to the specific physico-chemical properties of polymers and the exposure to solvent during microfluidic process. Encapsulation of porous materials improves the drug loading capacity and also provides a possibility for combining drugs in the same delivery system..$^{[171,172]}$ In addition, it is possible to introduce different surface functions for both inner porous materials and the outer polymer layers, to achieve a multifunctional sequential delivery system (Figure 9). ${ }^{[171,172]}$ As an example, a multifunctional nano-in-micro platform has been fabricated by encapsulating porous silica (PSi) nanoparticles inside $\mathrm{pH}$-responsive polymers for targeted cancer drug delivery to colon cancer cells in culture. ${ }^{[173]}$ In addition, it is also possible to simultaneously coencapsulate gold nanorods, DNA nanostructures, magnetic nanoparticles, PSi, and several drugs to a giant liposome using microfluidic double emulsion technique. ${ }^{[174]}$ A microfluidic-templated PSi@acetalated dextran nanocomposite has also been shown to precisely deliver cancer drug combinations in cell culture studies. ${ }^{[175]}$

\subsection{Materials for Drug Delivery}

\subsection{Excipients for Pharmaceutical Use}

There is a wide range of materials available that can be used for the fabrication of drug delivery systems. When it comes to oral dosage forms such as tablets, capsules, chewable systems suspensions, or solutions, or more recently introduced dosage forms, oromucosal films, ${ }^{[176]}$ the choice of excipients always depends on the desired administration and functionality. ${ }^{[177]}$ As an example for solid dosage in tablet form, functional polymer coatings can be applied either on the complete dosage form to achieve a protection film or for sustained drug release properties. 


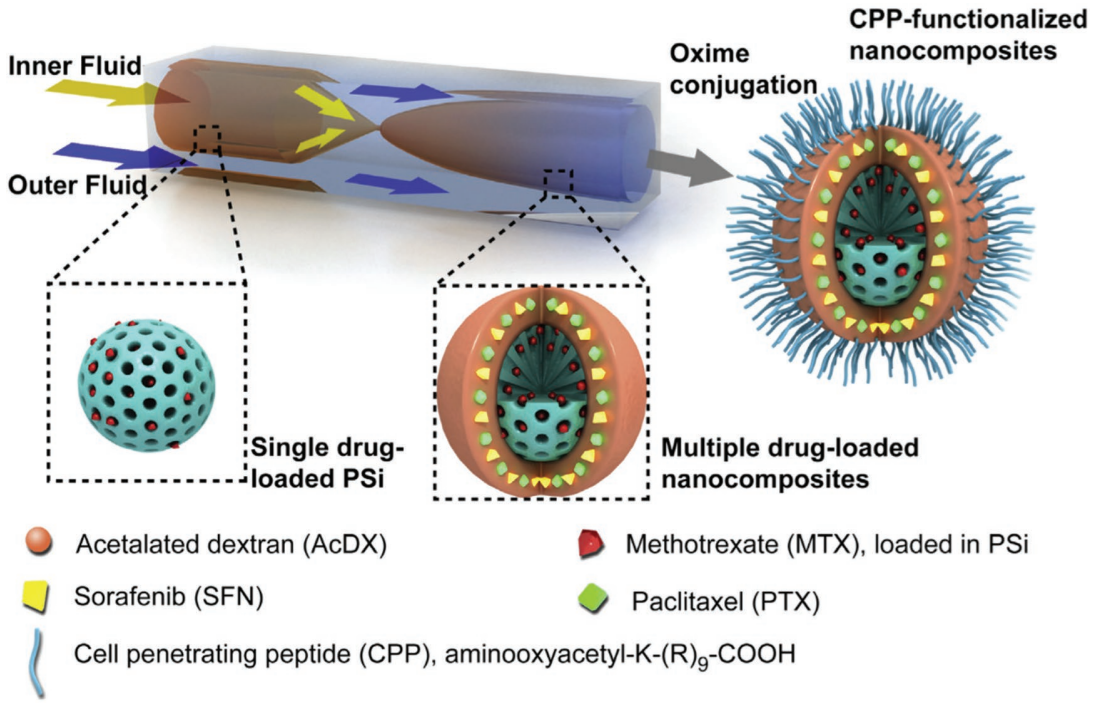

Figure 9. Schematic depicting the process to synthesize CPP-functionalized multi-drug-loaded acid-degradable PSi/polymer nanocomposites (PSi@AcDX-CPP). Microfluidic coflow focusing nanoprecipitation is used to prepare multi-drug-loaded PSi/polymer nanocomposites, after which CPP is attached to the surface of the nanocomposite through oxime clicking. Reproduced with permission. ${ }^{[15]}$ Copyright 2013, ACS.

Furthermore, it is possible to encapsulate or preprocess the active pharmaceutical ingredient with suitable excipients to achieve the desired effects. Examples are hot-melt extrusion of a drug with a polymer and subsequent incorporation of the resulting extrudates in a tablet formulation. ${ }^{[178]}$ Liquid dosage forms, either for oral or parenteral application, require the consideration of different excipients, such as viscosity modifiers (which could also be polymers), $\mathrm{pH}$ modifiers, stabilizing agents, and possible preservatives. Topical applications, such as patches or wound dressings with active ingredients, represent an interdisciplinary group for different types of drug delivery systems, since liquid and solid components can be included, together with dressing material or medical devices for the application.

One has to keep in mind that when it comes to excipients, the rule "one size fits all" does not necessarily apply. Different administration routes but even more important different patient groups may require different types of excipients that are suitable for the designated age or disease. As an example for pediatric patients, acceptable daily intake (ADI) levels and recommendations can be found in different databases, for example, provided by the European Pediatric Formulation Initiative (EuPFI, 2016) or the European Food Safety Agency. ${ }^{[179]}$ Moreover, as already mentioned above new materials need to go through safety and toxicity assessments as described in the relevant regulatory guidelines.

\subsubsection{Natural Polymers as Drug Carrier Materials}

To date a number of polymers have been utilized in biomedical applications. Due to their similarities with the ECM and their good compatibility and minimal cytotoxicity, biopolymers of natural origin are particularly attractive options. The widely considered biopolymers include collagen, gelatin, alginate, chitosan, and cellulose. Some of them are existing components of ECM. ${ }^{[180]}$ The biopolymers have been shown to regulate division, adhesion, differentiation, and migration of cells. There are several reports that suggest the beneficial cellular responses of biopolymers and their performance over synthetic polymers for tissue regeneration. ${ }^{[181-183]}$ Moreover, compared to synthetic polymers, biopolymers such as polysaccharides, which are discussed in this review, have more available functional groups, for example, amino and hydroxyl groups, and thus offer diverse and highly selective coupling functionality that can meet the requirements in desired applications.

Natural polymers such as polysaccharides from different sources, for example, bacterial cellulose and cellulose from plants, chitosan, and polysaccharides from other origins have been studied extensively in applications for controlled drug delivery. ${ }^{[184]}$ Cellulose is the most abundant natural polymer on earth and can be extracted or produced from plants and bacteria. With the emergence of nanotechnology in designing of biomaterials, nanocellulose, as a new form of cellulose polymer has been extensively investigated in the use of constructing novel materials. Depending on the processing approaches, nanocellulose can be achieved in the forms of nanocrystals or nanofibrils, which have elastic moduli in the range of 100-200 GPa. ${ }^{185,186]}$ The strong mechanical properties of the materials allow their potential use as load-bearing matrix for a broad spectrum of host materials. ${ }^{[187]}$ A few reports have shown that the cellulose and nanocellulose have promising biocompatibility and hemocompatibility. ${ }^{[188,189]}$ Cellulose as such is not biodegradable in the human body due to the lack of cellulolytic enzymes. Degradability of cellulose can be enhanced by oxidation. ${ }^{[190]}$ Moreover, the studies of in vitro cell cultures of a variety of cell lines and in vivo organ and animal experiments showed that cellulose and nanocellulose have no or only low toxicity, the latter comparable to that of salt. ${ }^{[191-194]}$ Studies also showed that the wood nanocellulose prepared by TEMPO oxidation could support crucial cellular processes during cell growth and proliferation of fibroblast cells. ${ }^{[194]}$ Lou et al. successfully cultured human pluripotent stem cells in 3D nanocellulose hydrogels, ${ }^{[195]}$ which was further commercialized by UPM Biochemicals in Finland for 3D cell culture applications. The highly porous structure of nanocellulose scaffolds allows them to be used as efficient drug carrier systems. To tailor the drug-eluting rate for different utilization conditions, loading of drug compounds can be realized by simply mixing, covalent coupling, or functionalizing the matrix surface, for example, creating hydrophobic character that can improve the binding ability of drugs. ${ }^{[188,192,196,197]}$ Yet, the impact on the drug activity and stability of the chemistry of the matrix surface before and after modifications need to be carefully evaluated.

Chitosan is the second most abundant polysaccharide after cellulose. Chitosan can be prepared from deacetylation of chitin, which is found in the shells of crustaceans, as a waste 
product of seafood industries. ${ }^{[198,199]}$ Different than cellulose, chitosan can be hydrolyzed by lysozyme, thus being biodegradable. ${ }^{[200,201]}$ Moreover, chitosan is biocompatible and also possesses hemostatic, antibacterial, and mucoadhesive properties, ${ }^{[188,202,203]}$ thus potentially offering a broad spectrum of applications in tissue engineering and drug delivery. Compared to hydrogels and scaffolds, nanoparticles based on chitosan have attracted more interest. ${ }^{[204-206]}$ In addition, other polysaccharides possessing biological properties in their native forms or after functionalization, for example, hyaluronic acid, chondroitin sulfate, alginates, heparin, as well as plant-derived heteropolysaccharides (also called hemicelluloses) have also been investigated for various biomedical applications. ${ }^{[188,207]}$

\subsubsection{Biopolymer-Based Stimuli-Responsive Materials}

To increase the efficiency of drug delivery, incorporation of stimuli responsiveness is one of the most promising strategies to create functional surface properties on the biopolymeric matrix or nanoparticles, thus allowing tailored dosing and targeted drug delivery. ${ }^{[208-211]}$ It can be realized by various means such as chemical and biochemical functionalization approaches to make the natural polymers "smart." Drug delivery systems should apply to externally temperature changes, light and electric fields, magnetic fields, or respond to the changes of $\mathrm{pH}$, redox potential, and concentration of specific analytes in the exposed environment. ${ }^{[212-216]}$ Yet, the adoption of strategy should take into account the complex condition of applications and the stability of delivered subjects, such as drugs, growth factors, and cells.

\subsection{Construction of Composites from Natural and Functional Polymers}

The field of controlled drug delivery drives much current innovation in polymeric biomaterials. The first attempts to achieve sustained delivery of macromolecules often failed due to the improper biocompatibility of the polymers used, for example, polyvinylpyrrolidone and polyacrylamide. Since those early days in the $1970 \mathrm{~s}$, a vast number of polymer candidates, both bioinert and bioresorbable, have emerged as potential matrices in sustained and targeted drug delivery applications. ${ }^{[217]}$ Obviously, the drug administration route places specific requirements on the polymer and depends on whether the drug will be taken orally, injected, or implanted. Furthermore, the drug, a low molecular weight compound or an array of new protein and nucleic acid-based drugs, which cannot be administered by classical routes will also influence on the matrix choice. Thus, both in situ forming injectable hydrogels ${ }^{[218]}$ and injectable microsphere systems ${ }^{[219]}$ have been intensively studied to enable the delivery of sensitive biological pharmaceuticals. ${ }^{[156]}$ The mentioned new fabrication technologies such as $3 \mathrm{D}$ printing give the opportunity to process new functional polymers and composites into defined shapes and scaffolds, which can subsequently be used as drug delivery devices. For example, the printing of a drug-releasing system may be customized in dimensions and shapes. Polylactic acid (PLA) has been successfully used to manufacture thin small-sized sheets loaded with a drug substance either prior to or after the $3 \mathrm{D}$ printing process. Furthermore, the impact of the printing process on the crystallization of poorly soluble drugs has been investigated. ${ }^{[220]}$ Neat porous racemic PLA and PLA-silicon dioxide $\left(\mathrm{SiO}_{2}\right.$, silica) composites have been used to study the release of toremifene, a first generation nonsteroidal selective estrogen receptor modulator (SERM). ${ }^{[221]}$

Polylactides have been used as matrix materials for drug release, but the clear and sudden changes in structure, for example, steep decrease in molecular weight caused by enhanced autocatalytic degradation, ${ }^{[222,223]}$ is a problem with respect to the controlled release of drugs. Biodegradable, solgel derived $\mathrm{SiO}_{2}$ is known to be biocompatible, and it has been used for controlled drug delivery as such. The induced porosity in the polymer and the polymer composites containing $\mathrm{SiO}_{2}$ torimifene particles were able to afford a better control over the drug release kinetics, and the release of toremifene citrate was adjusted from $30 \mathrm{~d}$ to 6 months by adding silica and/or pores to the biodegradable polymeric carrier system. Similar macroporous polymer/silica composites have been successfully applied in regenerative medicine. We have shown that it is possible to release silica, calcium, and phosphate ions to induce bioactivity and control the formation of bone-like calcium phosphate in vitro ${ }^{[224-226]}$ and in vivo.

Owing to their structural integrity, cellulose in the form of fibrils acts as promising matrices for loading drugs. ${ }^{[192,196,197]}$ However, chitosan and other water-soluble polysaccharides are preferably tailored to form nanoparticles that are more efficient in targeted delivery. ${ }^{[202,205]}$ Moreover, construction of composites from those natural polymers as well as other functional polymers or porous nanoparticles can extend the application of natural polymers to a broad spectrum of products. ${ }^{[227]}$ This will allow combining the benefits of natural polymers and other hybrid components. In an example approach, mesoporous bioactive glass was embedded into a nanocellulose matrix, which could deliver $\mathrm{Cu}^{2+}$ as therapeutic ion to promote angiogenesis in 3D spheroid culture systems of human umbilical vein endothelial cells. ${ }^{[228]}$ Similar mesoporous nanoparticles have been applied as nanocarriers to load drugs. ${ }^{[229]}$ This type of highly porous materials is suitable for carrying a broad chemical spectrum of drug substances, especially poorly soluble drug molecules and can be designed with in-built controlled release functionality ${ }^{[230]}$ (Figure 7). Chitosans have particularly been applied as hybrid nanoparticles to achieve controlled and sustainable drug release profiles. ${ }^{[231]}$ In addition, composites of natural polymers and stimuli-responsive synesthetic polymers, for example, thermal-responsive poly(N-isopropyl acrylamide), have also been intensively studied as a drug delivery device. ${ }^{[188,205,211]}$

\subsection{Modern Approaches for Molecular Sensing and Diagnostics}

Diagnostics and sensing are essentially related to the basic phenomena of adsorption and immobilization of biomolecules. ${ }^{\text {[232] }}$ In a thermodynamic sense, adsorption can be viewed as a process that aims to lower the interracial free energy or the surface tension. Biophysically, proteins adsorb because they are 
large molecules, are amphiphilic in nature, have a relatively low solubility, and have an ability to change conformation easily. The sensitivity and specificity of sensing are closely related to the type of binding as well as orientation and distribution of the sensing molecules, not to forget nonspecific binding, whether it is caused by intrinsic or external factors. ${ }^{[232]}$ Therefore, tailoring of the sensor surfaces onto which adsorption will take place becomes very important. Uncontrolled adsorption at a surface can adversely affect the activity and stability of the biomolecule. On the other hand, immobilized biomolecules may be further used for controlling cellular adhesion or increasing biocompatibility of, for example, implants. ${ }^{[233]}$ From manufacturing point of view, the fabrication of the sensors should be easy yet precise and up-scalable.

Printed sensors and diagnostic platforms represent a novel approach, where the print substrate is optimized for the ink bringing the function to the surface. Printing can be realized on a conventional print substrate like paper, but also on, for example, glass, metal, or polymers of different types. Tailored paper substrates with optimized roughness, surface energy, and porosity have been developed on which optical, electrical, and electrochemical sensors have been successfully demonstrated. ${ }^{[234]}$ Key properties of a print substrate controlling the ink-setting (spreading and adsorption/absorption) are roughness, surface energy, charge, critical surface tension, and porosity. ${ }^{[235,236]}$ Equally important is to pay attention to the ink formulation, its composition, surface tension, rheology, and colloidal stability. ${ }^{[237]}$ Depending on the material combinations and solubilities, the ink may represent a suspension or an emulsion. Emulsions, especially micelles and microemulsions, provide a very important possibility for printing poorly soluble biomolecules. ${ }^{[238]}$ Optical sensors typically yield a visual readout, as a color change, as a result of the ligand-analyte reaction. ${ }^{[239]}$ This type of sensor provides qualitative information, but is typically very fast, easy to use, and can, therefore, be regarded as a potential choice for point-of-care (POC) applications, even for analysis by a semiskilled nonprofessional, for example, the patent himself. These kind of user-friendly, flexible, disposable, robust, affordable, and easily deliverable sensors are believed to find uses especially in resource-limited locations such as in developing countries or on the field. ${ }^{[240,241]}$ Optical test assays have also been developed for viral diseases such as dengue fever ${ }^{[242]}$ and malaria ${ }^{[243]}$ and for measuring markers of liver function. ${ }^{[244]}$

The development of microfluidic paper-based analytical devices ( $\mu$ PADs) with improved capabilities for liquid handling have enabled the development of increasingly complex devices. ${ }^{[245,246]}$ Printed electrical and electrochemical sensors offer more accuracy and the possibility for connecting the system directly to electrical healthcare systems and decision-making. Besides physisorption being typical in optical sensors, immobilization onto electrodes can be attained in many different ways, such as through covalent binding or via binding affinity, or by electrochemical methods, for example, electropolymerization. ${ }^{[247,248]}$ Metal electrodes, especially gold, enable fabrication of supramolecular structures based on layer-by-layer growth of surfactant and protein layers through thiol and biotin-streptavidin chemistry, for example, C-reactive protein (CRP) detection of inflammation from blood. ${ }^{[249]}$
The most advanced systems include a sensor, battery, display, and circuitry being printed on paper or plastics, only the logic component being silicon-based. ${ }^{[250]}$ Such stand-alone devices have been used, for example, for analysis of artificial urine samples, ${ }^{[251]}$ ATP in human serum samples, ${ }^{[252]}$ as well as cholesterol, lactate, and alcohol in blood and urine. ${ }^{[242]}$ Thin film transistors (TFT) have been used for developing linear glucose sensors based on reduction/oxidation reactions. ${ }^{[253]}$ In addition, paper-based electrochemical ELISA test intended for pathogen detection has been developed, especially for use in developing countries. When wireless captures of sensor data is an issue, radio-frequency identification (RFID) technology is considered especially attractive, enabling wireless collection of large amounts of data from a matrix of sensors. Such sensor systems have been used for health monitoring by using, for example, a skin sensor. ${ }^{[254]}$ Also microfluidic structures can be created into a paper substrate, the pore network of which can be utilized for transport of liquid-soluble analytes by the capillary action. ${ }^{[241,242,245,246]}$ Modern printers equipped with a matrix of print heads enable simultaneous processing of different functional inks, boosting the possibilities for manufacturing smart sensor systems, which may offer novel alternatives for preventive healthcare with reduced costs. ${ }^{[255,256]}$

Patterned reaction arrays have also been constructed by one-step printing of a pattern of strongly hydrophobic polydimethylsiloxane (PDMS) onto a coated or noncoated paper substrate. ${ }^{[239,257]}$ Using this array, both optical and electrical sensors for glucose detection have been demonstrated. ${ }^{[239,247]}$ Paper-based test platforms also enable many surface properties to be adjusted and tested under cell culture experiments. Recent reports show that surface topography (roughness) and chemistry (surface energy, polar and dispersive components) have an effect on cell growth. ${ }^{[258]}$ Likewise, proteins intermediating cell adhesion and proliferation adhere selectively to surfaces of varying charge, hydrophilicity, and contact potential. ${ }^{[235]}$ Besides these passive ways of controlling cell adhesion and growth, a step toward active control and stimuli can be taken by combining printed electrodes and fluidic operations. When furthermore incorporating drugs or vitamins in the substrate bulk matrix, studies on dissolution rate and release kinetics become possible. For example, growth factor presentation for cell differentiation has been steered through electrochemical control. ${ }^{[259]}$ Graphene with its excellent electronic conductivity and optical transparency has been used for cell-culture studies as recently reviewed by Goenka et al. ${ }^{[260]}$ Graphene can be made into graphene oxide (GO) containing carboxylic, epoxy, and hydroxide groups allowing for further functionalization. The amphiphilicity of the GO allows for a multitude of functionalization pathways including both hydrophilic as well as hydrophobic drug molecules. ${ }^{[260]}$ Dynamic control of the cell growth substrate using both redox-active materials for peptide release ${ }^{[261]}$ and using potential control has been demonstrated. ${ }^{[262]}$ The use of stimuli-responsive materials for making dynamic in cell culture substrates has recently been reviewed by Kim and Hayward. [263] $\mathrm{GO}$ is here an especially interesting alternative, since it allows for precise control of the reduction rates and thereby also the amount of drug release in vitro.

Furthermore, successful electrochemical experiments with semitransparent electrodes prepared on transparent substrates 
is foreseen to enable combined electrochemical and optical studies of different stages of cell culture. ${ }^{[264]}$

\section{Model Systems to Decipher Mechanisms of Disease, for Drug Screening, and for the Evaluation of Efficacy and Safety}

Advances in biological knowledge accelerate the discovery of the molecular basis of human diseases and aid in the identification of therapeutic targets. This allows for the development of new therapeutics and diagnostics, the efficacy and safety of which need to be properly evaluated in appropriate disease models. Today, a variety of model systems exists to gain more insight into disease processes and for the evaluation of diagnostic and therapeutic approaches. These model systems include cells cultured in vitro, 3D "organoid" cultures that mimic tissue-like or organ-like structures and various in vivo animal systems (Figure 10). Recently, more complex engineered disease models that incorporate mechanical and physical cues, cell composition and organization, as well as the electrical and chemical signals of tissues and organs have been developed. While each system has its advantage and may lead to important insights into cellular disease mechanisms and responses to therapy, each system also has its limitations. Simple cellular systems are not physiological and lack the functional cross-regulation between cell types and organs. Animal models may fail to recapitulate the human response. There may be limitations to visualize molecularscale disease processes at high resolution in real time or to carry out biochemical and genetic analyses to understand how tissuetissue interactions contribute to the pathophysiology and response to therapy. For an efficient drug discovery and development process and predictive evaluation of safety and efficacy, we need to be aware of the advantages and disadvantages of different model systems. Figure 11 summarizes the models discussed in this review and highlights the pros and cons of each model system.

\subsection{In Vivo Models}

\subsubsection{Murine Models}

Rodent disease models are still central and irreplaceable mammalian models in DDD and for preclinical in vivo studies. ${ }^{[265]}$
Model system
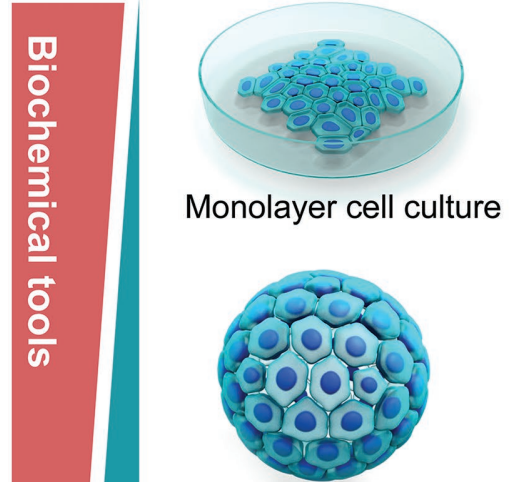

Spheroid
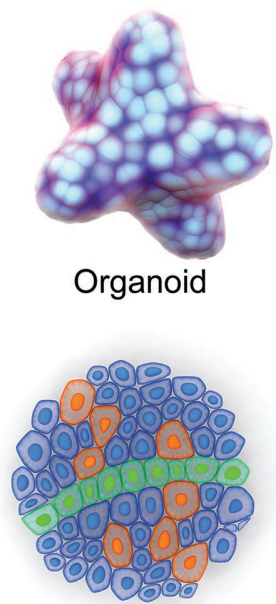

Tissue explant

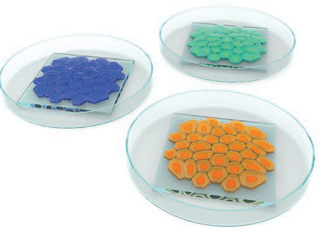

Multiplexed models "on-a-chip"
Organization of

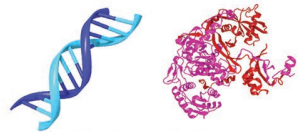

Subcellular

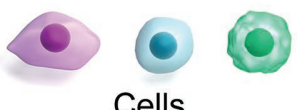

Cells

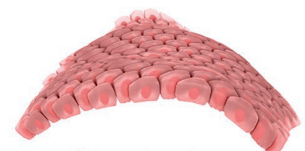

Simple tissue

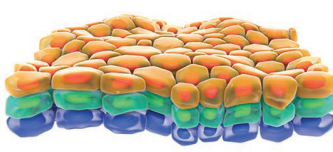

Layered tissue

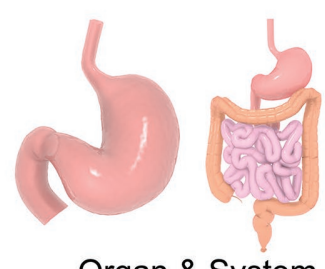

Organ \& System

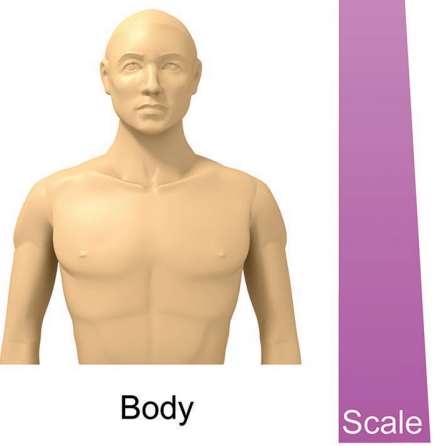

Figure 10. Cell-based model systems in life sciences and the organization of the body.

Mice are the most commonly used rodents, due to the availability of many disease and transgenic models that allow for the discovery of new druggable pathways and for preclinical studies to test novel drugs, drug modulations, or diagnostics technologies. ${ }^{[266]}$ Although only a few disease models in mice are identical to the human disease, drug efficacy, toxicity, and biodistribution of materials, material-based drugs, or diagnostics tools are often similar enough to warrant testing in mice prior to clinical trials. ${ }^{[266]}$ Mouse disease models can be chemically induced (e.g., carcinogens, compounds inducing a specific disease such as colitis), induced by mechanical injury to tissues (e.g., skin wounds, muscle damage), induced by biologically 


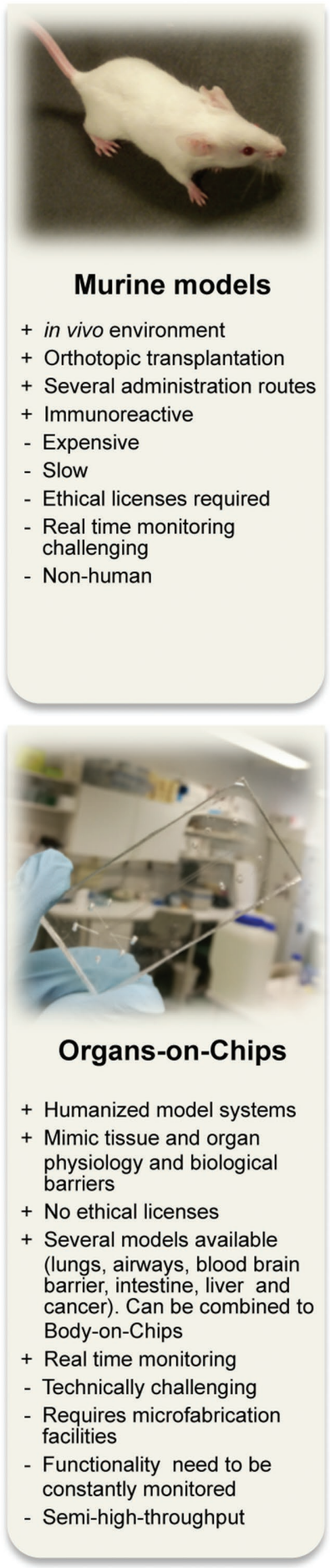

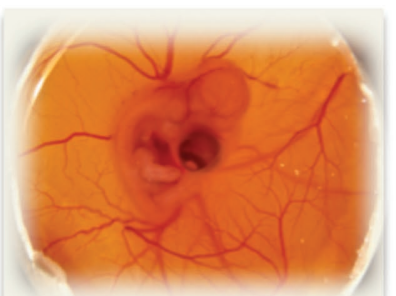

\section{Chorionallantoic membrane}

+ Cheap

+ Rapid

+ Semi-high throughput

+ No ethical licenses

+ Several administration routes; i.v., i.p., local

+ Vascularized and immunodeficient

+ Real time monitoring

- Not suitable for evaluation of immune reactions

- Non-human

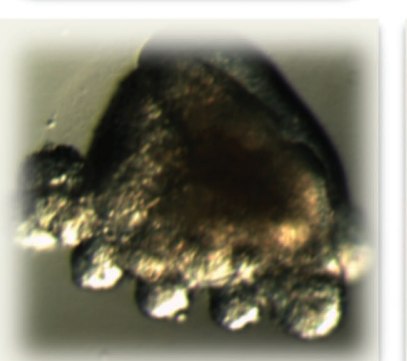

Organoids and 3D microtissues

+ Easy to obtained an

+ Fairly easy to culture

+ Patient-derived

+ Mimic tissue organization in vivo

- Culturing protocols till need to be optimized

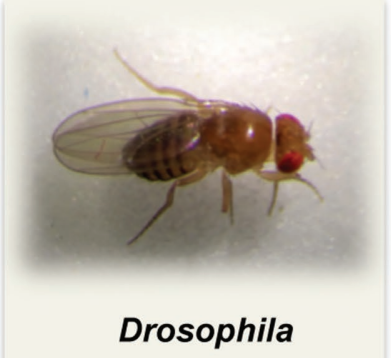

+ in vivo environment

+ Easy and cheap to culture

+ Short life cycle

+ Large number of offspring

+ Genetic manipulations easy

+ No ethical permissions

+ Non-invasive imaging techniques

- No adaptive immune system

- Open circulatory system, without blood vessels

- Invertebrate, many organs missing

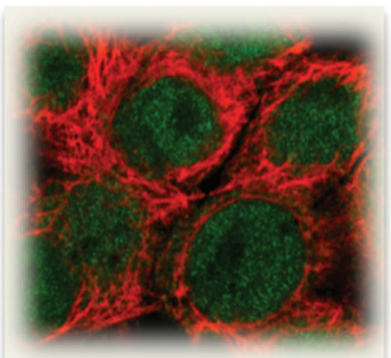

2D cell cultures

+ Easy to obtained and culture

+ Cheap and fast

+ Patient-derived and induced pluripotency

+ High-throughput analysis

+ No ethical licenses

+ Easy to genetically modify

+ Real-time monitoring, good spatial and temporal resolution

- Do not mimic physiological conditions in vivo
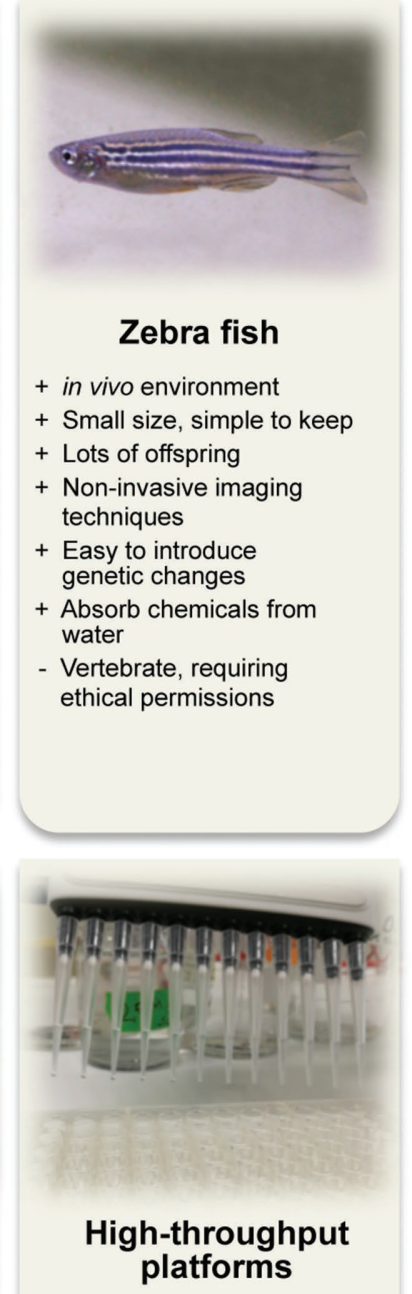

+ Robust

+ Accurate

+ Test multiple parameters in parallel experiments

+ Walk-away high throughput automation of sample preparation, image acquisition and data analysis

+ Real-time monitoring, good spatial and temporal resolution to better understand the cell and tissue dynamics

- 3D and in vivo highthroughput screening is a challenge

- Special instruments are required

Figure 11. Overview of biological model systems and the advantages and disadvantages of each model.

agents (e.g., bacteria, virus), or genetically induced models. ${ }^{[266]}$ Genetic models have disease phenotypes caused by overexpression of a mutation or by knockout of a gene central for the disease process. More recently, developed humanized knock-in models, in which the murine gene is replaced by the human gene, modified or unmodified, may give greater insight into the molecular mechanisms of the human disease. Mice engrafted with functional human cells or tissues are also considered as humanized models, ${ }^{[267]}$ and mice can further be utilized as bioreactors for production of biopharmaceuticals. ${ }^{[268]}$ Mice can, thus, be physiological hosts for human tumor cells, such as in orthotropic xenograft implants, where cultured cancer cells are 
introduced to the mouse and the tumor growth and the effect of, for example, cancer nanotherapy can be easily monitored by measuring changes in tumor size by tumor palpitation and in vivo imaging of a diagnostic markers (e.g., fluorescent) loaded into the particles. ${ }^{[269]}$ An example of this is the orthotropic introduction of a human breast cancer cell line to the flank of mice where the gamma secretase inhibitor DAPT loaded into functionalized mesoporous silica nanoparticles was successfully used to inhibit tumor growth with improved inhibition and tumor growth. ${ }^{[269,270]}$ Genetically engineered cancer cells, for example, cells with a potential oncogene mutation, can also be combined to this technology for specific genetic disease analyses or to test molecular mechanism hypothesis. Using this technique and cells expressing high or low levels of the cell fate signaling molecular, Notch was shown in breast cancer orthotopical transplants to induce distinct mechanisms in the glycolytic switch. ${ }^{[271]}$ This molecular finding was later used to develop nanoparticles formulations with surface-functionalized glucose moieties and loaded with Notch inhibitors, which could be targeted to breast cancer cells with high Notch activity and was shown to successfully inhibit Notch signaling and reduce the number of cancer stem cells. ${ }^{\text {[270] }}$

Mice are versatile to test for drug delivery systems, since most human delivery routes can be tested in these models, and since sampling of different organs as well as imaging and blood and urine analysis are easily doable. ${ }^{[269]}$ Murine models are also valuable for analyses of biodistribution. ${ }^{[269,270,272]}$ Interestingly, not only the drug carrier itself, but also the cargo, determines the biodistribution in mice, as shown for 19F-loaded hollow mesoporous silica nanoparticles accumulating in the liver ${ }^{[273]}$ and needs to be tested and controlled for each modulation in vivo.

A mammalian test organism is necessary when establishing formulations for oral drug delivery, since the drug formulation has to pass and survive the harsh environment with low $\mathrm{pH}$ and digestive enzymes of the human gastrointestinal tract. [275] Sheltering the drug from the environment needs to be considered for material-based formulations, which provide systems for lower drug dosing and reduced side effects, as most of the drug is expected to be delivered intact only to the target tissue. Of interest, a useful in vitro test tube analysis for gastrointestinal delivery is to determine the durability of the formulation and drug using simulated gastric or intestinal fluids in vitro. ${ }^{[274]}$ Proof-of-concept studies of targeted delivery of orally distributed nanomedicines show that drug-containing particles can be targeted to different parts of the digestive track using different particle surface modifications. ${ }^{[274]}$ For example, PEI and PEGfunctionalized mesoporous silica particles were superior to target the colonic mucosa while PEI functionalization was more optimal for the small intestine. In this study, functionalized mesoporous silica particles loaded with the gamma-secretase inhibitor had improved biological activity (Notch inhibition and cell fate switch) at lower drug concentrations compared to drug alone. ${ }^{[274]}$

Main challenges in animal studies are that humans and mice do have many differences. As an example, most murine genetic models for human colorectal cancer develop tumors in the functionally different small intestine, where they rarely develop in humans, and thus, more disease specific models are still needed. ${ }^{[275]}$ With respect to drug delivery to inflammatory bowel diseases such as ulcerative colitis, novel materialbased rectal formulations have shown successful facilitation of mucosal healing by using drugs in hydrogels to target the inflamed colonic mucosa ${ }^{[276]}$ or thermo-sensitive polymer platforms ${ }^{[277]}$ in murine models of colitis. Development and use of in vivo diagnostic imaging modalities is essential to follow effects of drugs and disease progression over time, for example, for intestinal inflammation by optical imaging and $\mathrm{PET}^{[278]}$ or optical imaging of cancer growth. ${ }^{[279]}$ A crucial challenge in utilizing nanodiagnostics if the nanoparticles carry the diagnostic probe is particle integrity (e.g., that the label remain attached to the particle during imaging). The choice of label and imaging modality also needs to be considered as many different options exist (PET, MRI, ultrasound, and optical). Importantly, the chosen cargo may have an influence on the particle degradation and biodistribution. ${ }^{[273]}$

In summary, mice are very useful preclinical model systems for assessing delivery options, toxicity, biodistribution, as well as the biological effect of the technology platform in basal conditions and in disease models. Further benefits for antitumorogenic drug studies are that human-derived cells, where cell function and signal activity can be modulated to mimic patient situation prior to transplantation, can be used. It is important to keep in mind that mice are not human hosts, for example, most tumor studies must be done in immunocompromised mice, which may not always be directly translatable to a human response to therapy (Figure 11), and that murine models must be performed under strict ethical and stringent protocols. ${ }^{[280]}$

\subsubsection{Nonmammalian In Vivo Disease Models}

Although mammalian models are crucial for development of drugs and diagnostic tools, they are expensive and require special ethical considerations. Nonmammalian models such as the fruit fly Drosophila melanogaster and the zebra fish Danio rerio are of great value for drug development and diagnostics, as they provide fast, ethical, and cost-efficient platforms for initial testing of drug effects on target molecules, the effects on target cells, and the effects on target tissues in vivo. In addition, these models are convenient for finding conserved druggable target molecules, and for testing molecular markers, target specificity, delivery to target cells, and compound stability in vivo faster than in mammalian models. ${ }^{[281-285]}$ Although many mammalian organs are missing in these lower organisms, several tissues are strikingly similar to their human equivalents. For example, the intestinal structure and function is well conserved throughout evolution. ${ }^{[286]}$ As many drugs are orally administered, lower organisms may be used to study uptake of small molecules in the digestive tract. To date, most studies with new materials in nonmammalian model organisms have been focused on biosafety testing. ${ }^{287,288]}$ However, these models have also been used for testing, for example, the delivery properties of nanomaterials in vivo. ${ }^{289,290]}$ As many biological processes, including signaling that regulates inflammation, proliferation, growth, cell death, and cell survival, are conserved in evolution, nonmammalian model organisms have been extensively used to understand the molecular and 
genetic principles behind human disease such as malignant, immunological, cardiovascular, neurological, endocrine, and skeletal disorders. Convincingly, around $80 \%$ of the described human disease genes have homologues in both zebra fish and fruit flies. ${ }^{[291,292]}$ This knowledge has been used to create disease model strains, which are genetically manipulated to mimic diseased states, such as malignant, metabolic, muscle, and neurological disorders. ${ }^{[281,292,293]}$ Furthermore, as cellular processes regulating health and disease are conserved, nonmammalian models may be useful for initial drug screening, as a cheap and fast model to test effects of libraries of compounds on molecular modulators of disease-promoting signaling pathways.

\subsection{Ex Vivo and In Vitro Model Systems}

\subsubsection{Cell Culture and Organoids}

Cells can be grown ex vivo with different levels of complexity for DDD applications. The most simple, often initial, and still mostly used biological model system is cells growing in $2 \mathrm{D}$ monolayer cultures. ${ }^{[294]}$ Primary cells, immortalized or cancer cell lines, grow directly on plastic or on plastic coated with thin layers of extracellular matrix proteins (e.g., collagen, laminin). Traditional cell cultures are simple and rather inexpensive to set up in most research facilities with a cell incubator and a laminar flow hood. Another benefit of a 2D cell culture is that a homogeneous cell population from a specific origin/tissue type (e.g., neurons, muscle, epithelia) can be studied. Such single cell type cultures enable testing for organ or cell type-specific effects such as toxicity. If the cultured cells have preserved features of the physiological cell or organ, they are also suitable for targeting drugs to a specific cell type. 2D cell culture systems are also relatively easy to control, image, analyze, manipulate, sample, and follow over time. In some cases, they can be initiated to differentiate (e.g., muscle cells) or form barriers (e.g., colorectal Caco2 cells form an intestinal polarized barrier after culture in 2D for three weeks ${ }^{[295]}$. Importantly, human pluripotent stem cells can be grown in culture and can be differentiated into virtually any cell type, providing potential to elucidate molecular mechanisms of human diseases and help for development of therapies for treating diseases. Patient-specific induced pluripotent stem cells (iPS), where skin cells have been genetically reprogrammed to pluripotent stem cells, are expected to revolutionize drug screening and development, provide possibilities for gene therapy of genetic diseases, and solve many of the problems related to animal and cellular models of human disease. ${ }^{[296]}$

Disadvantages from 2D cell culture systems are the artificial 2D setup, and the fact that cancer cells and immortalized cells may function very differently compared to cells in a tissue, especially when approaching nontumor disease targeting. This is especially problematic for nontransformed epithelial cells, which are difficult to maintain functional in 2D culture, as they tend to require a $3 \mathrm{D}$ environment simulating the original tissue to grow. For example, primary hepatocytes lose their characteristic shape and functions in a few days. ${ }^{[297]}$
To overcome the drawbacks of 2D cultures, spheroid cultures, organoid or "mini-tissue" models have recently been developed, in which cancer cells are grown in 3D spheroids, or in which isolated stem cell compartments from a tissue are propagated in a 3D-favorable environment (e.g., matrigel) in organoids. ${ }^{[298-302]}$ These organoids have revolutionized the cell culture field and brought in the crucial third dimension to better mimic the original tissue architecture. Since intestinal epithelial cells, for example, are nearly impossible to grow in 2D cultures, small intestinal or colonic organoids can now be successfully grown in 3D, with the formation of typical features of the intestine such as a central lumen, budding of crypt-structures, and differentiation of stem cells to specialized goblet cells, enterocytes, enteroendocrine cells, and Paneth cells of the intestinal crypts and villi. ${ }^{[303]}$ Further development of matrix composition, matrix patterning, and air-liquid interphase systems for intestinal organoids should provide better in vivo mimicking systems. Organoids from many other complex organs like the brain, ${ }^{[304]}$ liver, and pancreas ${ }^{[305]}$ have also been established. Kidney organoid proximal tubule cultures, for example, have been shown successful in predicting in vitro toxicity of hydroxylated generation-5 PAMAM dendrimer (G5-OH), when compared to murine nephrotoxic data. ${ }^{[306]}$

Disadvantages with 3D cultures are that they are comparatively expensive to maintain due to the cost of matrigel and growth and differentiation factors required in the medium. 3D cultures of nontransformed cells typically also grow slowly and organoids and spheroids require optimization for imaging ${ }^{[307]}$ and sampling. In addition, organoids may not be the most suitable for studying, for example, luminal delivery options of drugs, since the lumen in this model is an enclosed structure without an in/outlet, and the delivery of nanocarriers to organoids in 3D matrixes is still challenging. The following step of complexity is also to include other cellular components from a certain tissue environment, such as fibroblasts, blood vessels, neurons, and lymphatics (see tissue on chip Chapter 5.3.2). The development of biocompatible materials opens up new possibilities to generate material-based patterns mimicking in vivo conditions, enabling optimal mini-tissue modeling. Future diagnostics and drug design should enable personalized medicine applications, where patient-derived cells or organoids are used for defining successful drug combinations for each patient. These cultures may be used in combination with material-based target drug delivery modulations and theranostics for successful treatment and disease monitoring. ${ }^{308-310]}$

\subsubsection{Chorion Allantoic Membrane Model for Cancer and Tissue Regeneration}

The chorioallantoic membrane (CAM) of the developing chick provides a highly vascularized and immunodeficient environment, which is widely used in cancer research. ${ }^{[311]}$ The model is suitable to monitor the growth, invasiveness, and angiogenic potential of tumor xenografts during approximately one week. Drugs targeting both cancer cell growth and neoangiogenesis can be analyzed subsequent to topical application, i.v. injection, or injection into the yolk sac, which corresponds to oral/intraperitoneal application. The CAM model does not violate animal 
protection laws and is a good alternative system to avoid and reduce animal trials. The model can be used to perform shortterm in vivo assessment of anticancer drugs in a rapid manner at low cost, using small amounts of agents. The xenografts are grown superficially and can be easily analyzed by confocal fluorescence microscopy ex vivo. The model is especially suitable for 3D real-time imaging of cancer cell behavior, tumor growth and retraction, as well as responses to therapy. The CAM can also be used to evaluate the repair and regeneration of adult tissues transplanted into the CAM. ${ }^{[312]}$ The model is also well suited to assess vascularization of regenerating tissues and material-based engineered tissues for regenerative medicine. ${ }^{[313]}$ The CAM model can thus be employed to evaluate drug delivery systems as well as functional materials in both cancer and regenerative therapies ${ }^{[311,313-315]}$ and to evaluate the utilization of cellular and molecular probes. ${ }^{[316]}$ The drawback of the system is that it is not human and that the chick embryos do not have a developed immune system during the experimental window. While this allows the growth of humanderived tissues and cells, it prevents the study of the impact of the immune response on treatment.

\subsection{Engineered Model Systems}

\subsubsection{Cell Imaging Assays and High-Throughput Techniques}

In order to address the important factors required to obtain optimal responses from complex biological systems, robust and accurate methods are needed to test multiple parameters in parallel experiments. To this end, a selection of integrated imagebased techniques has been developed, collectively referred to as high-throughput and high-content screening (HTS and HCS). These techniques include methods, hardware, and software for sample preparation, for real-time image acquisition, and for subsequent analysis of imaging data. HTS and HCS platforms help streamline experimental procedures and increase throughput for large-scale genetics, biochemical, biomedical, and pharmacological studies. ${ }^{[317]}$

Since the introduction of the first high-throughput imaging (HTI) platforms in the mid-1990s, a variety of automated commercial HTI systems have been developed, for example, ArrayScan (ThermoFisher), CelliQ (TSE spol. s r.o.), Cell Voyager (Yokogawa), Image Express (Molecular Devices), IN Cell Analyzer (GE Healthcare), Opera and Operetta (PerkinElmer), and IncuCyte (Essen Bioscience). Examples of systems with true HCS capacity are semiautomatic systems Nikon A1MP (Nikon), Zeiss Lightsheet Z.1 (Zeiss), and Leica HCS A (Leica Microsystems). ${ }^{[18]}$ These systems have been developed and evolved to the extent that they are firmly established in industrial and academic settings for a broad spectrum of applications. True "walk-away" high-throughput automation is achieved when an inverted microscope with a long-range air objective is integrated with automated liquid handling systems. The core technologies of HCS are automated fast image acquisition modules, with robust data management systems combined with image analysis capabilities. Image-processing software should be robust enough to handle images with variable quality, remove noise, separate subcellular compartments, and convert image features such as object shape, area, intensity level, and localization into numerical values for quantitative analysis. The systems are to an increasing extent also able to incorporate multicolor fluorescence techniques. Additional parameters, such as $\mathrm{pH}$, oxygen content, electrical impedance, and force, can be measured by integrating various biosensors in the HCS system. ${ }^{[319]}$ The multiparametric nature of the HTS/HCS-based cellular assays allows monitoring cell activity such as cell cycle, cell proliferation, migration, differentiation, invasion, as well as subcellular morphology, organelle tracking, molecular dynamics, and interactions.

Drug screening requires assays, which identify compounds that would ideally be highly efficacious in the human disease. Typically, a multistage process is implemented, where assays of increasing complexity, that is, from molecules to cells, organoids, and in vivo studies are required. Cell-based FRET assays can be highly advantageous as they detect events close to a physiological target (protein or other biomolecule) (Scheme 2).

The current challenge of HTS is to obtain sufficient image resolution and throughput simultaneously in cells and tissues. Emerging new technologies, including multiphoton microscopy, ${ }^{[320]}$ different forms of super-resolution imaging, ${ }^{[321]}$ and light-sheet microscopy, ${ }^{[322]}$ will become available in formats that are compatible with HCS. This kind of technologies will pave toward understanding the physiological role of molecules in the context of tissue functions and disease processes. ${ }^{[323,324]}$ Highthroughput drug screening is one major application of these advancements, being able to obtain qualitative and quantitative data of cell and tissue responses to compounds. ${ }^{[318,325]}$

\subsubsection{Engineered Wound Healing and Tissue Regeneration Models}

Multiple complex epithelial cell layers and epithelial-mesenchymal interactions characterize the external and internal epithelia. These features of native tissues are generally absent in the in vitro model systems that are available for wound healing studies. ${ }^{[326,327]}$ Therefore, new injury models recapitulating the healing processes in, for example, skin, cornea, and liver, are desired tools for tissue engineering and tissue therapy screening. The basic building blocks of engineered wound healing models are cells, signals (mechanical, electrical, or biochemical), and scaffolding material. Both natural and synthetic materials have been employed to build scaffolds for tissue repair. Exogenous scaffolds are able to provide structure to a developing tissue, allowing cells to adhere, proliferate, differentiate, and secrete ECM in a 3D fashion. ${ }^{[328]}$ Because cells respond differently to substrates of different scaffold stiffness and porosity, manipulating scaffold parameters can be a useful technique to control cell behavior. ${ }^{[192]}$ In addition, to elicit a desired cellular response, growth factor-binding sequences/ domains can be incorporated within the scaffold. ${ }^{[329]}$

Novel biomaterials-based strategies are aiming to recapitulate structural and functional features in acute wound healing and also enable modeling of the pathobiology of chronic wounds. ${ }^{[30,331]}$ For instance, cultured keratinocyte graft models have been used to study repair of partial-thickness wounds, where the major damage is to the epidermis. ${ }^{[32]}$ However, cultured keratinocyte systems lack a dermal component that, if 


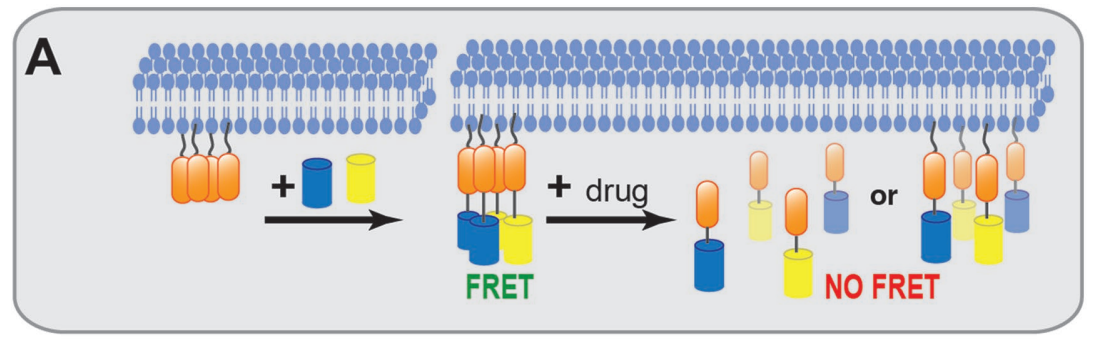

B
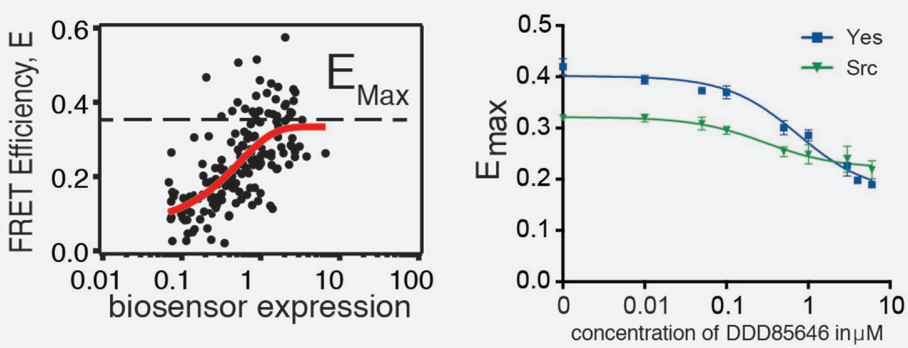

C

mGFP-H-rasG12V mGFP-H-rasG12V mRFP-RBD
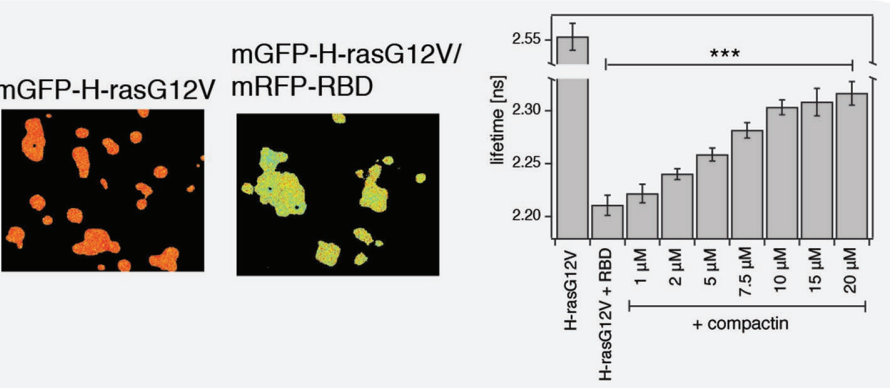

D

\section{$0.05 \mu \mathrm{M}$}
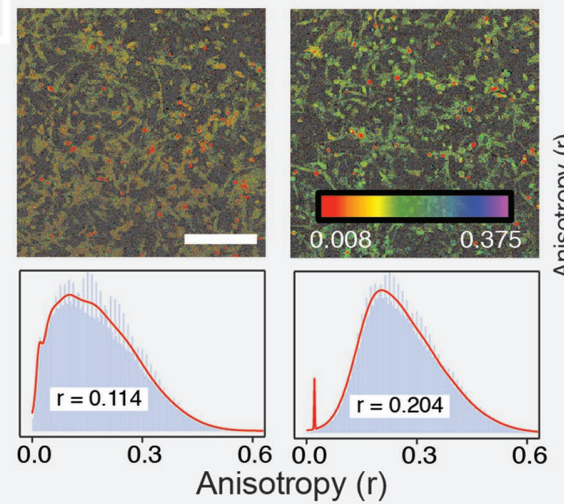

$1 \mu \mathrm{M}$

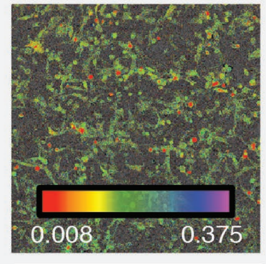

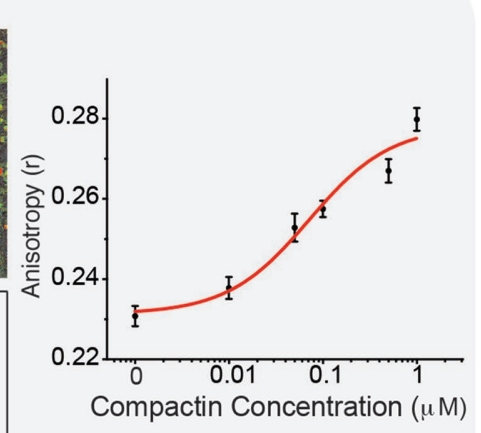

Scheme 2. Design of FRET-based high-content screening assays. Cell-based FRET (fluorescence resonance energy transfer) assays allow detecting physiological events, such as protein interactions, conformational changes, or posttranslational modifications, directly at the drug target. FRET biosensors that can detect membrane anchorage of lipid-modified proteins, such as small GTPases (e.g., K-ras), heterotrimeric G-proteins (coupling to GPCRs), and Srckinases, are particularly simple to implement and interesting for both screening and target/ hit validation. ${ }^{[34-36]}$ If membrane nano- or microscale membrane organization is disrupted, a loss of FRET is observed (A). This loss of FRET can be easily monitored at least in the medium throughput format using, for example, flow cytometry (B). ${ }^{[37,38]}$ Automated FLIM (fluorescence lifetime imaging microscopy ${ }^{[39]}$ (C) and anisotropy readout on plate readers (D). A) Cellbased FRET-assay design for lipid-anchored membrane signaling proteins (orange). FRET fluorophores are in blue and yellow. B) FRET readout using a fluorescence flow cytometer. Analysis of the FRET efficiency in dependence of the biosensor expression to derive $E_{\max }$. This value can report about the change in membrane anchorage of two myristoylation biosensors, which were derived from Yes- and Src kinases, upon treatment with a myristoylation inhibitor. C) FLIM-FRET imaging of cells expressing a related biosensor construct mGFP-HRasG12V present, would provide greater mechanical stability and possibly prevent wound contraction. To mimic the full thickness of wounds that involve the loss of both the epidermal and dermal layers of the skin, a bilayered skin composite model has been developed, consisting of a collagen lattice with dermal fibroblasts covered with epidermal keratinocytes. This invention is not only used for basic research, but also undergoing evaluation in clinical trials for the treatment of burns and the epidermolysis bullosa skinblistering disease. ${ }^{[333]}$ Another innovation is an engineered cornea model with a multilayered structure, in which accelerated wound healing is observed after treatment with epidermal growth factor (EGF) and fibrin, similarly as in native tissue. ${ }^{[34]}$ Recently, 3D biofabrication techniques have been further developed, enabling manufacturing of constructing or patterning materials with a high degree of control to create complex material geometries and cellular environments resembling endogenous tissues. ${ }^{[35]}$ As no ideal wound therapy has been identified, these novel tissue-engineering approaches are showing remarkable promise for the treatment of various types of chronic wounds. These engineered models can also be used for experimental applications, such as drug screening.

\subsubsection{Disease Models on Chips}

Organs-on-chips are microfluidic cell culture devices, which can incorporate mechanical, chemical, and electrical stimuli to mimic the physiological context. ${ }^{[36,337]}$ Several different cell types can be cultured in these devices in ordered geometries, and the physical and chemical environment in these systems can be tightly controlled. The devices are well

(left, donor-construct only) and together with the acceptor mRFP-RBD. The increase in fluorescence lifetime reports on the loss of FRET, due to loss of membrane anchorage after treatment with the inhibitor compactin. D) Fluorescence anisotropy/ polarization-based homo-FRET analysis requires only expression of one labeled species (here mGFPtagged Ras-NANOPS). Left: Imaging-based anisotropy measurements show the increase in anisotropy, as the sample becomes more polarized due to the loss of FRET, which depolarizes. Right: Such assays are also easily implemented on fluorescence plate readers and sensitively report on changes of homoFRET after treatment of Ras-NANOPS expressing cells with compactin. 
suited for detailed studies of material-bio interactions and evaluation of therapeutic efficacy in a more physiological context. The chips can incorporate primary cell isolated from patients or cells differentiated from induced pluripotent cells ${ }^{[338,339]}$ to mimic human pathophysiology. This enables the evaluation of individual responses to therapies. The devices can be used to study toxicity and therapeutic efficacy over many days. They are also suitable for high-resolution imaging, enabling detailed analysis of the interaction of nanomaterials with cells, cellular structures, and biological barriers. Small airway-on-chips enable analysis of human lung inflammation and drug responses in vitro, ${ }^{[340]}$ and a lung-on-chip was recently developed as a human disease model of drug toxicity-induced pulmonary edema and used to identify potential new therapeutics. ${ }^{[341]}$ A blood-brainbarrier (BBB)-on-chip was used to elucidate the mechanisms of neuroinflammation ${ }^{[342]}$ and should be a valuable tool to evaluate drug delivery vehicles developed to cross the BBB. The BBB was formed by human brain microvascular endothelial cells (hBMVECs) that were grown in the absence or presence of and human brain pericytes or primary human brain astrocytes. The model was used to study the contribution of astrocytes and pericytes to neuroinflammation but could easily be adopted to evaluate drug delivery over the BBB. Technologies combining several tissues in one device, for example, multi organ-on-chip, can be used to evaluate systemic and toxic responses to nanoparticles. ${ }^{[343]}$ Cancer-on-chip devices are valuable tools to study processes of metastasis, interactions within the tumor microenvironment, ${ }^{[344]}$ as well as to evaluate efficacy of drugs and tumor-targeted nanotechnology. These body-on-chip devices are relevant in vitro models for evaluating nanoparticle interactions with human tissues, as well as pharmacokinetics and pharmacodynamics and therapeutic efficacy of new therapeutics. They can be very useful for predicting human response to new compounds, which has been traditionally challenging. The organ-on-chip technology is still an emerging field. There are however several engineering challenges linked to these technologies. Manufacturing is slow, expensive, and requires skills and special biofabrication facilities. The functionality of the tissue, as well as the environmental components (flow, mechanical movement, chemical environment) need to be constantly monitored. [345,346] However, with these challenges met, the technology can be valuable for predictive and translational discoveries within the fields of drug development and diagnostics.

\section{Conclusions}

The introduction of novel materials technologies and materials in health applications raises new challenges. Safety, biodistribution, and therapeutic efficacy need to be systematically addressed by certified testing systems. The behavior in physiological relevant contexts of each novel system needs to be tested for different administration routes. Equally important is to elucidate the interactions of, and mechanisms behind, different materials with biological barriers and biomembranes, and the immune system. Another dimension is the effect of novel materials on cellular and subcellular molecular processes. Efficacy assessment is often a "hit-and-run approach," where the study ends when the desired effect is achieved. Few research efforts focus on understanding the interaction between materials and cellular and molecular processes in detail, although good examples of such approaches do exist.

Technological advances have led to the generation of delivery systems that enable multidrug delivery and controlled release. More rigid synthesis protocols and creative solutions to gain control of physicochemical parameters of the given technology have given rise to "smart" health care materials to meet any defined need. The clinical value of these advances and the necessary knowledge base for future development will only be gained through feedback from standardized testing of biological and physiological performance. Information on the behavior on a cellular level, toxicity on the nanoscale level, and interaction with cellular and biochemical mechanisms is equally important. This knowledge is a necessity for the translation of novel materials to the clinic.

Today, there is a tremendous variability in the methods used to assess the applicability and performance of novel materials. These methods are often semiquantitative or indicative, as quantitative methods in relevant model systems are timeconsuming, require a large number of animals and highthroughput methods, and become very expensive. Another problem is the lack of benchmarking to other materials and clinical standards. Different materials are tested in parallel in different research groups using different model systems. Hence, there is no relevant comparison between materials and we lack "specification sheets" for the given technology, a must in the pharmaceutical industry and for successful clinical translation. There is an urgent need to reach consensus on the models, methods, and biological platforms used to test medical applicability. A multitude of different disease models is used, and often the number of animals included does not allow for proper statistical evaluation of the significant benefit, as compared to controls or standards. In many cases, the animal disease models do not mimic the human disease, which itself can be very individual in patients. Equally important is the development of standardized, large-scale synthesis protocols, and standardized high-resolution and sensitive material characterization methods.

An interesting idea is to integrate mathematical modeling in the DDD process to be able to predict therapeutic efficacy and safety. Of note, such QSAR requires solid experimental data to be fed in as parameters for the prediction. Further integrating high-throughput OMICs technology such as genomics, proteomics, metabolomics, or epigenetics will bring beneficial advances to the development process.

\section{Outlook}

This review covers several central aspects of the advancement of the drug development process with focus on biomaterials and technologies to be used in biomedical applications. Below, we highlight future challenges and opportunities within the field:

- Integration of biological, materials science, and pharmacological processes at all levels from molecular signaling to animal-level physiology is important. 
- Nanoparticle- and other material-based targeted drug formulations require special consideration when tested for toxicity in any model system, since the different components, for example, the drug, the carrier material, the targeting molecule, or the diagnostic marker, may have individual or added safety concerns that are difficult to separate from each other.

- Structural data and the computational tools help explore molecular interactions and screen for potential ligands and novel scaffolds for drug development. Used responsibly, computational methods offer a way to explore the wide realm of possibilities and narrow down candidate hypotheses to a reasonable number that can then be investigated in more detail.

- Design and discovery work best when tightly integrated with molecular synthesis and testing for binding strength and biological activities. The results of these cycles of synthesis, testing, and design feed on each other and help optimize the discovery of chemistries that help fulfill the requirements for a given target.

- Combination of nano-sensor technology, smart nanomaterials with nano-scaffolding systems will allow to monitor and precisely control specific cellular components.

- Incorporation of functionality and tailoring of composites of natural polymers for versatile opportunities will help meet the individually desired solutions for drug delivery.

- Development of new manufacturing technologies, such as printing and integrated quality control, will pave the way for more individualized dosage forms in drug delivery.

- The use of patient-derived induced pluripotent stem cells will enable us to generate in vitro and in vivo models of human disease.

- Engineered complex model systems that incorporate not only the diseased cells but also the diseased microenvironment in 3D, together with the development of rapid and high-resolution readout assays (such as imaging) for evaluation of endpoints.

- New technologies for collecting and interpreting proteomic, genetic, and epigenetic data and biobanks, where patient material and medical data are stored will allow us to compare the molecular fingerprint of diseased tissues in human versus animal model systems, as well as responses to treatment.

\section{Acknowledgements}

C.S. and A.M. contributed equally to this work. This work would not have been possible without fruitful and critical discussions with local, national, and international colleagues of all authors and the recent support from the Academy of Finland to profile Drug Development and Diagnostics at the Åbo Akademi University. Advancing research and translational activities within the area are pursued in collaboration with colleagues at the University of Turku. The photos used in the figures are taken by Ilkka Paatero, Annika Meinander, Valeriy Paramonov, Malin Berg, Sebastian Landor, Rasmus Niemi, Jonas Silvander, and Iris Lähdeniemi.

\section{Conflict of Interest}

The authors declare no conflict of interest.

\section{Keywords}

biological model systems, computational approaches, drug development, nanotechnology, tailored technologies and materials

Received: February 26, 2017

Revised: May 4, 2017

Published online: September 11, 2017

[1] T. Schwede, Structure 2013, 21, 1531

[2] a) H. M. Berman, J. Westbrook, Z. Feng, G. Gilliland, T. N. Bhat, H. Weissig, I. N. Shindyalov, P. E. Bourne, Nucleic Acids Res. 2000, 28, 235; b) Protein Data Bank, http://www.rcsb.org (accessed: May 2017).

[3] T. A. Salminen, D. J. Smith, S. Jalkanen, M. S. Johnson, Protein Eng. 1998, 11, 1195.

[4] M. Salmi, G. G. Yegutkin, R. Lehvonen, K. Koskinen, T. Salminen, S. Jalkanen, Immunity 2001, 14, 265.

[5] G. G. Yegutkin, T. Salminen, K. Koskinen, C. Kurtis, M. J. McPherson, S. Jalkanen, M. Salmi, Eur. J. Immunol. 2004, 34, 2276.

[6] S.-M. Maula, T. Salminen, S. Kaitaniemi, Y. Nymalm, D. J. Smith, S. Jalkanen, Eur. J. Immunol. 2005, 35, 2718.

[7] Y. Nymalm, H. Kidron, A. Söderholm, L. Viitanen, K. Kaukonen, M. Pihlavisto, D. Smith, T. Veromaa, T. T. Airenne, M. S. Johnson, T. A. Salminen, Acta Crystallogr. D. Biol. Crystallogr. 2003, 59, 1288.

[8] T. T. Airenne, Y. Nymalm, H. Kidron, D. J. Smith, M. Pihlavisto, M. Salmi, S. Jalkanen, M. S. Johnson, T. A. Salminen, Protein Sci. 2005, 14, 1964.

[9] M. S. Johnson, N. Srinivasan, R. Sowdhamini, T. L. Blundell, Crit. Rev. Biochem. Mol. Biol. 1994, 29, 1.

[10] T. Liu, G. W. Tang, E. Capriotti, Comb. Chem. High Throughput Screen. 2011, 14, 532.

[11] A. Fiser, Methods Mol. Biol. 2010, 673, 73.

[12] A. Kryshtafovych, K. Fidelis, Drug Discov. Today 2009, 14, 386.

[13] H. Elovaara, H. Kidron, V. Parkash, Y. Nymalm, E. Bligt, P. Ollikka, D. J. Smith, M. Pihlavisto, M. Salmi, S. Jalkanen, T. A. Salminen, Biochemistry 2011, 50, 5507.

[14] C. Blikstad, K. M. Dahlström, T. A. Salminen, M. Widersten, FEBS J. 2014, 281, 2387.

[15] C. Blikstad, K. M. Dahlström, T. A. Salminen, M. Widersten, ACS Catal. 2013, 3, 3016.

[16] a) K. J. Kurppa, K. Denessiouk, M. S. Johnson, K. Elenius, Oncogene 2016, 35, 1283; b) World Health Organization, http://www. who.int/mediacentre/news/releases/2017/bacteria-antibioticsneeded/en/ (accessed: May 2017).

[17] D. Tvorogov, M. Sundvall, K. Kurppa, M. Hollmén, S. Repo, M. S. Johnson, K. Elenius, J. Biol. Chem. 2009, 284, 5582.

[18] J. A. E. Määttä, T. T. Airenne, H. R. Nordlund, J. Jänis, T. A. Paldanius, P. Vainiotalo, M. S. Johnson, M. S. Kulomaa, V. P. Hytönen, ChemBioChem 2008, 9, 1124.

[19] E. Bligt-Lindén, R. Arunachalam, V. Parkash, T. A. Salminen, J. Neural Transm. 2013, 120, 947.

[20] E. Bligt-Lindén, M. Pihlavisto, I. Szatmári, Z. Otwinowski, D. J. Smith, L. Lázár, F. Fülöp, T. A. Salminen, J. Med. Chem. 2013, 56, 9837.

[21] K. Illergård, D. H. Ardell, A. Elofsson, Proteins Struct. Funct. Bioinforma. 2009, 77, 499.

[22] H. Xhaard, V. Backström, K. Denessiouk, M. S. Johnson, J. Chem. Inf. Model. 2008, 48, 1423.

[23] O. M. H. Salo, M. Lahtela-Kakkonen, J. Gynther, T. Järvinen, A. Poso, J. Med. Chem. 2004, 47, 3048.

[24] K. M. Dahlström, T. A. Salminen, J. Theor. Biol. 2015, 386, 78. 
[25] E. Llobet, V. Martínez-Moliner, D. Moranta, K. M. Dahlström, V. Regueiro, A. Tomás, V. Cano, C. Pérez-Gutiérrez, C. G. Frank, H. Fernández-Carrasco, J. L. Insua, T. A. Salminen, J. Garmendia, J. A. Bengoechea, Proc. Natl. Acad. Sci. U. S. A. 2015, 112, E6369.

[26] A. Jazayeri, J. M. Dias, F. H. Marshall, J. Biol. Chem. 2015, 290, 19489.

[27] Y. Wang, J. Xing, Y. Xu, N. Zhou, J. Peng, Z. Xiong, X. Liu, X. Luo, C. Luo, K. Chen, M. Zheng, H. Jiang, Q. Rev. Biophys. 2015, 48, 488.

[28] M. S. Lawless, M. Waldman, R. Fraczkiewicz, R. D. Clark, Handb. Exp. Pharmacol. 2016, 232, 139.

[29] D. M. LeMaster, G. Hernandez, Curr. Mol. Pharmacol. 2015, 9, 5.

[30] K. Nikolic, L. Mavridis, T. Djikic, J. Vucicevic, D. Agbaba, K. Yelekci, J. B. O. Mitchell, Front. Neurosci. 2016, 10, 265.

[31] J. E. S. Wikberg, F. Mutulis, I. Mutule, S. Veiksina, M. Lapinsh, R. Petrovska, P. Prusis, Ann. N. Y. Acad. Sci. 2003, 994, 21.

[32] S. Cross, G. Cruciani, Drug Discov. Today 2010, 15, 23.

[33] S. Henrich, O. M. H. Salo-Ahen, B. Huang, F. F. Rippmann, G. Cruciani, R. C. Wade, J. Mol. Recognit. 2010, 23, 209.

[34] B. Ma, R. Nussinov, Curr. Pharm. Des. 2014, 20, 1293.

[35] B. O. Villoutreix, M. A. Kuenemann, J.-L. Poyet, H. BruzzoniGiovanelli, C. Labbé, D. Lagorce, O. Sperandio, M. A. Miteva, Mol. Inform. 2014, 33, 414.

[36] O. M. H. Salo-Ahen, A. Tochowicz, C. Pozzi, D. Cardinale, S. Ferrari, Y. Boum, S. Mangani, R. M. Stroud, P. Saxena, H. Myllykallio, M. P. Costi, G. Ponterini, R. C. Wade, J. Med. Chem. 2015, 58, 3572

[37] A. R. Leach, B. K. Shoichet, C. E. Peishoff, J. Med. Chem. 2006, 49, 5851.

[38] L. G. Ferreira, R. N. Dos Santos, G. Oliva, A. D. Andricopulo, Molecules 2015, 20, 13384 .

[39] I. Halperin, B. Ma, H. Wolfson, R. Nussinov, Proteins 2002, 47, 409.

[40] Q. Zhang, T. Feng, L. Xu, H. Sun, P. Pan, Y. Li, D. Li, T. Hou, Curr. Drug Targets 2016.

[41] N. Foloppe, R. Hubbard, Curr. Med. Chem. 2006, 13, 3583.

[42] R. Buonfiglio, M. Recanatini, M. Masetti, ChemMedChem 2015, 10, 1141.

[43] E. Moroni, A. Paladino, G. Colombo, Curr. Top. Med. Chem. 2015, 15, 2043.

[44] C. F. Wong, Expert Opin. Drug Discov. 2015, 10, 1189.

[45] D. A. Antunes, D. Devaurs, L. E. Kavraki, Expert Opin. Drug Discov. 2015, 10, 1301

[46] A. P. McGrath, K. M. Hilmer, C. A. Collyer, E. M. Shepard, B. O. Elmore, D. E. Brown, D. M. Dooley, J. M. Guss, Biochemistry 2009, 48, 9810.

[47] Q. U. Ain, A. Aleksandrova, F. D. Roessler, P. J. Ballester, Wiley Interdiscip. Rev. Comput. Mol. Sci. 2015, 5, 405.

[48] J.-C. Wang, J.-H. Lin, Curr. Pharm. Des. 2013, 19, 2174.

[49] D. Moser, J. M. Wisniewska, S. Hahn, J. Achenbach, E. la Buscató, F.-M. Klingler, B. Hofmann, D. Steinhilber, E. Proschak, ACS Med. Chem. Lett. 2012, 3, 155.

[50] V. V. Rantanen, K. A. Denessiouk, M. Gyllenberg, T. Koski, M. S. Johnson, J. Mol. Biol. 2001, 313, 197.

[51] V.-V. Rantanen, M. Gyllenberg, T. Koski, M. S. Johnson, J. Comput. Aided. Mol. Des. 2003, 17, 435.

[52] R. Hakulinen, S. Puranen, J. V. Lehtonen, M. S. Johnson, J. Corander, PLoS One 2012, 7, e49216.

[53] J. R. Savinainen, T. Kokkola, O. M. H. Salo, A. Poso, T. Järvinen, J. T. Laitinen, Br. J. Pharmacol. 2005, 145, 636.

[54] X. Yu, V. Cojocaru, G. Mustafa, O. M. H. Salo-Ahen, G. I. Lepesheva, R. C. Wade, J. Mol. Recognit. 2015, 28, 59.

[55] D. Cardinale, G. Guaitoli, D. Tondi, R. Luciani, S. Henrich, O. M. H. Salo-Ahen, S. Ferrari, G. Marverti, D. Guerrieri, A. Ligabue, C. Frassineti, C. Pozzi, S. Mangani, D. Fessas,
R. Guerrini, G. Ponterini, R. C. Wade, M. P. Costi, Proc. Natl. Acad. Sci. U. S. A. 2011, 108, E542.

[56] N. Petrovsky, P. D. Cooper, Expert Rev. Vaccines 2011, 10, 523.

[57] F. Caporuscio, G. Rastelli, Future Med. Chem. 2016, 8, 1887.

[58] I. G. Rodriguez-Bussey, U. Doshi, D. Hamelberg, Biopolymers 2016, 105, 35.

[59] P. Sneha, C. G. P. Doss, Adv. Protein Chem. Struct. Biol. 2016, 102, 181.

[60] D. B. Kokh, P. Czodrowski, F. Rippmann, R. C. Wade, J. Chem. Theory Comput. 2016, 12, 4100.

[61] K.-C. Chen, H.-Y. Chen, C. Y.-C. Chen, Evid. Based. Complement. Alternat. Med. 2014, 2014, 436863.

[62] J. D. Durrant, J. A. McCammon, R. Feynman, E. Fischer, S. Teague, B. Ma, S. Kumar, C. Tsai, R. Nussinov, S. Kumar, B. Ma, C. Tsai, H. Wolfson, R. Nussinov, C. Tsai, S. Kumar, B. Ma, R. Nussinov, B. Ma, M. Shatsky, H. Wolfson, R. Nussinov, C. Bouzat, F. Gumilar, G. Spitzmaul, H. Wang, D. Rayes, S. Hansen, P. Taylor, S. Sine, T. Talley, S. Yalda, K. Ho, Y. Tor, F. Soti, W. Kem, P. Taylor, A. Babakhani, T. Talley, P. Taylor, J. McCammon, C. Ulens, R. Hogg, P. Celie, D. Bertrand, V. Tsetlin, A. Smit, T. Sixma, Y. Bourne, T. Talley, S. Hansen, P. Taylor, P. Marchot, J. McCammon, B. Gelin, M. Karplus, W. Cornell, P. Cieplak, C. Bayly, I. Gould, K. Merz, D. Ferguson, D. Spellmeyer, T. Fox, J. Caldwell, P. Kollman, J. Lennard-Jones, J. Wang, R. Wolf, J. Caldwell, P. Kollman, D. Case, B. Brooks, R. Bruccoleri, B. Olafson, D. States, S. Swaminathan, M. Karplus, M. Christen, P. Hünenberger, D. Bakowies, R. Baron, R. Bürgi, D. Geerke, T. Heinz, M. Kastenholz, V. Kräutler, C. Oostenbrink, C. Peter, D. Trzesniak, W. van Gunsteren, D. Case, T. Cheatham, T. Darden, H. Gohlke, R. Luo, K. Merz, A. Onufriev, C. Simmerling, B. Wang, R. Woods, L. Kale, R. Skeel, M. Bhandarkar, R. Brunner, A. Gursoy, N. Krawetz, J. Phillips, A. Shinozaki, K. Varadarajan, K. Schulten, J. Phillips, R. Braun, W. Wang, J. Gumbart, E. Tajkhorshid, E. Villa, C. Chipot, R. Skeel, L. Kale, K. Schulten, W. van Gunsteren, J. Dolenc, A. Mark, L. LaConte, V. Voelz, W. Nelson, D. Thomas, C. Peter, M. Rueping, H. Worner, B. Jaun, D. Seebach, W. van Gunsteren, R. Bruschweiler, S. Showalter, P. Markwick, C. Cervantes, B. Abel, E. Komives, M. Blackledge, J. McCammon, J. Chodera, D. Mobley, M. Shirts, R. Dixon, K. Branson, V. Pande, G. Hong, A. Cornish, E. Hegg, R. Pachter, W. Jorgensen, P. Cieplak, F. Dupradeau, Y. Duan, J. Wang, D. Shaw, P. Maragakis, K. Lindorff-Larsen, S. Piana, R. Dror, M. Eastwood, J. Bank, J. Jumper, J. Salmon, Y. Shan, W. Wriggers, D. Hamelberg, J. Mongan, J. McCammon, D. Hamelberg, J. McCammon, J. Yang, Y. Wang, Y. Chen, W. Liu, B. Schmidt, G. Voss, W. Müller-Wittig, M. Friedrichs, P. Eastman, V. Vaidyanathan, M. Houston, S. Legrand, A. Beberg, D. Ensign, C. Bruns, V. Pande, Y. Shan, E. Kim, M. Eastwood, R. Dror, M. Seeliger, D. Shaw, D. Koshland, J. Schames, R. Henchman, J. Siegel, C. Sotriffer, H. Ni, J. McCammon, J. Durrant, H. Keranen, B. Wilson, J. McCammon, B. Grant, S. Lukman, H. Hocker, J. Sayyah, J. Brown, J. McCammon, A. Gorfe, D. Hazuda, N. Anthony, R. Gomez, S. Jolly, J. Wai, L. Zhuang, T. Fisher, M. Embrey, J. Guare, M. Egbertson, J. Vacca, J. Huff, P. Felock, M. Witmer, K. Stillmock, R. Danovich, J. Grobler, M. Miller, A. Espeseth, L. Jin, I. Chen, J. Lin, K. Kassahun, J. Ellis, B. Wong, W. Xu, P. Pearson, W. Schleif, R. Cortese, E. Emini, A. Ivetac, J. McCammon, R. Brenke, D. Kozakov, G. Chuang, D. Beglov, D. Hall, M. Landon, C. Mattos, S. Vajda, R. Amaro, R. Baron, 1. McCammon, J. Lin, A. Perryman, J. Schames, J. McCammon, J. Lin, A. Perryman, J. Schames, J. McCammon, R. Amaro, A. Schnaufer, H. Interthal, W. Hol, K. Stuart, I. McCammon, J. Durrant, L. Hall, R. Swift, M. Landon, A. Schnaufer, R. Amaro, J. Durrant, M. Urbaniak, M. Ferguson, J. McCammon, J. Durrant, R. Cao, A. Gorfe, W. Zhu, J. Li, A. Sankovsky, E. Oldfield, J. McCammon, Y. Wang, T. Hess, V. Jones, J. Zhou, M. McNeil, 
J. McCammon, D. Kitchen, H. Decornez, J. Furr, J. Bajorath, S. Adcock, J. McCammon, F. Schwab, W. van Gunsteren, B. Zagrovic, J. Kim, A. Hamilton, C. Bailey, R. Domaoal, L. Wang, K. Anderson, W. Jorgensen, B. Tembe, J. Mccammon, C. Chipot, D. Pearlman, C. Chipot, X. Rozanska, S. Dixit, B. Roux, Y. Deng, B. Roux, J. Wang, Y. Deng, W. Jorgensen, J. Zeevaart, L. Wang, V. Thakur, C. Leung, J. Tirado-Rives, C. Bailey, R. Domaoal, K. Anderson, P. Ren, D. Jiao, J. Zhang, R. Duke, G. Li, M. Schnieders, X. Ge, B. Roux, J. Michel, J. Essex, J. McCammon, BMC Biol. 2011, 9, 71.

[63] M. Luitz, R. Bomblies, K. Ostermeir, M. Zacharias, J. Phys. Condens. Matter 2015, 27, 323101.

[64] I. G. Rodriguez-Bussey, U. Doshi, D. Hamelberg, Biopolymers 2016, 105, 35.

[65] O. M. H. Salo-Ahen, R. C. Wade, Proteins 2011, 79, 2886.

[66] G. Klebe, Drug Discov. Today 2006, 11, 580.

[67] B. K. Shoichet, Nature 2004, 432, 862.

[68] C. Sotriffer, Virtual Screening: Principles, Challenges, and Practical Guidelines, Wiley-VCH, Weinheim, Germany 2011, 511.

[69] S. M. Saario, A. Poso, R. O. Juvonen, T. Järvinen, O. M. H. Salo-Ahen, J. Med. Chem. 2006, 49, 4650 .

[70] O. M. H. Salo, K. H. Raitio, J. R. Savinainen, T. Nevalainen, M. Lahtela-Kakkonen, J. T. Laitinen, T. Järvinen, A. Poso, J. Med. Chem. 2005, 48, 7166

[71] A. Manglik, H. Lin, D. K. Aryal, J. D. McCorvy, D. Dengler, G. Corder, A. Levit, R. C. Kling, V. Bernat, H. Hübner, X.-P. Huang, M. F. Sassano, P. M. Giguère, S. Löber, D. Da Duan, G. Scherrer, B. K. Kobilka, P. Gmeiner, B. L. Roth, B. K. Shoichet, Nature 2016 537, 185.

[72] C. A. Lipinski, F. Lombardo, B. W. Dominy, P. J. Feeney, Adv. Drug Deliv. Rev. 2001, 46, 3.

[73] E. Lionta, G. Spyrou, D. K. Vassilatis, Z. Cournia, Curr. Top. Med. Chem. 2014, 14, 1923.

[74] D. Horvath, Methods Mol. Biol. 2011, 672, 261

[75] C. Bissantz, G. Folkers, D. Rognan, J. Med. Chem. 2000, 43, 4759.

[76] T. Scior, A. Bender, G. Tresadern, J. L. Medina-Franco, K. Martínez-Mayorga, T. Langer, K. Cuanalo-Contreras, D. K. Agrafiotis, J. Chem. Inf. Model. 2012, 52, 867.

[77] J. Verma, V. M. Khedkar, E. C. Coutinho, Curr. Top. Med. Chem. 2010, 10, 95

[78] O. M. H. Salo, J. R. Savinainen, T. Parkkari, T. Nevalainen, M. Lahtela-Kakkonen, J. Gynther, J. T. Laitinen, T. Järvinen, A. Poso, J. Med. Chem. 2006, 49, 554.

[79] G. Moroy, V. Y. Martiny, P. Vayer, B. O. Villoutreix, M. A. Miteva, Drug Discov. Today 2012, 17, 44.

[80] N. G. Bakhtyari, G. Raitano, E. Benfenati, T. Martin, D. Young, J. Environ. Sci. Health. C. Environ. Carcinog. Ecotoxicol. Rev. 2013 31, 45.

[81] T. Katsila, G. A. Spyroulias, G. P. Patrinos, M.-T. Matsoukas, Comput. Struct. Biotechnol. J. 2016, 14, 177.

[82] A. R. Joyce, B. Ø. Palsson, Nat. Rev. Mol. Cell Biol. 2006, 7, 198.

[83] C. J. Tomlin, J. D. Axelrod, Nat. Rev. Genet. 2007, 8, 331

[84] G. W. Brodland, Semin. Cell Dev. Biol. 2015, 47, 62.

[85] L. Grieco, L. Calzone, I. Bernard-Pierrot, F. Radvanyi, B. Kahn-Perlès, D. Thieffry, PLoS Comput. Biol. 2013, 9, e1003286.

[86] N. Dalchau, A. Phillips, L. D. Goldstein, M. Howarth, L. Cardelli, S. Emmott, T. Elliott, J. M. Werner, PLoS Comput. Biol. 2011, 7, e1002144.

[87] A. Naldi, J. Carneiro, C. Chaouiya, D. Thieffry, PLoS Comput. Biol. 2010, 6, e1000912.

[88] S. D. Hester, J. M. Belmonte, J. S. Gens, S. G. Clendenon, J. A. Glazier, PLoS Comput. Biol. 2011, 7, e1002155.

[89] R. R. Vallabhajosyula, A. Raval, 2010, 97.

[90] A.-L. Barabási, Z. N. Oltvai, Nat. Rev. Genet. 2004, 5, 101.
[91] T. Rolland, M. Taşan, B. Charloteaux, S. J. Pevzner, Q. Zhong, N. Sahni, S. Yi, I. Lemmens, C. Fontanillo, R. Mosca, A. Kamburov, S. D. Ghiassian, X. Yang, L. Ghamsari, D. Balcha, B. E. Begg, P. Braun, M. Brehme, M. P. Broly, A.-R. Carvunis, D. Convery-Zupan, R. Corominas, J. Coulombe-Huntington, E. Dann, M. Dreze, A. Dricot, C. Fan, E. Franzosa, F. Gebreab, B. J. Gutierrez, M. F. Hardy, M. Jin, S. Kang, R. Kiros, G. N. Lin, K. Luck, A. MacWilliams, J. Menche, R. R. Murray, A. Palagi, M. M. Poulin, X. Rambout, J. Rasla, P. Reichert, V. Romero, E. Ruyssinck, J. M. Sahalie, A. Scholz, A. A. Shah, A. Sharma, Y. Shen, K. Spirohn, S. Tam, A. O. Tejeda, S. A. Trigg, J.-C. Twizere, K. Vega, J. Walsh, M. E. Cusick, Y. Xia, A.-L. Barabási, L. M. lakoucheva, P. Aloy, J. De Las Rivas, J. Tavernier, M. A. Calderwood, D. E. Hill, T. Hao, F. P. Roth, M. Vidal, Cell 2014, 159, 1212

[92] Y.-Y. Liu, J.-J. Slotine, A.-L. Barabási, Nature 2011, 473, 167

[93] J. Gao, Y.-Y. Liu, R. M. D’souza, A.-L. Barabási, Nat. Commun. 2014, 5, 5415

[94] I. Koch, B. H. Junker, M. Heiner, Bioinformatics 2005, 21, 1219.

[95] Target Controllability of Linear Networks in Computational Methods in Systems Biology (Eds: E. Czeizler, C. Gratie, W. K. Chiu, K. Kanhaiya, I. Petre), Springer International Publishing, 2016, 67.

[96] T. T. T. Nguyen, J. K. K. Chua, K. S. Seah, S. H. Koo, J. Y. Yee, E. G. Yang, K. K. Lim, S. Y. W. Pang, A. Yuen, L. Zhang, W. H. Ang, B. Dymock, E. J. D. Lee, E. S. Chen, F. Bray, A. Jemal, N. Grey, J. Ferlay, D. Forman, J. Munoz, C. Swanton, R. Kurzrock, K. Fujita, Y. Sasaki, G. Szakacs, J. K. Paterson, J. A. Ludwig, C. Booth-Genthe, M. M. Gottesman, E. Wiechec, L. L. Hansen, D. Hanahan, R. A. Weinberg, N. Bailon-Moscoso, J. C. Romero-Benavides, P. Ostrosky-Wegman, O. Zuk, E. Hechter, S. R. Sunyaev, E. S. Lander, D. Ghersi, M. Singh, F. J. Vizeacoumar, B. V. Sajesh, B. J. Guppy, K. J. McManus, C. Boone, W. Greenhalf, A. Thomas, K. Watanabe, N. Saban, M. Bujak, M. D. Wyatt, D. L. Pittman, G. L. Beretta, L. Gatti, P. Perego, N. Zaffaroni, Y. Hiraoka, T. Toda, M. Yanagida, J. M. Malinge, M. J. Giraud-Panis, M. Leng, G. Zhu, M. Myint, W. H. Ang, L. Song, S. J. Lippard, P. A. Marks, J. H. Lee, M. L. Choy, L. Ngo, S. S. Foster, P. A. Marks, L. Mojardin, J. Botet, S. Moreno, M. Salas, Z. Tay, Z. Tay, G. P. Deshpande, T. X. Han, X. Y. Xu, M. J. Zhang, X. Peng, L. L. Du, Z. Chu, E. Nicolas, H. Zhao, K. Tanaka, E. Nogochi, C. Nogochi, P. Russell, E. J. Blaikley, S. Takahashi, K. Kontani, Y. Araki, T. Katada, S. Singh, H. Le, S. J. Shih, B. Ho, A. T. Vaughan, Y. Lu, W. Leong, O. Guerin E. Gilson, J. Ye, M. Kawamukai, A. Franceschini, H. Keskin, Y. Wang, A. M. Carr, S. Lambert, I. Sugimoto, H. Murakami, Y. Tonami, A. Moriyama, M. Nakanishi, C. T. Nguyen, Y. C. Tay, L. Zhang, A. Y. Lee, I. Arnold, M. F. Bauer, M. Brunner, W. Neupert, R. A. Stuart, T. Iwaki, F. K. Khasanov, C. H. An, A. Aslam, S. Mittal, F. Koch, J. C. Andrau, G. S. Winkler, D. M. Spencer, H. Ying, Y. Yu, Y. Xu, T. L. Chang, A. Necchi, A. Baryshnikova, M. Costanzo, C. L. Myers, B. Andrews, C. Boone, H. Braberg, E. A. Moehle, M. Shales, C. Guthrie, N. J. Krogan, A. S. Schwartz, J. Yu, K. R. Gardenour, R. L. Finley, T. Ideker, D. M. van Pel, P. C. Stirling, S. W. Minaker, P. Sipahimalani, P. Hieter, J. P. Alao, A. M. Weber, A. Shabro, P. Sunnerhagen, H. Ohtsuka, L. Zhang, N. Ma, Q. Liu, Y. Ma, D. K. Breslow, A. Baryshnikova, A. Beyer, S. Bandyopadhyay, T. Ideker, A. Guenole, T. T. Nguyen, J. S. Lim, R. M. Tang, L. Zhang, E. S. Chen, Y. Li, Z. Erdei, A. M. Calcagno, J. A. Lugwig, J. M. Fostel, M. M. Gottesman, S. V. Ambudkar, S. Cascinu, S. Hacker, M. S. Kim, A. Thomas, H. Wang, S. Moreno, A. Klar, P. Nurse, Sci. Rep. 2016, 6, 18658

[97] A. Hafner, J. Lovrić, G. P. Lakoš, I. Pepić, Int. J. Nanomedicine 2014, 9, 1005

[98] T. Lammers, S. Aime, W. E. Hennink, G. Storm, F. Kiessling, Acc. Chem. Res. 2011, 44, 1029. 
[99] M. L. Etheridge, S. A. Campbell, A. G. Erdman, C. L. Haynes, S. M. Wolf, J. McCullough, Nanomedicine 2013, 9, 1.

[100] Nano on reflection, Nat. Nanotechnol. 2016, 11, 828.

[101] C. M. Sayes, G. V. Aquino, A. J. Hickey, AAPS J. 2017, $19,18$.

[102] A. Albanese, C. D. Walkey, J. B. Olsen, H. Guo, A. Emili, W. C. W. Chan, ACS Nano 2014, 8, 5515.

[103] S. Wilhelm, A. J. Tavares, Q. Dai, S. Ohta, J. Audet, H. F. Dvorak, W. C. W. Chan, Nat. Rev. Mater. 2016, 1, 16014.

[104] M. Henriksen-Lacey, S. Carregal-Romero, L. M. Liz-Marzán, Bioconjug. Chem. 2017, 28, 212.

[105] P. Rivera Gil, D. Hühn, L. L. del Mercato, D. Sasse, W. J. Parak, Pharmacol. Res. 2010, 62, 115.

[106] J. I. Hare, T. Lammers, M. B. Ashford, S. Puri, G. Storm, S. T. Barry, Adv. Drug Deliv. Rev. 2017, 108, 25.

[107] E. Aznar, M. Oroval, L. Pascual, J. R. Murguía, R. Martínez-Máñez, F. Sancenón, Chem. Rev. 2016, 116, 561.

[108] T. Lammers, F. Kiessling, W. E. Hennink, G. Storm, J. Control. Release 2012, 161, 175

[109] K. Raemdonck, S. C. De Smedt, Nat. Biotechnol. 2015, 33, 1026.

[110] J. Yao, M. Yang, Y. Duan, Chem. Rev. 2014, 114, 6130.

[111] J. M. Rosenholm, T. Gulin-Sarfraz, V. Mamaeva, R. Niemi, E. Özliseli, D. Desai, D. Antfolk, E. von Haartman, D. Lindberg, N. Prabhakar, T. Näreoja, C. Sahlgren, Small 2016, 12, 1578.

[112] H. Mansur, A. Mansur, S. Carvalho, Z. Lobato, M. I. Guedes, M. de F. Leite, Int. J. Nanomedicine 2016, Volume 11, 4669.

[113] J. Estelrich, M. J. Sánchez-Martín, M. A. Busquets, Int. J. Nanomedicine 2015, 10, 1727

[114] J. Leary, J. Key, Int. J. Nanomedicine 2014, 9, 711.

[115] J. Grimm, D. A. Scheinberg, Semin. Radiat. Oncol. 2011, 21, 80.

[116] B. Pelaz, C. Alexiou, R. A. Alvarez-Puebla, F. Alves, A. M. Andrews, S. Ashraf, L. P. Balogh, L. Ballerini, A. Bestetti, C. Brendel, S. Bosi, M. Carril, W. C. W. Chan, C. Chen, X. Chen, X. Chen, Z. Cheng, D. Cui, J. Du, C. Dullin, A. Escudero, N. Feliu, M. Gao, M. George, Y. Gogotsi, A. Grünweller, Z. Gu, N. J. Halas, N. Hampp, R. K. Hartmann, M. C. Hersam, P. Hunziker, J. Jian, X. Jiang, P. Jungebluth, P. Kadhiresan, K. Kataoka, A. Khademhosseini, J. Kopeček, N. A. Kotov, H. F. Krug, D. S. Lee, C.-M. Lehr, K. W. Leong, X.-J. Liang, M. Ling Lim, L. M. Liz-Marzán, X. Ma, P. Macchiarini, H. Meng, H. Möhwald, P. Mulvaney, A. E. Nel, S. Nie, P. Nordlander, T. Okano, J. Oliveira, T. H. Park, R. M. Penner, M. Prato, V. Puntes, V. M. Rotello, A. Samarakoon, R. E. Schaak, Y. Shen, S. Sjöqvist, A. G. Skirtach, M. G. Soliman, M. M. Stevens, H.-W. Sung, B. Z. Tang, R. Tietze, B. N. Udugama, J. S. VanEpps, T. Weil, P. S. Weiss, I. Willner, Y. Wu, L. Yang, Z. Yue, Q. Zhang, Q. Zhang, X.-E. Zhang, Y. Zhao, X. Zhou, W. J. Parak, ACS Nano 2017, 11, 2313

[117] M.-A. Shahbazi, N. Shrestha, E. Mäkilä, F. Araújo, A. Correia, T. Ramos, B. Sarmento, J. Salonen, J. Hirvonen, H. A. Santos, Nano Res. 2015, 8, 1505.

[118] K. Shao, S. Singha, X. Clemente-Casares, S. Tsai, Y. Yang, P. Santamaria, ACS Nano 2015, 9, 16.

[119] H. Maeda, H. Nakamura, J. Fang, Adv. Drug Deliv. Rev. 2013, 65, 71.

[120] R. Wittig, J. M. Rosenholm, E. von Haartman, J. Hemming, F. Genze, L. Bergman, T. Simmet, M. Lindén, C. Sahlgren, Nanomedicine 2014, 9, 971.

[121] V. Mamaeva, J. M. Rosenholm, L. T. Bate-Eya, L. Bergman, E. Peuhu, A. Duchanoy, L. E. Fortelius, S. Landor, D. M. Toivola, M. Lindén, C. Sahlgren, Mol. Ther. 2011, 19, 1538.

[122] C.-F. Wang, M. P. Sarparanta, E. M. Mäkilä, M. L. K. Hyvönen, P. M. Laakkonen, J. J. Salonen, J. T. Hirvonen, A. J. Airaksinen, H. A. Santos, Biomaterials 2015, 48, 108.

[123] P. J. Kinnari, M. L. K. Hyvönen, E. M. Mäkilä, M. H. Kaasalainen, A. Rivinoja, J. J. Salonen, J. T. Hirvonen, P. M. Laakkonen, H. A. Santos, Biomaterials 2013, 34, 9134.
[124] R. van der Meel, T. Lammers, W. E. Hennink, Expert Opin. Drug Deliv. 2017, 14, 1.

[125] A. J. Huh, Y. J. Kwon, J. Control. Release 2011, 156, 128

[126] E. Weir, A. Lawlor, A. Whelan, F. Regan, Analyst 2008, 133, 835.

[127] S. Pal, Y. K. Tak, J. M. Song, Appl. Environ. Microbiol. 2007, 73, 1712.

[128] I. Sondi, B. Salopek-Sondi, J. Colloid Interface Sci. 2004, 275, 177.

[129] X. Li, S. M. Robinson, A. Gupta, K. Saha, Z. Jiang, D. F. Moyano, A. Sahar, M. A. Riley, V. M. Rotello, ACS Nano 2014, 8, 10682.

[130] M. S. Usman, M. E. El Zowalaty, K. Shameli, N. Zainuddin, M. Salama, N. A. Ibrahim, Int. J. Nanomedicine 2013, 8, 4467.

[131] R. Ahmad, M. Sardar, Int. J. Innov. Res. Sci. Eng. Technol. 2013, 2, 3297.

[132] D. Şen Karaman, S. Manner, A. Fallarero, J. M. Rosenholm, Current Approaches for Exploration of Nanoparticles as Antibacterial Agents, in Biochemistry, Genetics, and Molecular Biology (Ed.: R. N. Kumavath), InTech, 2017.

[133] R. Wu, H. Zhang, J. Pan, H. Zhu, Y. Ma, W. Cui, H. A. Santos, G. Pan, Adv. Mater. Interfaces 2016, 3, 1600472.

[134] Does this 25 Year-old Hold the Key to Winning the War Against Superbugs? www.telegraph.co.uk/women/health/does-this-25-year-oldhold-the-key-to-winning-the-war-against-th/ (accessed: May 2017).

[135] D. Sen Karaman, S. Sarwar, D. Desai, E. M. Björk, M. Odén, P. Chakrabarti, J. M. Rosenholm, S. Chakraborti, J. Olivares, B. Alejandra, G.-L. Guillermo, C. Fernando, B. S. Maria, L. M. Jose, P. A. William, M. Miller, H. J. Binder, M. M. Levine, R. Dillingham, R. L. Guerrant, S. M. Faruque, M. J. Albert, J. J. Mekalanos, A. J. Huh, Y. J. Kwon, L. B. Rice, R. Y. Pelgrift, A. J. Friedman, T. J. Webster, I. Seil, L. Zhang, D. Pornpattananangku, J. Hu, C.-M. Huang, F. Tang, L. Li, D. Chen, H. Qianjun, S. Jianlin, A. J. Sushilkumar, L. Canham, H. A. Santos, G. Palestino, T. Maldiney, B. Benoit, M. Bessodes, D. Scherman, R. Cyrille, F. Tang, L. Li, D. Chen, S. Bhattacharyya, H. Wang, P. Ducheyne, L. M. Jurkić, I. Cepanec, S. K. Pavelić, K. Pavelić, M. Sajid, M. Ilyas, C. Basheer, M. Tariq, M. Daud, N. Baig, F. Shehzad, J. Song, K. Hyunyoung, J. Yoonsun, J. Jyongsik, K. Hotta, H. Yamamoto, Y. Okami, H. Umezawa, G. J. Alangaden, B. N. Kreiswirth, A. Aouad, M. Khetarpal, F. R. Igno, S. L. Moghazeh, K. Elias, E. K. Manavathu, S. A. Lerner, E. M. Björk, F. Söderlind, M. Odén, E. M. Johansson, A. B. Mohamed, J. M. Córdoba, M. Odén, C. A. Schneider, W. S. Rasband, K. W. Eliceiri, S. Chakraborti, A. K. Mandal, S. Sarwar, P. Singh, R. Chakraborty, P. Chakrabarti, V. Meunier, M. Bourrie, Y. Berger, G. Fabre, R. Senthilkumar, D. Sen Karaman, P. Paul, E. M. Björk, M. Oden, J. E. Eriksson, J. M. Rosenholm, D. Desai, D. Sen Karaman, N. Prabhakar, S. Tadayon, A. Duchanoy, D. M. Toivola, S. Rajput, T. Näreoja, J. M. Rosenholm, D. Ş. Karaman, D. Desai, J. Zhang, S. Tadayon, G. Unal, J. Teuho, J. Sarfraz, J.-H. Smått, H. Gu, T. Näreoja, J. M. Rosenholm, D. Ș. Karaman, T. Gulin-Sarfraz, G. Hedström, A. Duchanoy, P. Eklund, J. M. Rosenholm, E. Casals, T. Pfaller, A. Duschl, G. J. Oostingh, V. F. Puntes, A. K. Chatterjee, R. K. Sarkar, A. P. Chattopadhyay, P. Aich, R. Chakraborty, T. Basu, D. R. Korber, G. A. James, J. W. Costerton, J. Zahller, P. S. Stewart, A. W. Bission-Filho, K. F. Discola, P. Castellen, V. Blasios, A. Martins, M. L. Sforça, W. Garcia, P. Sass, M. Josten, K. Famulla, G. Schiffer, H.-G. Sahl, L. Hamoen, H. Brotz-Oesterhelt, S. T. Hossain, S. K. Mukherjee, E. Taylor, T. J. Webster, S. Chakraborti, S. Bhattacharya, R. Chowdhury, P. Chakrabarti, M. Vincent, L. S. England, J. T. Trevors, A. Kumar, A. K. Pandey, S. Singh, R. Shanker, A. Dhawan, M. Premanathan, K. Krishnamoorthy, J. Kadarkaraithangam, M. Govindasamy, L. Fangfei, E. J. Harry, A. L. Bottomley, M. D. Edstein, G. W. Birrell, C. E. Woodward, F. R. Keene, J. G. Collins, C. L. Rene, M. Vimalanathan, P. Prabhakaran, K. B. A. Ahmed, I. Bastin, S. Sandhiya, v. Mohan, A. Veerappan, S. Nagarajan, 
M. F. Varela, S. Kumar, G. He, S. K. Misra, A. Dybowska, D. Berhanu, S. N. Luoma, E. Valsami-Jones, N. B. Hartmann, C. Engelbrekt, J. Zhang, J. Ulstrup, K. O. Kusk, A. Baun, W. H. De Jong, P. J. A. Borm, A. R. Gliga, S. Skoglund, I. O. Wallinder, B. Fadeel, H. L. Karlsson, C. Tank, S. Raman, S. Karan, S. Gosavi, N. P. Lalla, V. Sathe, R. Berndt, W. N. Gade, S. V. Bhoraskar, V. L. Mathe, M. Liong, B. France, K. A. Bradley, J. I. Zink, J. Song, H. Kim, Y. Jang, J. Jang, D. Sen Karaman, D. Desai, R. Senthilkumar, E. M. Johansson, N. Råtts, M. Odén, J. E. Eriksson, C. Sahlgren, D. Toivola, J. M. Rosenholm, M. R. Reithofer, A. Lakshmanan, A. T. K. Ping, J. M. Chin, C. A. E. Hauser, S. Pal, Y. K. Tak, J. M. Song, L. B. Capeletti, L. F. de Oliveria, K. de A. Goncalves, J. F. A. de Oliveira, A. Saito, J. Kobarg, J. H. Z. dos Santos, M. B. Cardoso, A. E. Nel, L. Madler, D. Velegol, T. Xia, E. M. V. Hoek, P. Somasundaran, F. Klaessig, V. Castranova, M. Thompson, I. I. Slowing, C.-W. Wu, J. L. Vivero-Escoto, V. S. Y. Lin, R. C. Goy, D. Britto, O. B. G. Assis, D. Raafat, K. von Bargen, A. Haas, H. G. Sahl, X. Wang, Y. Du, L. Fan, H. Lui, Y. Hu, I. Sondi, B. Salopek-Sondi, D. Vinella, M. Cashel, R. D'Ari, S. Sarwar, S. Chakraborti, S. Bera, I. A. Sheikh, K. M. Hoque, P. Chakrabarti, A. C. Pride, C. M. Herrera, Z. Guan, D. K. Giles, J. Mater. Chem. B 2016, 4, 3292.

[136] A. Kumar, Nanomedicine in Drug Delivery, CRC Press/Taylor \& Francis Group, Boca Raton, USA 2013.

[137] H. Chen, P. Jia, H. Kang, H. Zhang, Y. Liu, P. Yang, Y. Yan, G. Zuo, L. Guo, M. Jiang, J. Qi, Y. Liu, W. Cui, H. A. Santos, L. Deng, Adv. Healthc. Mater. 2016, 5, 907.

[138] J.-G. Leu, S.-A. Chen, H.-M. Chen, W.-M. Wu, C.-F. Hung, Y.-D. Yao, C.-S. Tu, Y.-J. Liang, Nanomedicine 2012, 8, 767.

[139] J. Tian, K. K. Y. Wong, C.-M. Ho, C.-N. Lok, W.-Y. Yu, C.-M. Che, J.-F. Chiu, P. K. H. Tam, ChemMedChem 2007, 2, 129.

[140] European Technology Platform Nanomedicine, http://www.etpnanomedicine.eu/public/about-nanomedicine/nanomedicinetranslation (accessed: May 2017).

[141] U. A. Md Faiyazuddin, Intellect. Prop. Rights Open Access 2014, 2, e104.

[142] L. Lévy, Nanomedicine (Lond). 2014, 9, 389.

[143] Y. Zhang, H. F. Chan, K. W. Leong, Adv. Drug Deliv. Rev. 2013, 65, 104.

[144] G. Gregoriadis, N. Engl. J. Med. 1976, 295, 765.

[145] R. Bawa, G. F. Audette, I. Rubenstein, Handbook of Clinical Nanomedicine, CRC Press/Taylor \& Francis Group, Boca Raton, USA, 2013.

[146] F. S. Collins, H. Varmus, N. Engl. J. Med. 2015, 372, 793.

[147] M. A. Hamburg, F. S. Collins, N. Engl. J. Med. 2010, 363, 301.

[148] D. Jones, Nat. Rev. Drug Discov. 2007, 6, 770.

[149] Guidance for Industry Nonclinical Studies for the Safety Evaluation of Pharmaceutical Excipients 20852-1448, https://www.fda.gov/ ohrms/dockets/98fr/2002d-0389-gdl0002.pdf (accessed: May 2017).

[150] Qualification of Excipients for Use in Pharmaceuticals, http://ipecamericas.org/sites/default/files/ExcipientQualificationGuide.pdf (accessed: May 2017).

[151] H. Gupta, D. Bhandari, A. Sharma, Recent Pat. Drug Deliv. Formul. 2009, 3, 162.

[152] S. Kalepu, M. Manthina, V. Padavala, Acta Pharm. Sin. B 2013, 3, 361.

[153] R. Langer, Nat. Med. 1996, 2, 742.

[154] T. R. Hoare, D. S. Kohane, Polymer (Guildf). 2008, 49, 1993.

[155] N. K. Varde, D. W. Pack, Expert Opin. Biol. Ther. 2004, 4, 35.

[156] J. Lee, K. Y. Lee, Macromol. Biosci. 2009, 9, 671.

[157] J. Rantanen, J. Khinast, J. Pharm. Sci. 2015, 104, 3612.

[158] N. Sandler, I. Salmela, A. Fallarero, A. Rosling, M. Khajeheian, R. Kolakovic, N. Genina, J. Nyman, P. Vuorela, Int. J. Pharm, 2014, $459,62$.
[159] R. Kolakovic, T. Viitala, P. Ihalainen, N. Genina, J. Peltonen, N. Sandler, Expert Opin. Drug Deliv. 2013, 10, 1711.

[160] M. Preis, J. Breitkreutz, N. Sandler, Int. J. Pharm. 2015, 494, 578.

[161] N. Sandler, A. Määttänen, P. Ihalainen, L. Kronberg, A. Meierjohann, T. Viitala, J. Peltonen, J. Pharm. Sci. 2011, 100, 3386.

[162] N. Genina, D. Fors, H. Vakili, P. Ihalainen, L. Pohjala, H. Ehlers, I. Kassamakov, E. Haeggström, P. Vuorela, J. Peltonen, N. Sandler, Eur. J. Pharm. Sci. 2012, 47, 615.

[163] N. Genina, J. Holländer, H. Jukarainen, E. Mäkilä, J. Salonen, N. Sandler, Eur. J. Pharm. Sci. 2016, 90, 53.

[164] N. Sandler, M. Preis, Trends Pharmacol. Sci. 2016, 37, 1070.

[165] M. Palo, K. Kogermann, I. Laidmäe, A. Meos, M. Preis, I. Heinämäki, N. Sander, Mol. Pharmceutics 2017, 14, 108.

[166] Y. Song, J. Hormes, C. S. S. R. Kumar, Small 2008, 4, 698.

[167] E. K. Sackmann, A. L. Fulton, D. J. Beebe, Nature 2014, 507, 181.

[168] P. M. Valencia, E. M. Pridgen, M. Rhee, R. Langer, O. C. Farokhzad, R. Karnik, ACS Nano 2013, 7, 10671.

[169] Q. Feng, J. Sun, X. Jiang, Nanoscale 2016, 8, 12430.

[170] E. Aznar, M. Oroval, L. Pascual, J. R. Murguía, R. Martínez-Máñez, F. Sancenón, Chem. Rev. 2016, 116, 561.

[171] H. Zhang, D. Liu, M.-A. Shahbazi, E. Mäkilä, B. Herranz-Blanco, J. Salonen, J. Hirvonen, H. A. Santos, Adv. Mater. 2014, 26, 4497.

[172] D. Liu, H. Zhang, E. Mäkilä, J. Fan, B. Herranz-Blanco, C.-F. Wang, R. Rosa, A. J. Ribeiro, J. Salonen, J. Hirvonen, H. A. Santos, Biomaterials 2015, 39, 249.

[173] H. Zhang, D. Liu, M.-A. Shahbazi, E. Mäkilä, B. Herranz-Blanco, J. Salonen, J. Hirvonen, H. A. Santos, Adv. Mater. 2014, 26, 4497.

[174] F. Kong, X. Zhang, H. Zhang, X. Qu, D. Chen, M. Servos, E. Mäkilä, J. Salonen, H. A. Santos, M. Hai, D. A. Weitz, Adv. Funct. Mater. 2015, 25, 3330.

[175] D. Liu, H. Zhang, E. Mäkilä, J. Fan, B. Herranz-Blanco, C.-F. Wang, R. Rosa, A. J. Ribeiro, J. Salonen, J. Hirvonen, H. A. Santos, Biomaterials 2015, 39, 249.

[176] R. Krampe, J. C. Visser, H. W. Frijlink, J. Breitkreutz, H. J. Woerdenbag, M. Preis, Expert Opin. Drug Deliv. 2016, 13, 493.

[177] R. C. Rowe, P. J. Sheskey, W. G. Cook, M. E. Fenton, Handbook of Pharmaceutical Excipients, RSC, UK, 2012.

[178] M. A. Repka, S. Majumdar, S. Kumar Battu, R. Srirangam, S. B. Upadhye, Expert Opin. Drug Deliv. 2008, 5, 1357.

[179] European Food Safety Agency, http://www.efsa.europa.eu (accessed: May 2017).

[180] D. A. Grande, C. Halberstadt, G. Naughton, R. Schwartz, R. Manji, J. Biomed. Mater. Res. 1997, 34, 211.

[181] T. J. Klein, S. C. Rizzi, K. Schrobback, J. C. Reichert, J. E. Jeon, R. W. Crawford, D. W. Hutmacher, S. S. Chen, Y. H. Falcovitz, R. Schneiderman, A. Maroudas, R. L. Sah, E. M. Darling, J. C. Hu, K. A. Athanasiou, M. B. Aydelotte, R. R. Greenhill, K. E. Kuettner, B. L. Schumacher, C. E. Hughes, K. E. Kuettner, B. Caterson, M. B. Aydelotte, G. D. Jay, J. R. Torres, M. L. Warman, M. C. Laderer K. S. Breuer, M. Brittberg, L. Peterson, E. Sjogren-Jansson, T. Tallheden, A. Lindahl, W. Bartlett, J. A. Skinner, C. R. Gooding, R. W. Carrington, A. M. Flanagan, T. W. Briggs, G. Bentley, S. Roberts, J. Menage, L. J. Sandell, E. H. Evans, J. B. Richardson, P. D. Benya, J. D. Shaffer, J. Bonaventure, N. Kadhom, L. Cohen-Solal, K. H. Ng, J. Bourguignon, C. Lasselin, P. Freisinger, U. Noth L. Rackwitz, A. Heymer, M. Weber, B. Baumann, A. Steinert, N. Schutze, F. Jakob, J. Eulert, H. A. Awad, M. Q. Wickham, H. A. Leddy, J. M. Gimble, F. Guilak, T. M. Quinn, P. Schmid, E. B. Hunziker, A. J. Grodzinsky, T. A. Ahmed, E. V. Dare, M. Hincke, A. D. Augst, H. J. Kong, D. J. Mooney, T. A. Selmi, P. Verdonk, P. Chambat, F. Dubrana, J. F. Potel, L. Barnouin, P. Neyret, S. Chubinskaya, K. Huch, M. Schulze, L. Otten, M. B. Aydelotte, A. A. Cole, A. S. Sawhney, C. P. Pathak, J. J. van Rensburg, 
R. C. Dunn, J. A. Hubbell, Y. Park, M. P. Lutolf, J. A. Hubbell, E. B. Hunziker, M. Wong, M. P. Lutolf, J. A. Hubbell, M. Ehrbar, S. C. Rizzi, R. G. Schoenmakers, B. S. Miguel, J. A. Hubbell, F. E. Weber, M. P. Lutolf, M. P. Lutolf, J. L. Lauer-Fields, H. G. Schmoekel, A. T. Metters, F. E. Weber, G. B. Fields, J. A. Hubbell, C. N. Salinas, K. S. Anseth, S. J. Bryant, R. J. Bender, K. L. Durand, K. S. Anseth, K. Bott, Z. Upton, K. Schrobback, M. Ehrbar, J. A. Hubbell, M. P. Lutolf, S. C. Rizzi, M. B. Mueller, R. S. Tuan, A. Barlic, M. Drobnic, E. Malicev, N. Kregar-Velikonja, K. G. Yang, D. B. Saris, R. E. Geuze, M. H. van Rijen, Y. J. van der Helm, A. J. Verbout, L. B. Creemers, W. J. Dhert, T. Dehne, C. Karlsson, J. Ringe, M. Sittinger, A. Lindahl, S. Weiss, T. Hennig, R. Bock, E. Steck, W. Richter, J. Guo, U. I. Chung, D. Yang, G. Karsenty, F. R. Bringhurst, H. M. Kronenberg, E. K. Harrington, L. E. Lunsford, K. K. Svoboda, M. Ehrbar, S. C. Rizzi, R. Hlushchuk, V. Djonov, A. H. Zisch, J. A. Hubbell, F. E. Weber, M. P. Lutolf, I. Sekiya, J. T. Vuoristo, B. L. Larson, D. J. Prockop, B. A. Byers, R. L. Mauck, I. E. Chiang, R. S. Tuan, I. Tchetverikov, L. S. Lohmander, N. Verzijl, T. W. Huizinga, J. M. TeKoppele, R. Hanemaaijer, J. DeGroot, L. C. Tetlow, D. J. Adlam, D. E. Woolley, J. T. Connelly, A. J. Garcia, M. E. Levenston, L. M. Kock, R. M. Schulz, C. C. van Donkelaar, C. B. Thummler, A. Bader, K. Ito, S. J. Bryant, G. D. Nicodemus, I. Villanueva, C. N. Salinas, K. S. Anseth, V. C. Mow, C. C. Wang, C. T. Hung, H. J. Kwon, K. Yasuda, Y. Ohmiya, K. I. Honma, Y. M. Chen, J. P. Gong, N. S. Hwang, S. Varghese, H. J. Lee, P. Theprungsirikul, A. Canver, B. Sharma, J. Elisseeff, S. J. Bryant, I. A. Arthur, K. S. Anseth, T. J. Klein, S. C. Rizzi, J. C. Reichert, N. Georgi, J. Malda, W. Schuurman, R. W. Crawford, D. W. Hutmacher, K. D. Jadin, W. C. Bae, B. L. Schumacher, R. L. Sah, H. A. Leddy, H. A. Awad, F. Guilak, J. Malda, E. Kreijveld, J. S. Temenoff, C. A. van Blitterswijk, J. Riesle, R. W. Farndale, C. A. Sayers, A. J. Barrett, R. W. Farndale, D. J. Buttle, A. J. Barrett, B. O. Enobakhare, D. L. Bader, D. A. Lee, I. Martin, M. Jakob, D. Schafer, W. Dick, G. Spagnoli, M. Heberer, S. Daouti, B. Latario, S. Nagulapalli, F. Buxton, S. Uziel-Fusi, G. W. Chirn, D. Bodian, C. Song, M. Labow, M. Lotz, J. Quintavalla, C. Kumar, S. J. Song, D. Hutmacher, V. Nurcombe, S. M. Cool, Soft Matter 2010, 6, 5175 .

[182] S. Nishimoto, M. Takagi, S. Wakitani, T. Nihira, T. Yoshida, J. Biosci. Bioeng. 2005, 100, 123.

[183] P. B. Malafaya, G. A. Silva, R. L. Reis, Adv. Drug Deliv. Rev. 2007, 59, 207.

[184] J. Liu, S. Willför, C. Xu, Bioact. Carbohydrates Diet. Fibre 2015, 5, 31.

[185] A. Isogai, T. Saito, H. Fukuzumi, Nanoscale 2011, 3, 71.

[186] Y. Habibi, L. A. Lucia, O. J. Rojas, Chem. Rev. 2010, 110, 3479.

[187] D. Klemm, F. Kramer, S. Moritz, T. Lindström, M. Ankerfors, D. Gray, A. Dorris, Angew. Chemie Int. Ed. 2011, 50, 5438.

[188] N. B. Shelke, R. James, C. T. Laurencin, S. G. Kumbar, Polym. Adv. Technol. 2014, 25, 448

[189] D. Wanna, C. Alam, D. M. Toivola, P. Alam, Adv. Nat. Sci. Nanosci. Nanotechnol. 2013, 4, 45002

[190] S. D. Dimitrijevich, M. Tatarko, R. W. Gracy, G. E. Wise, L. X. Oakford, C. B. Linsky, L. Kamp, Carbohydr. Res. 1990, 198, 331.

[191] L. Alexandrescu, K. Syverud, A. Gatti, G. Chinga-Carrasco, Cellulose 2013, 20, 1765 .

[192] N. Lin, A. Dufresne, Eur. Polym. J. 2014, 59, 302.

[193] J. Liu, F. Cheng, H. Grénman, S. Spoljaric, J. Seppälä, J. E. Eriksson, S. Willför, C. Xu, Carbohydr. Polym. 2016, 148, 259.

[194] J. Liu, G. Chinga-Carrasco, F. Cheng, W. Xu, S. Willför, K. Syverud, C. Xu, Cellulose 2016, 23, 3129.

[195] Y.-R. Lou, L. Kanninen, T. Kuisma, J. Niklander, L. A. Noon, D. Burks, A. Urtti, M. Yliperttula, Stem Cells Dev. 2014, 23, 380.
[196] J. M. Rajwade, K. M. Paknikar, J. V. Kumbhar, Appl. Microbiol. Biotechnol. 2015, 99, 2491.

[197] M. M. Abeer, M. C. I. Mohd Amin, C. Martin, J. Pharm. Pharmacol. 2014, 66, 1047

[198] J. Vinsova, E. Vavrikova, Curr. Pharm. Des. 2008, 14, 1311

[199] T. Kean, M. Thanou, RSC Polymer Chemistry Series, RSC Press, UK, 2011, pp. 292-318.

[200] N. N. Inamdar, V. Mourya, in Adv. Biomater. Biodevices, John Wiley \& Sons, Inc., Hoboken, NJ, USA 2014, 183.

[201] T. Wu, C. Wu, S. Fu, L. Wang, C. Yuan, S. Chen, Y. Hu, Carbohydr. Polym. 2017, 155, 192

[202] Y. Hou, J. Hu, H. Park, M. Lee, J. Biomed. Mater. Res. A 2012, 100, 939.

[203] A. M. Abdel-Mohsen, J. Jancar, D. Massoud, Z. Fohlerova, H. Elhadidy, Z. Spotz, A. Hebeish, Int. J. Pharm. 2016, 510, 86.

[204] L. Hu, Y. Sun, Y. Wu, Nanoscale 2013, 5, 3103.

[205] A. Bernkop-Schnürch, S. Dünnhaupt, Eur. J. Pharm. Biopharm. 2012, 81, 463.

[206] K. Pal, B. Behera, S. Roy, S. Sekhar Ray, G. Thakur, Soft Mater. 2013, 11, 125.

[207] S. Daus, T. Heinze, Macromol. Biosci. 2010, 10, 211.

[208] S. Mura, J. Nicolas, P. Couvreur, Nat. Mater. 2013, 12, 991.

[209] L. Yan, X. Li, Curr. Pharm. Biotechnol. 2016, 17, 227.

[210] T. Vermonden, R. Censi, W. E. Hennink, Chem. Rev. 2012, 112, 2853.

[211] S. Dutta, P. Samanta, D. Dhara, Int. J. Biol. Macromol. 2016, 87, 92.

[212] Z. Poon, J. A. Lee, S. Huang, R. J. Prevost, P. T. Hammond, Nanomedicine 2011, 7, 201.

[213] A. J. Convertine, C. Diab, M. Prieve, A. Paschal, A. S. Hoffman, P. H. Johnson, P. S. Stayton, Biomacromolecules 2010, 11, 2904.

[214] R. A. Petros, J. M. DeSimone, Nat. Rev. Drug Discov. 2010, $9,615$.

[215] Y. Geng, P. Dalhaimer, S. Cai, R. Tsai, M. Tewari, T. Minko, D. E. Discher, Nat. Nanotechnol. 2007, 2, 249.

[216] M. R. Kano, Y. Bae, C. Iwata, Y. Morishita, M. Yashiro, M. Oka, T. Fujii, A. Komuro, K. Kiyono, M. Kaminishi, K. Hirakawa, Y. Ouchi, N. Nishiyama, K. Kataoka, K. Miyazono, 2007, 104, 3460.

[217] W. B. Liechty, D. R. Kryscio, B. V. Slaughter, N. A. Peppas, Annu. Rev. Chem. Biomol. Eng. 2010, 1, 149.

[218] S. Atta, S. Khaliq, A. Islam, I. Javeria, T. Jamil, M. M. Athar, M. I. Shafiq, A. Ghaffar, Int. J. Biol. Macromol. 2015, 80, 240.

[219] R. Jalil, J. R. Nixon, J. Microencapsul. 1990, 7, 297.

[220] H. Öblom, J. Berg, I. Alanko, M. Preis, N. Sandler, Int. J. Pharm. 2016, 511, 1134 .

[221] M. Vaahtio, M. Jokinen, A. Rosling, P. Kortesuo, J. Kiesvaara, A. Yli-Urpo, Key Eng. Mater. 2004, 254-256, 489

[222] C. G. Pitt, A. R. Jeffcoat, R. A. Zweidinger, A. Schindler, J. Biomed. Mater. Res. 1979, 13, 497.

[223] M. Malin, M. Hiljanen-Vainio, T. Karjalainen, J. Seppälä, J. Appl. Polym. Sci. 1996, 59, 1289

[224] E. Orava, J. Korventausta, M. Rosenberg, M. Jokinen, A. Rosling, Polym. Degrad. Stab. 2007, 92, 14.

[225] J. Korventausta, M. Jokinen, A. Rosling, T. Peltola, A. Yli-Urpo, Biomaterials 2003, 24, 5173 .

[226] J. Korventausta, A. Rosling, J. Andersson, A. Lind, M. Linden, M. Jokinen, A. Yli-Urpo, Key Eng. Mater. 2004, 254-256, 557.

[227] P. Bober, J. Liu, K. S. Mikkonen, P. Ihalainen, M. Pesonen, C. Plumed-Ferrer, A. von Wright, T. Lindfors, C. Xu, R.-M. Latonen, Biomacromolecules 2014, 15, 3655.

[228] X. Wang, F. Cheng, J. Liu, J.-H. Smått, D. Gepperth, M. Lastusaari, C. Xu, L. Hupa, Acta Biomater. 2016.

[229] J. M. Rosenholm, J. Zhang, M. Linden, C. Sahlgren, Nanomedicine (Lond). 2016, 11, 391 
[230] J. Zhang, J. M. Rosenholm, Ther. Deliv. 2015, 6, 891

[231] R. Senthilkumar, D. Ş. Karaman, P. Paul, E. M. Björk, M. Odén, J. E. Eriksson, J. M. Rosenholm, Biomater. Sci. 2015, 3, 103.

[232] W. M. Alberts, I. Vikholm, T. Viitala, J. Peltonen, Handbook of Surfaces and Interfaces of Materials, Interfacial and Materials Aspectsof the Immobilization of Biomolecules onto Solid Surfaces, (Ed: H. S. Nalwa), Academic Press, San Diego, USA 2001.

[233] B. D. Ratner, D. G. Castner, T. A. Horbett, T. J. Lenk, K. B. Lewis, R. J. Rapoza, J. Vac. Sci. Technol. A 1990, 8, 2306.

[234] R. Bollström, A. Määttänen, D. Tobjörk, P. Ihalainen, N. Kaihovirta, R. Österbacka, J. Peltonen, M. Toivakka, Org. Electron. 2009, 10, 1020.

[235] H. Juvonen, A. Määttänen, P. Ihalainen, T. Viitala, J. Sarfraz, J. Peltonen, Colloids Surfaces B Biointerfaces 2014, 118, 261.

[236] D. Tobjörk, R. Österbacka, Adv. Mater. 2011, 23, 1935.

[237] J. Sarfraz, P. Ihalainen, A. Määttänen, R. Bollström, T. Gulin-Sarfraz, J. Peltonen, M. Lindén, Colloids Surfaces A Physicochem. Eng. Asp. 2014, 460, 401.

[238] H. Wickström, M. Palo, K. Rijckaert, R. Kolakovic, J. O. Nyman, A. Määttänen, P. Ihalainen, J. Peltonen, N. Genina, T. de Beer, K. Löbmann, T. Rades, N. Sandler, Eur. J. Pharm. Sci. 2015, 75, 91.

[239] A. Määttänen, D. Fors, S. Wang, D. Valtakari, P. Ihalainen, J. Peltonen, Sensors Actuators B Chem. 2011, 160, 1404.

[240] D. D. Liana, B. Raguse, J. J. Gooding, E. Chow, Sensors 2012, 12, 11505

[241] X. Li, D. R. Ballerini, W. Shen, Biomicrofluidics 2012, 6, 11301.

[242] Z. Nie, F. Deiss, X. Liu, O. Akbulut, G. M. Whitesides, Lab Chip 2010, 10, 3163.

[243] E. Fu, T. Liang, P. Spicar-Mihalic, J. Houghtaling, S. Ramachandran, P. Yager, Anal. Chem. 2012, 84, 4574.

[244] S. J. Vella, P. Beattie, R. Cademartiri, A. Laromaine, A. W. Martinez, S. T. Phillips, K. A. Mirica, G. M. Whitesides, Anal. Chem. 2012, 84, 2883.

[245] A. W. Martinez, S. T. Phillips, G. M. Whitesides, E. Carrilho, Anal. Chem. 2010, 82, 3

[246] A. W. Martinez, S. T. Phillips, M. J. Butte, G. M. Whitesides, Angew. Chemie Int. Ed. 2007, 46, 1318.

[247] A. Määttänen, U. Vanamo, P. Ihalainen, P. Pulkkinen, H. Tenhu, J. Bobacka, J. Peltonen, Sensors Actuators B Chem. 2013, 177, 153.

[248] P. Ihalainen, F. Pettersson, M. Pesonen, T. Viitala, A. Määttänen, R. Österbacka, J. Peltonen, Nanotechnology 2014, 25, 094009.

[249] P. Ihalainen, H. Majumdar, T. Viitala, B. Törngren, T. Närjeoja, A. Määttänen, J. Sarfraz, H. Härmä, M. Yliperttula, R. Österbacka, J. Peltonen, Biosensors 2012, 3, 1 .

[250] A. P. F. Turner, Chem. Soc. Rev 2013, 42, 3184.

[251] H. Liu, R. M. Crooks, Anal. Chem. 2012, 84, 2528.

[252] L. Ge, P. Wang, S. Ge, N. Li, J. Yu, M. Yan, J. Huang, Anal. Chem. 2013, 85, 3961.

[253] J. Liu, M. Agarwal, K. Varahramyan, Sensors Actuators B Chem. 2008, 135, 195

[254] B. S. Cook, A. Shamim, M. M. Tentzeris, IET Microwaves, Antennas Propag. 2012, 6, 1536 .

[255] D. A. Giljohann, C. A. Mirkin, Nature 2009, 462, 461.

[256] K. Abe, K. Suzuki, D. Citterio, Anal. Chem. 2008, 80, 6928

[257] A. Määttänen, P. Ihalainen, P. Pulkkinen, S. Wang, H. Tenhu, J. Peltonen, ACS Appl. Mater. Interfaces 2012, 4, 955.

[258] H. Juvonen, A. Määttänen, P. Laurén, P. Ihalainen, A. Urtti, M. Yliperttula, J. Peltonen, Acta Biomater. 2013, 9, 6704.

[259] A. Herland, K. M. Persson, V. Lundin, M. Fahlman, M. Berggren, E. W. H. Jager, A. I. Teixeira, Angew. Chemie Int. Ed. 2011, 50, 12529.

[260] S. Goenka, V. Sant, S. Sant, J. Control. Release 2014, 173, 75.

[261] B. M. Lamb, M. N. Yousaf, J. Am. Chem. Soc. 2011, 133, 8870.

[262] J. Li, Y. Lei, C.-L. Sun, W. Zheng, X. Jiang, H.-L. Zhang, Adv. Mater. Interfaces 2015, 2, 1500335.
[263] J. Kim, R. C. Hayward, Trends Biotechnol. 2012, 30, 426.

[264] A. Määttänen, P. Ihalainen, B. Törngren, E. Rosqvist, M. Pesonen, J. Peltonen, Appl. Surf. Sci. 2016, 364, 37

[265] D. Zhang, G. Luo, X. Ding, C. Lu, Acta Pharm. Sin. B 2012, 2, 549.

[266] T. F. Vandamme, J. Pharm. Bioallied Sci. 2014, 6, 2.

[267] R. Ito, T. Takahashi, I. Katano, M. Ito, Cell. Mol. Immunol. 2012, 9, 208.

[268] L. M. Chaible, M. A. Corat, E. Abdelhay, M. L. Dagli, Genet. Mol. Res 2010, 9, 1469.

[269] V. Mamaeva, J. M. Rosenholm, L. T. Bate-Eya, L. Bergman, E. Peuhu, A. Duchanoy, L. E. Fortelius, S. Landor, D. M. Toivola, M. Lindén, C. Sahlgren, Mol. Ther. 2011, 19, 1538.

[270] V. Mamaeva, R. Niemi, M. Beck, E. Özliseli, D. Desai, S. Landor, T. Gronroos, P. Kronqvist, I. K. N. Pettersen, E. McCormack J. M. Rosenholm, M. Linden, C. Sahlgren, Mol. Ther. 2016 24, 926.

[271] S. K.-J. Landor, A. P. Mutvei, V. Mamaeva, S. Jin, M. Busk, R. Borra, T. J. Grönroos, P. Kronqvist, U. Lendahl, C. M. Sahlgren, Proc. Natl. Acad. Sci. U. S. A. 2011, 108, 18814.

[272] H. Baghirov, D. Karaman, T. Viitala, A. Duchanoy, Y.-R. Lou, V. Mamaeva, E. Pryazhnikov, L. Khiroug, C. de Lange Davies, C. Sahlgren, J. M. Rosenholm, PLoS One 2016, 11, e0160705.

[273] A. Pochert, I. Vernikouskaya, F. Pascher, V. Rasche, M. Lindén, J. Colloid Interface Sci. 2017, 488, 1.

[274] D. Desai, N. Prabhakar, V. Mamaeva, D. S. Karaman, I. A. Lähdeniemi, C. Sahlgren, J. M. Rosenholm, D. M. Toivola Int. J. Nanomedicine 2016, 11, 299.

[275] J. O. Misiorek, I. A. K. Lähdeniemi, J. H. Nyström, V. M. Paramonov, J. A. Gullmets, H. Saarento, A. Rivero-Müller T. Husøy, P. Taimen, D. M. Toivola, Carcinogenesis 2016, 37, 777.

[276] L. Bronsart, L. Nguyen, A. Habtezion, C. Contag, Mol. Imaging Biol. 2016, 18, 473.

[277] S. Zhang, J. Ermann, M. D. Succi, A. Zhou, M. J. Hamilton, B. Cao, J. R. Korzenik, J. N. Glickman, P. K. Vemula, L. H. Glimcher, G. Traverso, R. Langer, J. M. Karp, Sci. Transl. Med. 2015, 7 , 300ra128.

[278] M. N. Asghar, R. Emani, C. Alam, T. O. Helenius, T. J. Grönroos O. Sareila, M. U. Din, R. Holmdahl, A. Hänninen, D. M. Toivola, Inflamm. Bowel Dis. 2014, 20, 1435.

[279] J. M. Rosenholm, T. Gulin-Sarfraz, V. Mamaeva, R. Niemi, E. Özliseli, D. Desai, D. Antfolk, E. von Haartman, D. Lindberg, N. Prabhakar, T. Näreoja, C. Sahlgren, Small 2016, 12, 1578.

[280] M. J. Justice, L. D. Siracusa, A. F. Stewart, Dis. Model. Mech. 2011, 4, 305 .

[281] J. Giacomotto, L. Ségalat, Br. J. Pharmacol. 2010, 160, 204.

[282] A. J. Bell, S. M. J. McBride, T. C. Dockendorff, Fly (Austin). 2009, 3,39 .

[283] J. Ablain, L. I. Zon, Trends Cell Biol. 2013, 23, 584

[284] Y. Kasai, R. Cagan, Per. Med. 2010, 7, 621.

[285] C. Santoriello, L. I. Zon, J. Clin. Invest. 2012, 122, 2337.

[286] Y. Apidianakis, L. G. Rahme, Dis. Model. Mech. 2011, 4, 21.

[287] M. C. Chifiriuc, A. C. Ratiu, M. Popa, A. Al Ecovoiu, Int. J. Mol. Sci. 2016, 17, 36

[288] C. Chakraborty, A. R. Sharma, G. Sharma, S.-S. Lee, J. Nanobiotechnology 2016, 14, 65

[289] L. Evensen, P. L. Johansen, G. Koster, K. Zhu, L. Herfindal, M. Speth, F. Fenaroli, J. Hildahl, S. Bagherifam, C. Tulotta, L. Prasmickaite, G. M. Mælandsmo, E. Snaar-Jagalska, G. Griffiths, Nanoscale 2016, 8, 862

[290] S. Jiang, C. P. Teng, W. C. Puah, M. Wasser, K. Y. Win, M.-Y. Han, ACS Biomater. Sci. Eng. 2015, 1, 1077.

[291] U. B. Pandey, C. D. Nichols, Pharmacol. Rev. 2011, 63, 411.

[292] L. T. Reiter, L. Potocki, S. Chien, M. Gribskov, E. Bier, Genome Res. 2001, 11, 1114 .

[293] C. Gonzalez, Nat. Rev. Cancer 2013, 13, 172. 
[294] R. Edmondson, J. J. Broglie, A. F. Adcock, L. Yang, Assay Drug Dev. Technol. 2014, 12, 207.

[295] J. Wang, S. Skolnik, Curr. Top. Med. Chem. 2013, 13, 1308.

[296] Y. Avior, I. Sagi, N. Benvenisty, Nat. Rev. Mol. Cell Biol. 2016, 17, 170.

[297] M. Shulman, Y. Nahmias, Methods Mol. Biol. 2013, 945, 287.

[298] H. Clevers, Cell 2016, 165, 1586.

[299] J. A. Hickman, R. Graeser, R. de Hoogt, S. Vidic, C. Brito, M. Gutekunst, H. van der Kuip, Biotechnol. J. 2014, 9, 1115.

[300] M. Ravi, V. Paramesh, S. R. Kaviya, E. Anuradha, F. D. P. Solomon, J. Cell. Physiol. 2015, 230, 16

[301] X. Yin, B. E. Mead, H. Safaee, R. Langer, J. M. Karp, O. Levy, Cell Stem Cell 2016,18, 25.

[302] K. Kretzschmar, H. Clevers, Dev. Cell 2016, 38, 590.

[303] T. Sato, H. Clevers, Science 2013, 340, 1190

[304] I. Kelava, M. A. Lancaster, Dev. Biol. 2016, 420, 199.

[305] C. J. Hindley, L. Cordero-Espinoza, M. Huch, Dev. Biol. 2016, 420, 251.

[306] A. I. Astashkina, C. F. Jones, G. Thiagarajan, K. Kurtzeborn, H. Ghandehari, B. D. Brooks, D. W. Grainger, Biomaterials 2014, $35,6323$.

[307] L. Li, Q. Zhou, T. C. Voss, K. L. Quick, D. V. LaBarbera, Methods 2016, 96, 97.

[308] M. van de Wetering, H. E. Francies, J. M. Francis, G. Bounova, F. Iorio, A. Pronk, W. van Houdt, J. van Gorp, A. Taylor-Weiner, L. Kester, A. McLaren-Douglas, J. Blokker, S. Jaksani, S. Bartfeld, R. Volckman, P. van Sluis, V. S. W. Li, S. Seepo, C. Sekhar Pedamallu, K. Cibulskis, S. L. Carter, A. McKenna, M. S. Lawrence, L. Lichtenstein, C. Stewart, J. Koster, R. Versteeg, A. van Oudenaarden, J. Saez-Rodriguez, R. G. J. Vries, G. Getz, L. Wessels, M. R. Stratton, U. McDermott, M. Meyerson, M. J. Garnett, H. Clevers, Cell 2015, 161, 933.

[309] N. Sachs, H. Clevers, Curr. Opin. Genet. Dev. 2014, 24, 68

[310] R. Kojima, D. Aubel, M. Fussenegger, Curr. Opin. Chem. Biol. 2015, 28, 29.

[311] A. Vargas, M. Zeisser-Labouèbe, N. Lange, R. Gurny, F. Delie, Adv. Drug Deliv. Rev. 2007, 59, 1162.

[312] C. M. Coleman, Birth Defects Res. C. Embryo Today 2008, 84, 245.

[313] H. Shokry, U. Vanamo, O. Wiltschka, J. Niinimäki, M. Lerche, K. Levon, M. Linden, C. Sahlgren, Nanoscale 2015, 7, 14434.

[314] V. Mamaeva, R. Niemi, M. Beck, E. Özliseli, D. Desai, S. Landor, T. Gronroos, P. Kronqvist, I. K. N. Pettersen, E. McCormack, J. M. Rosenholm, M. Linden, C. Sahlgren, Mol. Ther. 2016, 24, 926.

[315] V. Mamaeva, J. M. Rosenholm, L. T. Bate-Eya, L. Bergman, E. Peuhu, A. Duchanoy, L. E. Fortelius, S. Landor, D. M. Toivola, M. Lindén, C. Sahlgren, Mol. Ther. 2011, 19, 1538.

[316] J. M. Rosenholm, T. Gulin-Sarfraz, V. Mamaeva, R. Niemi, E. Özliseli, D. Desai, D. Antfolk, E. von Haartman, D. Lindberg, N. Prabhakar, T. Näreoja, C. Sahlgren, Small 2016, 12, 1578.

[317] H. Rauwerda, M. Roos, B. O. Hertzberger, T. M. Breit, Drug Discov. Today 2006, 11, 228.

[318] L. Li, Q. Zhou, T. C. Voss, K. L. Quick, D. V. LaBarbera, Methods 2016, 96, 97.
[319] V. Lob, T. Geisler, M. Brischwein, R. Uhl, B. Wolf, Med. Biol. Eng. Comput. 2007, 45, 1023.

[320] E. E. Hoover, J. A. Squier, Nat. Photonics 2013, 7, 93.

[321] P. Engerer, C. Fecher, T. Misgeld, Nat. Biotechnol. 2016, 34, 928.

[322] G. de Medeiros, B. Balázs, L. Hufnagel, Semin. Cell Dev. Biol. 2016, $55,148$.

[323] P. J. Keller, A. D. Schmidt, J. Wittbrodt, E. H. K. Stelzer, Science 2008, 322, 1065.

[324] N. C. Gauthier, M. A. Fardin, P. Roca-Cusachs, M. P. Sheetz, Proc. Natl. Acad. Sci. U. S. A. 2011, 108, 14467.

[325] H. Vandenburgh, Tissue Eng. Part B. Rev. 2010, 16, 55.

[326] G. C. Gurtner, S. Werner, Y. Barrandon, M. T. Longaker, Nature 2008, 453, 314

[327] A. J. Singer, R. A. Clark, N. Engl. J. Med. 1999, 341, 738.

[328] D. E. Discher, P. Janmey, Y.-L. Wang, Science 2005, 310, 1139.

[329] M. Witting, K. Obst, W. Friess, S. Hedtrich, Biotechnol. Adv. 2015, 33, 1355 .

[330] B. Baroli, J. Pharm. Sci. 2010, 99, 21.

[331] N. Naseri, C. Algan, V. Jacobs, M. John, K. Oksman, A. P. Mathew, Carbohydr. Polym. 2014, 109, 7.

[332] E. Matousková, L. Broz, V. Stolbová, L. Klein, R. Konigová, P. Veselý, Biomed. Mater. Eng. 2006, 16, S63.

[333] M. P. Curran, G. L. Plosker, BioDrugs 2002, 16, 439.

[334] P. Carrier, A. Deschambeault, M. Talbot, C. J. Giasson, F. A. Auger, S. L. Guérin, L. Germain, Invest. Ophthalmol. Vis. Sci. 2008, 49, 1376

[335] P. Bajaj, R. M. Schweller, A. Khademhosseini, J. L. West, R. Bashir, Annu. Rev. Biomed. Eng. 2014, 16, 247.

[336] E. W. Esch, A. Bahinski, D. Huh, Nat. Rev. Drug Discov. 2015, 14, 248.

[337] D. E. Ingber, Cell 2016, 164, 1105.

[338] G. G. Giobbe, F. Michielin, C. Luni, S. Giulitti, S. Martewicz, S. Dupont, A. Floreani, N. Elvassore, Nat. Methods 2015, 12, 1.

[339] A. Schepers, C. Li, A. Chhabra, B. T. Seney, S. Bhatia, Lab Chip 2016, 16, 2644

[340] K. H. Benam, R. Villenave, C. Lucchesi, A. Varone, C. Hubeau, H.-H. Lee, S. E. Alves, M. Salmon, T. C. Ferrante, J. C. Weaver, A. Bahinski, G. A. Hamilton, D. E. Ingber, Nat. Methods 2016, 13, 151.

[341] D. Huh, D. C. Leslie, B. D. Matthews, J. P. Fraser, S. Jurek, G. A. Hamilton, K. S. Thorneloe, M. A. McAlexander, D. E. Ingber, Sci. Transl. Med. 2012, 4, 159ra147.

[342] A. Herland, A. D. van der Meer, E. A. FitzGerald, T.-E. Park, J. J. F. Sleeboom, D. E. Ingber, PLoS One 2016, 11, e0150360.

[343] M. B. Esch, G. J. Mahler, T. Stokol, M. L. Shuler, Lab Chip 2014, 14 3081

[344] E. Lee, H.-H. G. Song, C. S. Chen, Curr. Opin. Chem. Eng. 2016 , $11,20$.

[345] E. W. K. Young, Integr. Biol. (Camb). 2013, 5, 1096.

[346] A. Polini, L. Prodanov, N. S. Bhise, V. Manoharan, M. R. Dokmeci, A. Khademhosseini, Expert Opin. Drug Discov. 2014, 9, 335. 